INTERNATIONAL MONETARY FUND

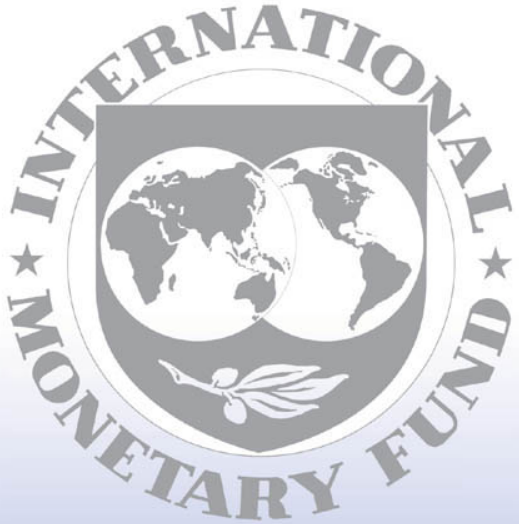

Staff

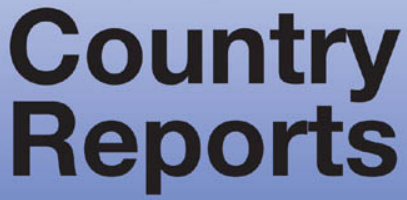




\section{Bosnia and Herzegovina: Report on the Observance of Standards and Codes- Data Module, Response by the Authorities, and Detailed Assessment Using the Data Quality Assessment Framework (DQAF)}

This Report on the Observance of Standards and Codes on Data Module for Bosnia and Herzegovina was prepared by a staff team of the International Monetary Fund as background documentation for the periodic consultation with the member country. It is based on the information available at the time it was completed on January 7, 2008. The views expressed in this document are those of the staff team and do not necessarily reflect the views of the government of Bosnia and Herzegovina or the Executive Board of the IMF.

The Response by the Authorities to this report, and the Detailed Assessments Using the Data Quality Assessment Framework (DQAF) are also included.

The policy of publication of staff reports and other documents by the IMF allows for the deletion of market-sensitive information.

To assist the IMF in evaluating the publication policy, reader comments are invited and may be sent by e-mail to publicationpolicy@imf.org.

Copies of this report are available to the public from

International Monetary Fund • Publication Services

700 19th Street, N.W. • Washington, D.C. 20431

Telephone: (202) 6237430 • Telefax: (202) 6237201

E-mail: publications@imf.org • Internet: http://www.imf.org

Price: $\$ 18.00$ a copy

\section{International Monetary Fund Washington, D.C.}


This page intentionally left blank

CInternational Monetary Fund. Not for Redistribution 
INTERNATIONAL MONETARY FUND

BOSNIA AND HERZEGOVINA

\title{
Report on the Observance of Standards and Codes (ROSC)—Data Module
}

\author{
Prepared by the Statistics Department \\ Approved by Robert W. Edwards and Michael C. Deppler
}

January 7, 2008

The Report on the Observance of Standards and Codes (ROSC) data module provides an assessment of Bosnia and Herzegovina's macroeconomic statistics against the recommendations of the General Data Dissemination System (GDDS), complemented by an assessment of data quality based on the IMF's Data Quality Assessment Framework (DQAF July 2003). The DQAF lays out internationally accepted practices in statistics, ranging from good governance in data producing agencies to practices specific to datasets.

The datasets covered in this report are the national accounts, price, government finance, monetary, and balance of payments statistics. The institutions that compile the datasets assessed in this report are the statistical institutions of Bosnia and Herzegovina (Bosnia and Herzegovina Agency for Statistics, Federal Institute of Statistics of the Federation of Bosnia and Herzegovina, and Republika Srpska Institute of Statistics) and the Central Bank of Bosnia and Herzegovina.

The datasets to which this report pertains can be accessed in print and on the Internet at the following websites:

Agency for Statistics of BiH: www.bhas.ba

BiH Federal Institute of Statistics: www.fzs.ba

Republika Srpska Institute of Statistics: www.rzs.rs.ba

CBBH: www.cbbh.ba

This report is based on information provided prior to and during a staff mission from March 13-28, 2007 and publicly available information. The mission team was headed by Mr. Keith Dublin, and comprised Mmes. Xiu-zhen Zhao and Silvia Matei, and Messrs. Rob Dippelsman, Louis Venter, and Silvano Spencer (all STA), and Segismundo Fassler (Resident Statistical Advisor). 


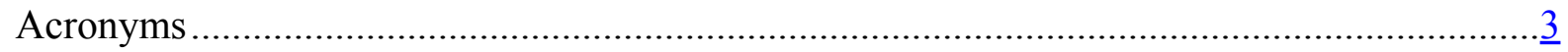

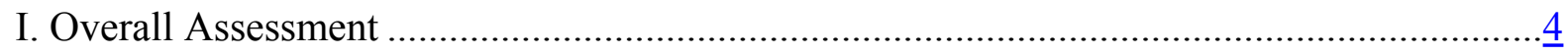

II. Assessment by Institution and Dataset..........................................................................

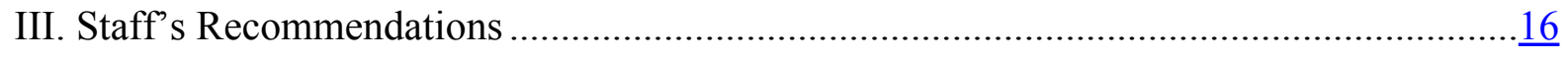

Tables

1. DQAF July 2003 - Summary Results......................................................................

2a. Assessment of Data Quality - Dimensions 0 and 1-Agency for Statistics, Federal

Institute of Statistics, and RepubliKa Srpska Institute of Statistics..................................

2b. Assessment of Data Quality—Dimensions 0 and 1-Central Bank of Bosnia and

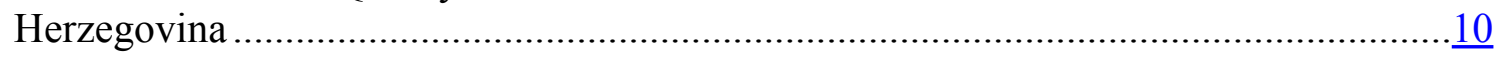

3a. Assessment of Data Quality—Dimensions 2 to 5-National Accounts ..............................11

3b. Assessment of Data Quality_-Dimensions 2 to 5-Consumer Price Index ........................12

3c. Assessment of Data Quality—Dimensions 2 to $5-$ Government Finance Statistics...........13

3d. Assessment of Data Quality-Dimensions 2 to 5-Monetary Statistics............................14

3e. Assessment of Data Quality—Dimensions 2 to 5-Balance of Payments Statistics........... 15

4. Practices Compared to the GDDS Coverage Periodicity, and Timeliness of Data .............19 


\section{ACRONYMS}

1995 ESA

BHAS

$\mathrm{BiH}$

BPM5

$\mathrm{CBBH}$

CPI

DQAF 2003

EU

FIS

GDDS

GDP

GFS

GFSM 2001

HBS

IMF/Fund

ISWGNA

KM

MFSM

MFTER

MoU

ODCs

ROSC

RPI

RS

RSIS
European System of Accounts 1995

Bosnia and Herzegovina Agency for Statistics

Bosnia and Herzegovina

Balance of Payments Manual, fifth edition

Central Bank of Bosnia and Herzegovina

Consumer Price Index

Data Quality Assessment Framework

European Union

Federal Institute of Statistics

General Data Dissemination System

Gross Domestic Product

Government Finance Statistics

Government Finance Statistics Manual 2001

Household Budget Survey

International Monetary Fund

Inter-Secretariat Working Group on National Accounts

Convertible Marka

Monetary and Financial Statistics Manual

Ministry of Foreign Trade and Economic Relations

Memorandum of Understanding

Other Depository Corporations

Report on the Observance of Standards and Codes

Retail Price Index

Republika Srpska

Republika Srpska Institute of Statistics 


\section{Overall Assessment}

1. Although Bosnia and Herzegovina $(\mathrm{BiH})$ does not at present participate in the General Data Dissemination System (GDDS), data dissemination practices in $\mathrm{BiH}$ meet or exceed many of the GDDS recommendations for dissemination of macroeconomic statistics in terms of coverage, periodicity, and timeliness (see Appendix I). The main exceptions are the unavailability of annual GDP at constant prices, central government domestic debt, and the consumer price index. Significant advances are, however, being made in compiling GDP estimates with the assistance of the IMF real-sector advisor and in developing a consumer price index (CPI) with the assistance of the Italian Government. The authorities have also developed metadata for some of the statistical datasets.

2. This Report on the Observance of Standards and Codes (ROSC) data module, which was prepared during March 13-28, 2007, assesses the quality of the national accounts, prices, government finance (GFS), monetary, and balance of payments statistics. In the absence of a CPI, which is under development, the retail price index (RPI) is assessed in this report. The report also assesses the three statistical institutions and the Central Bank that compile these macroeconomic statistics.

3. The assignment of legal authority and responsibilities for statistical functions across the three statistical institutions in the country mirrors the sharing of political powers between the state, on the one hand, and the two entities, on the other. The functional responsibilities that define the working relationships between these institutions are set out in the State Law on Statistics that was enacted in 2002 and established a single statistical framework in which the Bosnia and Herzegovina Agency for Statistics (BHAS), the statistical agency at the level of the state, was given a central role for coordinating a national work program in statistics. The statistical institutions at the state and entity levels are assigned responsibilities for statistical functions that were expected to be both separate and complementary. From the inception, however, the effective functioning of this arrangement fell far short of expectations as many stipulations of the law were never implemented, due partly to the fragmentation and duplication of functions across the statistical institutions and the lack of effective cooperation among these institutions to support the development of a country-wide statistical program. Subsequent reforms introduced to improve the effectiveness of the statistical system have had only a limited impact.

4. The Central Bank of Bosnia and Herzegovina (CBBH) has the exclusive mandate to compile GFS, monetary, and balance of payments statistics for $\mathrm{BiH}$. This institutional environment fosters clarity in the identification of statistical objectives and efficiency in their implementation. A formal agreement signed with the BHAS specifies responsibilities for the compilation of macroeconomic statistics of $\mathrm{BiH}$ and the areas of cooperation between the two institutions.

5. The strength of the conceptual and analytical framework used to compile macroeconomic statistics, as shown in Table 1, varies across datasets. In most cases, the shortcomings identified in the source data and the inability of the statistical institutions to meet users' needs negatively impact on the analytical usefulness of the datasets. 
6. The remainder of this section presents the mission's main conclusions on the quality of five macroeconomic datasets, using the IMF's Data Quality Assessment Framework (DQAF July 2003). The presentation is done at the level of the DQAF's quality dimensions, by institution for the first two dimensions, and across datasets for the remaining four. Section II provides a summary assessment by institution and dataset based on a four-part scale. This is followed by staff recommendations in Section III. An overview of current practices regarding coverage, periodicity, and timeliness of macroeconomic data compared to the GDDS is provided in Appendix I. The authorities' response to this report and a volume of detailed assessments are presented in separate documents.

7. Prerequisite of quality and assurances of integrity. The main agencies that compile statistics assessed in this report are the three statistical institutions within $\mathrm{BiH}$ and the $\mathrm{CBBH}$.

- $\quad$ The statistical institutions comprise the state-level BHAS and the two statistical institutes at the level of the entities--the Federal Institute of Statistics of the Federation of BiH (FIS) and the Republika Srpska Institute of Statistics (RSIS).

Following the enactment of the State Law on Statistics in 2002, a period during which the effectiveness of the statistical system was hampered by a lack of clarity with regard to the allocation of legal authority and institutional responsibilities between the statistical institutions at the level of the state and those at the entity level, reforms were introduced in late 2004 with the objective of improving the institutional environment in which these organizations operate. As well, in November 2005, an agreement was signed between the ministries of finance at the level of the state and the entities and the counterpart statistical institutions that set out a framework for coordinating and disseminating statistical data. Serious difficulties still remain in reaching agreement on a cohesive statistical program with clear priorities that can be supported and implemented by all statistical institutions. Decisions of strategic importance on implementing statistical policies continue to be made on an ad hoc basis and involve significant compromise among the institutions, resulting at times in sub-optimal outcomes. Against this background, the Statistical Council, which was established as an advisory group to steer the work of the BHAS, is ineffective in providing guidance for the development of a viable national statistical program that is acceptable to all parties. While staff resources of the statistical institutions are generally adequate to carry out routine statistical tasks, these resources are inadequate for responding to demands for new statistical activities proposed by some external donors, including absorbing their corresponding technical assistance. The relevance of a number of these statistical activities is questionable since they may not adequately reflect the needs of national users but give priority to complying with the proposals made by external donors in the ongoing work programs. Despite the difficult situation in which they function, the statistical institutions operate in an environment that promotes impartiality and transparency in the choice of techniques and practices that are followed to compile statistical data.

- $\quad$ The $C B B H$ By-law, which was enacted in 2002 and amended in 2006, specifies the scope of the responsibility of the $\mathrm{CBBH}$ for collecting, compiling, and disseminating monetary, balance of payments, and GFS, among others. These statistical responsibilities are reaffirmed by the Memorandum of Understanding (MoU) that was 
signed between the $\mathrm{CBBH}$ and the BHAS and clarifies their respective functional responsibilities. Staff resources in the $\mathrm{CBBH}$ divisions that compile the statistics are professionally well qualified and have technical expertise in the areas of their respective statistical responsibilities. However, staffing levels are not considered to be adequate to carry out their statistical tasks in a proficient manner. Informal consultations take place periodically with other government agencies, the media, and other data users to identify new statistical needs, but there is no formal process of monitoring user needs. Consistent with the independent legal status of the $\mathrm{CBBH}$, statistical functions are performed exclusively on the basis of professional and ethical considerations. The policies followed by which statistical data are made available to the public and to official government agencies are consistent with international practices on transparency.

8. Methodological soundness. In contrast to monetary and balance of payments statistics, which are compiled according to international methodologies, there are significant weaknesses in the national accounts and the RPI. In addition to shortcomings in the areas of classification/sectorization and the basis of recording for these datasets, significant inadequacies have been identified with respect to their scope. In this connection, no constant price GDP estimates are available and national accounts are limited to production account data compiled at current prices. Moreover, these estimates do not adequately capture activities in the informal and non-observed economy. No country-wide price indices are published in $\mathrm{BiH}$, although RPIs are compiled separately by each entity. The general government includes the state government, entity governments, cantons, the Brcko District, almost all extrabudgetary funds (including social security funds), and local governments. The scope of the GFS, however, falls short of international standards as a result of the unavailability of a cash statement, a balance sheet, projects directly financed by foreign donors, and the omission of an extrabudgetary fund in one of the entities. In addition, data on the level of outstanding government domestic debt are currently not available.

9. Accuracy and reliability. Except for monetary statistics, the accuracy and reliability of all datasets suffer from substantial deficiencies in the underlying source data. Weaknesses are particularly obvious in: (i) the national accounts, where a statistical register of enterprises does not exist; source data rely heavily on administrative records and cover the informal economy inadequately; (ii) the balance of payments, where source data are inadequate due to the lack of comprehensive surveys on services and remittances and to the difficulty of recording the large number of small cash transactions; and (iii) the RPI, where the weights are significantly outdated and quality adjustments are not routinely undertaken. With respect to the GFS, limited source data are available from administrative records and significant transformations are required to bring these source data into consistency with the methodological principles required for the GFS. In most datasets, statistical techniques applied to these source data conform to sound statistical procedures. For the most part, revision studies are not conducted routinely and for those that are carried out - for the national accounts and balance of payments - little use is made of the results to improve statistical processes.

10. Serviceability. All disseminated data meet or exceed the GDDS recommendations on periodicity and timeliness, with consistent time series over a reasonable time-period 
(Table 4). However, significant inconsistencies exist within datasets (balance of payments) and across datasets (GFS and national accounts; GFS and monetary statistics), raising notable concerns about the serviceability of these datasets. In most cases, these inconsistencies can be explained by inadequate source data. Revised data are clearly identified for all datasets, except for the RPI, where they are not applicable. However, in some cases, these revisions do not follow a regular and transparent schedule.

11. Accessibility. All datasets are readily accessible in hardcopy and electronic form, although the level of detail made available to users varies among the statistical institutions and the electronic format is not always user-friendly. With regard to the national accounts and the RPIs, these are disseminated separately for the country (GDP estimates) and for the entities (GDP estimates and RPI). Country-wide data are available for government finance, monetary statistics, and balance of payments. Metadata accessibility is adequate for those datasets compiled by the CBBH (GFS, monetary statistics, and balance of payments statistics) but is not well developed for the national accounts and RPI which are compiled by the statistical institutions. Assistance to users is broadly adequate and additional information is available upon request.

\section{ASSESSMEnt by InSTITUTION AND Dataset}

12. This section presents the results of the assessment at the level of the DQAF elements, including the use of a four-point rating scale (Table 1). Assessments of the prerequisites of data quality and the assurances of integrity (Dimensions "0" and " 1 " of the DQAF) are presented in Tables $2 \mathrm{a}$ and $2 \mathrm{~b}$. For each dataset, the assessment of methodological soundness, accuracy and reliability, serviceability, and accessibility (Dimensions " 2 " to " 5 " of the DQAF) is shown in Tables 3a-3e.

13. As input to the mission's assessment of the quality of official statistics produced by $\mathrm{BiH}$, an informal survey of key users of macroeconomic statistics was conducted. While there was satisfaction with the coverage and detail of the published datasets, including their periodicity and timeliness and accessibility, satisfaction was considerably lower with regard to the methodological soundness and reliability of the data. The quality of BiH's statistics was largely perceived as worse than that of statistics disseminated by neighboring countries. 
Table 1. Bosnia and Herzegovina: Data Quality Assessment Framework July 2003—Summary Results

\begin{tabular}{|c|c|c|c|c|c|}
\hline \multicolumn{6}{|c|}{$\begin{array}{l}\text { Key to symbols: O = Practice Observed; LO = Practice Largely Observed; LNO =Practice Largely Not Observed; NO = Practice Not Observed; NA = Not } \\
\text { Applicable }\end{array}$} \\
\hline Dimensions/Elements & $\begin{array}{l}\text { National } \\
\text { Accounts }\end{array}$ & $\begin{array}{l}\text { Retail Price } \\
\text { Index }\end{array}$ & $\begin{array}{l}\text { Government } \\
\text { Finance } \\
\text { Statistics } \\
\end{array}$ & $\begin{array}{l}\text { Monetary } \\
\text { Statistics }\end{array}$ & $\begin{array}{l}\text { Balance of } \\
\text { Payments Statistics }\end{array}$ \\
\hline \multicolumn{6}{|l|}{0. Prerequisites of quality } \\
\hline $\begin{array}{ll}0.1 & \text { Legal and institutional environment } \\
0.2 & \text { Resources } \\
0.3 & \text { Relevance } \\
0.4 & \text { Other quality management } \\
\end{array}$ & $\begin{array}{l}\text { LNO } \\
\text { LNO } \\
\text { LNO } \\
\text { LNO }\end{array}$ & $\begin{array}{l}\text { LNO } \\
\text { LNO } \\
\text { LNO } \\
\text { LNO }\end{array}$ & $\begin{array}{l}\text { LO } \\
\text { LO } \\
\text { LO } \\
\text { O }\end{array}$ & $\begin{array}{l}\text { O } \\
\text { LO } \\
\text { LO } \\
\text { O }\end{array}$ & $\begin{array}{l}\text { LO } \\
\text { LNO } \\
\text { LO } \\
\text { LO }\end{array}$ \\
\hline \multicolumn{6}{|l|}{ 1. Assurances of integrity } \\
\hline 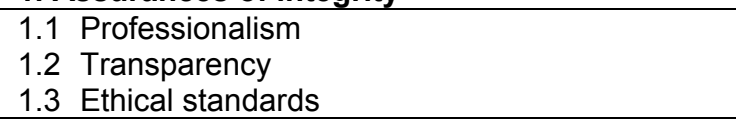 & $\begin{array}{l}\mathrm{O} \\
\mathrm{O} \\
\mathrm{O}\end{array}$ & $\begin{array}{l}\mathrm{O} \\
\mathrm{O} \\
\mathrm{O}\end{array}$ & $\begin{array}{l}\mathrm{O} \\
\mathrm{O} \\
\mathrm{O}\end{array}$ & $\begin{array}{l}\mathrm{O} \\
\mathrm{O} \\
\mathrm{O}\end{array}$ & $\begin{array}{l}\mathrm{O} \\
\mathrm{O} \\
\mathrm{O}\end{array}$ \\
\hline \multicolumn{6}{|l|}{ 2. Methodological soundness } \\
\hline $\begin{array}{l}\text { 2.1 } \text { Concepts and definitions } \\
2.2 \text { Scope } \\
\text { 2.3 Classification/sectorization } \\
\text { 2.4 Basis for recording } \\
\end{array}$ & $\begin{array}{l}\text { O } \\
\text { LNO } \\
\text { LO } \\
\text { LO }\end{array}$ & $\begin{array}{l}\text { LNO } \\
\text { NO } \\
\text { LNO } \\
\text { LO }\end{array}$ & $\begin{array}{l}\text { O } \\
\text { LNO } \\
\text { LO } \\
\text { LO }\end{array}$ & $\begin{array}{c}\text { O } \\
\text { O } \\
\text { LO } \\
\text { O }\end{array}$ & $\begin{array}{l}\text { O } \\
\text { O } \\
\text { LO } \\
\text { LO }\end{array}$ \\
\hline \multicolumn{6}{|l|}{ 3. Accuracy and reliability } \\
\hline $\begin{array}{ll}\text { 3.1 } & \text { Source data } \\
\text { 3.2 } & \text { Assessment of source data } \\
\text { 3.3 } & \text { Statistical techniques } \\
\text { 3.4 } & \text { Assessment and validation of intermediate } \\
\text { data and statistical outputs } \\
\text { 3.5 Revision studies }\end{array}$ & $\begin{array}{l}\text { LNO } \\
\text { LNO } \\
\text { LO } \\
\text { LO } \\
\text { LO }\end{array}$ & $\begin{array}{l}\text { LNO } \\
\text { LO } \\
\text { LNO } \\
\text { LO } \\
\text { LO }\end{array}$ & $\begin{array}{c}\text { LNO } \\
\mathrm{O} \\
\mathrm{O} \\
\mathrm{O} \\
\mathrm{O}\end{array}$ & $\begin{array}{l}0 \\
0 \\
0 \\
0 \\
0\end{array}$ & $\begin{array}{l}\text { LNO } \\
\text { O } \\
\text { LO } \\
\text { O } \\
\text { LO }\end{array}$ \\
\hline \multicolumn{6}{|l|}{ 4. Serviceability } \\
\hline $\begin{array}{l}\text { 4.1 } \text { Periodicity and timeliness } \\
\text { 4.2 Consistency } \\
\text { 4.3 Revision policy and practice }\end{array}$ & $\begin{array}{l}\mathrm{O} \\
\mathrm{LNO} \\
\mathrm{LO}\end{array}$ & $\begin{array}{c}\mathrm{O} \\
\mathrm{O} \\
\mathrm{LNO} \\
\end{array}$ & $\begin{array}{c}\mathrm{O} \\
\mathrm{LNO} \\
\mathrm{O}\end{array}$ & $\begin{array}{c}\mathrm{O} \\
\mathrm{LO} \\
\mathrm{O}\end{array}$ & $\begin{array}{c}\mathrm{O} \\
\mathrm{LO} \\
\mathrm{O}\end{array}$ \\
\hline \multicolumn{6}{|l|}{ 5. Accessibility } \\
\hline $\begin{array}{ll}\text { 5.1 } & \text { Data accessibility } \\
5.2 & \text { Metadata accessibility } \\
5.3 & \text { Assistance to users } \\
\end{array}$ & $\begin{array}{l}\text { LO } \\
\text { LNO } \\
\text { LO }\end{array}$ & $\begin{array}{l}\text { LO } \\
\text { LNO } \\
\text { LO }\end{array}$ & $\begin{array}{c}\text { LO } \\
\text { O } \\
\text { O }\end{array}$ & $\begin{array}{l}\mathrm{O} \\
\mathrm{O} \\
\mathrm{O}\end{array}$ & $\begin{array}{c}\mathrm{O} \\
\mathrm{LO} \\
\mathrm{O}\end{array}$ \\
\hline
\end{tabular}

Practice observed: current practices generally in observance meet or achieve the objectives of DQAF internationally accepted statistical practices without any significant deficiencies. Practice largely observed: some departures, but these are not seen as sufficient to raise doubts about the authorities' ability to observe the DQAF practices. Practice largely not observed: significant departures and the authorities will need to take significant action to achieve observance. Practice not observed: most DQAF practices are not met. Not applicable: used only exceptionally when statistical practices do not apply to a country's circumstances. 
Table 2a. Bosnia and Herzegovina: Assessment of Data Quality—Dimensions 0 and 1-Bosnia and Herzegovina Agency for Statistics, Federal Institute of Statistics, and Republika Srpska Institute of Statistics

\section{Prerequisites of quality}

\section{Legal and institutional environment}

The BiH Law on Statistics was enacted by the UN High Representative in 2002 and ratified by the State Parliament in 2004. It assigns the BHAS the responsibility for compiling countrywide statistics, coordination of statistical work, and setting the methodological standards for the statistical work in the country. The same Law attributes to the statistical institutions of the entities the responsibility for compiling the statistics at the entity level. The current entities' laws on statistics, issued in 2003, provide the legal bases for the statistical work at the entity level. The $\mathrm{BiH}$ Law and the entities' laws are not fully harmonized, thus undermining coordination and cooperation among the institutions. The main instrument of coordination of the statistical work is the four-year program that lays out the activities to be undertaken by the responsible institutions. In principle, this program is prepared by the BHAS in consultation with the entities and the State Statistical Council and is implemented through corresponding annual work plans. As similar planning instruments and procedures exist at the entity level, the four-year work program is not implemented as envisaged. These institutional arrangements complicate coordination across agencies as do pressures from external sources to approve proposals for new statistical projects. Data sharing between the entities and the BHAS is mandatory by law; however, transmission of data has, at times, been problematic and not in compliance with the spirit of the law. The dialogue among the institutions involved has not always been smooth to effectively foster a timely project implementation and application of standards. All three institutions guarantee in their laws the confidentiality of the data and establish penalties for non-compliance. Reporting for statistical purposes is mandatory for all natural and legal persons.

\section{Resources}

Staff resources are over stretched with the regular tasks and the numerous activities related to ongoing technical assistance projects for the development of the statistics. The number of staff dedicated to the compilation of national accounts and price statistics is not enough neither at the BHAS nor at the entities' institutions of statistics. Although the BHAS and the entities anticipate an increase of the staff, it is proving difficult to recruit suitable professionals. These problems are compounded by the relatively high turnover of staff, in particular of IT experts. Financial resources are provided from the budgets of the respective state and entity budgets. These resources are generally sufficient to conduct the regular work, but do not provide enough funds for capital investments. The development of new statistical activities is mainly financed by donors.

\section{Relevance}

The relevance of the statistics is largely driven by the commitments made to meet the data requirements of the European Union (EU), which are reflected in the work programs. These commitments do not take account of capacity constraints pointing thus to the need for prioritizing statistical activities, consistent with available resources. The statistical institutions of $\mathrm{BiH}$ have not established procedures of consultations with users on a regular basis.

\section{Other quality management}

Although awareness of data quality exists, the statistical institutions of $\mathrm{BiH}$ have not established systematic procedures to monitor the quality of the data produced. Nevertheless, the adoption of international standards with the support of the EU, international organizations, and bilateral donors, is introducing changes in data collection and compilation procedures contributing to improvements to the quality of the data.

\section{Assurances of integrity}

\section{Professionalism}

The state and entity laws on statistics and observed practices provide the institutions with legal independence to carry out their functions. In choosing data sources and methods for the compilation of the statistics, the statistical institutions are driven by statistical considerations. Although they are entitled to comment on misinterpretation of their data, they often prefer not to engage in debates that may be political in nature.

\section{Transparency}

The three statistical institutions publicize the terms and conditions under which data are collected, processed, and disseminated. The regulating laws and work programs are made available to the public on their websites. There is no government access to the data prior to their release and data are released simultaneously to all users. The statistical institutions clearly identify their data in all publications and request attribution when their data are reproduced by others.

\section{Ethical standards}

Employees of all statistical institutions of the $\mathrm{BiH}$ are subject to the rules that govern conduct as specified in the respective laws applicable to civil servants. Moreover, in support of these laws, the BHAS applies an ethical code to its staff. 


\section{Prerequisites of quality}

\section{Legal and institutional environment}

The CBBH Law and by-laws provide clear authority to CBBH to compile monetary, government finance, and balance of payments statistics. In addition, there is a MoU with BHAS that assigns exclusive responsibility to the $\mathrm{CBBH}$ for compilation of these statistics. While the arrangements for monetary statistics are appropriate, there is duplication of GFS compilation. The Macroeconomic Analysis Unit (MAU) of the Indirect Taxation Authority also compiles general government data for operational purposes. Although these data are not official statistics, they are available to users on the website of the MAU and are currently neither consistent nor reconciled with the GFS that are compiled by the $\mathrm{CBBH}$. In addition, there is some scope for expanding arrangements for sharing data with other agencies to improve balance of payments data. The relevant legislation protects the confidentiality of individual data and the procedures for handling data also support the maintenance of confidentiality. Reporting of data to $\mathrm{CBBH}$ is supported by good procedures for assistance and follow-up, and penalty measures for noncompliance with reporting requirements are in place.

\section{Resources}

Staff are well-trained and have technical expertise appropriate to their areas of responsibility. For monetary statistics, overall staff resources are considered adequate but inadequate for the main units (i.e., CBBH units outside the central office, which carry the responsibility for data collection and compilation). Each CBBH main unit has one staff member working on monetary statistics and no back-up arrangements are in place. For GFS and balance of payments statistics, the number of employees is considered to be inadequate. Computing resources are broadly adequate, although there is insufficient support for the specialized needs of balance of payments compilation. Facilities are acceptable, although there is scope for improvement. Management encourages the efficient use of resources.

\section{Relevance}

The relevance of CBBH statistics is supported by informal contacts with users and by following international standards as a guide to meeting users' needs. There are several cases where sources and methods have been refined over time. However, no proactive measures are in place to identify users' needs. CBBH staff participate in international and regional statistical meetings to keep abreast of developments in statistical standards and best practices that can be applied in $\mathrm{BiH}$.

\section{Other quality management}

Quality is considered by $\mathrm{CBBH}$, for example, in continuing improvement of methods, participation in training courses and seminars, and monitoring of performance, although communication with main units could be improved for balance of payments statistics.

\section{Assurances of integrity}

\section{Professionalism}

The legal provisions support statistical impartiality by $\mathrm{CBBH}$.

Staff are recruited and promoted on the basis of competence. Decisions concerning statistics are made on the basis of statistical considerations, and $\mathrm{CBBH}$ is entitled to comment on misuse of statistics.

\section{Transparency}

$\mathrm{CBBH}$ encourages transparency by publishing the relevant laws, keeping the public informed of its activities, and not providing early access to statistics to users, including government ministries. Statistical publications are clearly labeled as $\mathrm{CBBH}$ products. Information on major changes to source data and methods is released in advance.

\section{Ethical standards}

The $\mathrm{CBBH}$ has a code of conduct that provides comprehensive ethical guidelines for the staff of the $\mathrm{CBBH}$. Staff are informed of the requirements. 
Table 3a. Bosnia and Herzegovina: Assessment of Data Quality-Dimensions 2 to 5-National Accounts

\begin{tabular}{|c|c|c|c|}
\hline 2. Methodological soundness & 3. Accuracy and reliability & 4. Serviceability & 5. Accessibility \\
\hline $\begin{array}{l}\text { Concepts and definitions. The national accounts } \\
\text { are compiled following the conceptual framework } \\
\text { of the European System of Accounts } 1995 \text { (1995 } \\
\text { ESA). } \\
\text { Scope. Very few of the tables and accounts } \\
\text { prescribed by the ISWGNA are produced. The } \\
\text { aggregates produced are the annual value added and } \\
\text { GDP at current prices and estimates of the gross } \\
\text { national income and gross disposable income. A } \\
\text { few deviations from the international standards also } \\
\text { exist in the scope of the production and the assets } \\
\text { boundary. Work is advanced to produce constant } \\
\text { price estimates of GDP and the expenditure } \\
\text { components of GDP. Experimental estimates of } \\
\text { value added components are also at an advanced } \\
\text { stage. } \\
\text { Classification/sectorization. The Classification of } \\
\text { Activities NACE Rev.1 is used to classify the } \\
\text { activities. Other classifications have been } \\
\text { introduced for the purposes of compiling the GDP } \\
\text { by expenditure, i.e. the Classification of Products by } \\
\text { Activity (CPA) and the Classification of Individual } \\
\text { Consumption by Purpose (COICOP) for household } \\
\text { consumption classification. However, classification } \\
\text { of institutional units by sector is based on legal } \\
\text { status rather than economic criteria. } \\
\text { Basis for recording. Valuation of GDP and value } \\
\text { added broadly accord with international standards. } \\
\text { All transactions are recorded on an accrual basis } \\
\text { with the exception of government revenues (cash } \\
\text { basis). }\end{array}$ & $\begin{array}{l}\text { Source data. A statistical register has not yet been } \\
\text { established, the entities use separate address books for } \\
\text { legal enterprises. Compilation of GDP estimates relies } \\
\text { heavily on financial statements of enterprises in the } \\
\text { absence of a regular program of surveys suitable for } \\
\text { national accounts compilation. Source data providers } \\
\text { for the unincorporated enterprises are mainly the tax } \\
\text { authorities, complemented by other administrative } \\
\text { records. Price and volume measures are not entirely } \\
\text { suitable for compilation needs of constant price } \\
\text { estimates. } \\
\text { Assessment of source data. Data used in GDP } \\
\text { estimates' compilation are regularly assessed for } \\
\text { coverage, misreporting, and sampling errors, where } \\
\text { applicable. However, results of assessments are not } \\
\text { actively used to improve source data. Source data for } \\
\text { the informal sector, in particular agriculture, trade, and } \\
\text { catering are not fully reliable. } \\
\text { Statistical techniques used in compilation of GDP by } \\
\text { production are generally satisfactory. However, } \\
\text { consumption of fixed capital, adjustment for holding } \\
\text { gains, and accrual basis are not properly addressed. } \\
\text { Estimates of the nonobserved economy are not yet } \\
\text { incorporated into the accounts. } \\
\text { Assessment and validation of intermediate data and } \\
\text { statistical outputs Validation of data is made } \\
\text { separately by entities at all stages of data processing. } \\
\text { Assessment of discrepancies in intermediate results is } \\
\text { made when they occur. } \\
\text { Revision studies are carried out but adequate use of } \\
\text { the results is not made to improve on the statistical } \\
\text { processes }\end{array}$ & $\begin{array}{l}\text { Periodicity and timeliness } \\
\text { Periodicity and timeliness follow } \\
\text { the GDDS recommendations for } \\
\text { the GDP at current prices (see } \\
\text { Table 4). } \\
\text { Consistency. Internal } \\
\text { consistency is difficult to analyze } \\
\text { in the absence of complementary } \\
\text { GDP estimates. However, efforts } \\
\text { should be made to improve } \\
\text { internal and inter-sectoral } \\
\text { consistency of data. In particular, } \\
\text { national accounts need to be } \\
\text { reconciled with GFS. Data are } \\
\text { generally consistent over time. } \\
\text { Recent revisions to GDP } \\
\text { estimates have been incorporated } \\
\text { consistently in the 2000-2005 } \\
\text { series. } \\
\text { Revision policy and practice. } \\
\text { The revision cycle at BHAS is, } \\
\text { in principle, coordinated with } \\
\text { those at the entity level, but } \\
\text { delays occur occasionally in its } \\
\text { implementation. Preliminary data } \\
\text { are clearly identified in all } \\
\text { institutions' publications. Causes } \\
\text { of revisions are mentioned in all } \\
\text { publications but no analyses on } \\
\text { revisions are made available to } \\
\text { users. }\end{array}$ & $\begin{array}{l}\text { Data accessibility GDP } \\
\text { estimates are disseminated in } \\
\text { publications and on the websites } \\
\text { separately by the BHAS and by } \\
\text { the entities. Presentation and } \\
\text { level of detail are adequate for } \\
\text { the BHAS and the Federation but } \\
\text { less satisfactory for the RS. No } \\
\text { publication includes data } \\
\text { analyses and commentaries. } \\
\text { Statistics are released } \\
\text { simultaneously to all users. Data } \\
\text { are usually released regularly } \\
\text { although a preannounced } \\
\text { schedule is not available. } \\
\text { Metadata accessibility. A } \\
\text { metadata summary is available in } \\
\text { the institutions' publications and } \\
\text { on their websites. However, no } \\
\text { comprehensive source and } \\
\text { methods document is available. } \\
\text { Assistance to users. National } \\
\text { accounts publications do not } \\
\text { identify a contact person or, in } \\
\text { some cases, BHAS does not } \\
\text { provide sufficient contact } \\
\text { information. Catalogs of } \\
\text { publications are not available but } \\
\text { each website includes a listing of } \\
\text { publications and main survey } \\
\text { results. }\end{array}$ \\
\hline
\end{tabular}

CInternational Monetary Fund. Not for Redistribution 
Table 3b. Bosnia and Herzegovina: Assessment of Data Quality-Dimensions 2 to 5-Retail Price Index

\begin{tabular}{|c|c|c|c|}
\hline 2. Methodological soundness & 3. Accuracy and reliability & 4. Serviceability & 5. Accessibility \\
\hline $\begin{array}{l}\text { Concepts and definitions } \\
\text { The RPI is used in the entities as the official } \\
\text { indicator of inflation. However it should be } \\
\text { noted that a Consumer Price Index (CPI) is } \\
\text { being developed according to international } \\
\text { standards. } \\
\text { The concept underlying the weights of the } \\
\text { RPI is the trade turnover, including services. } \\
\text { It has a broader coverage than a CPI as it also } \\
\text { includes products not used by consumers. } \\
\text { The RPI is based on the methodology } \\
\text { inherited from the former Yugoslavia, and } \\
\text { therefore it predates the current international } \\
\text { standards. Market prices are used in the } \\
\text { compilation of the RPI, thus following } \\
\text { international recommended practices. } \\
\text { Scope } \\
\text { No countrywide index is compiled. } \\
\text { Separate RPIs are compiled for the entities } \\
\text { and the district of Brcko. } \\
\text { Classification/sectorization } \\
\text { For the collection of prices and compilation } \\
\text { of the RPI the old classification of products } \\
\text { of the former Yugoslavia is used. } \\
\text { Basis for recording } \\
\text { Actual market prices charged by all types of } \\
\text { outlets and service providers are collected for } \\
\text { the compilation of the RPI every month. } \\
\text { However, the product specifications slightly } \\
\text { deviate from good practices as the terms of } \\
\text { transactions are not part of the characteristics } \\
\text { of the prices collected. }\end{array}$ & $\begin{array}{l}\text { Source data } \\
\text { A comprehensive price survey is conducted } \\
\text { monthly by the entities. However, no } \\
\text { comprehensive data collection system exists to } \\
\text { update the weights. Source data used to derive the } \\
\text { weight system of the current RPIs are older than } \\
\text { fifteen years. Additionally, these data are no } \\
\text { longer available nor is the detailed underlying } \\
\text { methodology. } \\
\text { Assessment of source data } \\
\text { Price data are regularly assessed by compilers but } \\
\text { field inspection checks are limited. } \\
\text { Statistical techniques } \\
\text { A Laspeyres type formula is used for aggregating } \\
\text { the elementary product price indices. However, } \\
\text { weights are not aligned with the price reference } \\
\text { period thus likely introducing a bias in the index. } \\
\text { No specific adjustment for quality changes is made } \\
\text { when introducing new products. } \\
\text { Assessment and validation of intermediate data } \\
\text { and statistical outputs } \\
\text { Validation of intermediate results is limited and } \\
\text { not systematic. A shortcoming is the lack of other } \\
\text { comparable price indices that can be used for } \\
\text { comparison. } \\
\text { Revision studies } \\
\text { No studies of revisions have been carried out since } \\
\text { no major revisions have been introduced since the } \\
\text { inception of the RPIs. Improvements in data } \\
\text { collection have followed the identification of } \\
\text { problems in the field work. }\end{array}$ & $\begin{array}{l}\text { Periodicity and timeliness } \\
\text { The RPIs meet the GDDS } \\
\text { recommendations for the } \\
\text { inflation measures with } \\
\text { respect to periodicity and } \\
\text { timeliness. The indices are } \\
\text { published regularly before the } \\
15^{\text {th }} \text { of the month following } \\
\text { the reference period. } \\
\text { Consistency } \\
\text { Consistent data series have } \\
\text { been produced for more than } \\
\text { ten years. The indices are } \\
\text { calculated at the entity level } \\
\text { only. No indices are } \\
\text { calculated for cities, therefore } \\
\text { no discrepancies arise from } \\
\text { different typologies of } \\
\text { aggregation. } \\
\text { Revision policy and practice } \\
\text { There is no revision policy } \\
\text { established for revising the } \\
\text { RPIs or updating their } \\
\text { underlying weights, although } \\
\text { the list of products composing } \\
\text { the basket is updated every } \\
\text { year to take into account the } \\
\text { increasing share of new } \\
\text { products. }\end{array}$ & $\begin{array}{l}\text { Data accessibility } \\
\text { Data accessibility is in } \\
\text { general good, although long- } \\
\text { term series are not } \\
\text { disseminated. The data on } \\
\text { the RPI are available on the } \\
\text { websites of the respective } \\
\text { statistical institutions. } \\
\text { Metadata accessibility } \\
\text { There is no detailed } \\
\text { metadata available on the } \\
\text { compilation of the RPIs. } \\
\text { Very limited description of } \\
\text { sources and methods is } \\
\text { published. } \\
\text { Assistance to users } \\
\text { Additional data and special } \\
\text { tabulations are provided free } \\
\text { of charge upon written } \\
\text { request to the statistical } \\
\text { institutions. Compilers are } \\
\text { also keen to provide } \\
\text { clarifications as needed. } \\
\text { Although no specific names } \\
\text { are given, the publications } \\
\text { (also posted on the websites) } \\
\text { provide all contact details } \\
\text { for addressing inquiries, } \\
\text { which are promptly handled } \\
\text { by the institutions. }\end{array}$ \\
\hline
\end{tabular}

CInternational Monetary Fund. Not for Redistribution 
Table 3c. Bosnia and Herzegovina: Assessment of Data Quality-Dimensions 2 to 5-Government Finance Statistics

\section{Methodological soundness}

\section{Concepts and definitions}

Since the inception of the compilation of Government Finance Statistics (GFS) in

$\mathrm{BiH}$ in 2003, the $\mathrm{CBBH}$ follows the definitions and concepts of the IMF's GFSM 2001.

\section{Scope}

Although the institutional coverage of GFS (general government) is broadly consistent with the GFSM 2001 and other

internationally accepted guidelines, the coverage of transactions is not. The GFS does not cover the stocks and the cash flows of the institutional units that comprise general government, nor transactions relating to projects directly financed by international donors. The $\mathrm{CBBH}$ compiles only the Statement of Government Operations.

\section{Classification/sectorization}

The sectorization of government and the economic classification of transactions are broadly consistent with the GFSM 2001. Limited data on expense by function are available due to the differences in the functional classifications used in the entities.

\section{Basis for recording}

Stocks are valued at market prices.

Transactions are recorded on a mixed accrual/cash basis.

\section{Accuracy and reliability}

Source data

Data are obtained from administrative records, financial accounts, and the Oracle Treasury system. Most data received cannot be

electronically processed. Not all the statements recommended in the GFSM 2001 are compiled because the full range of economic stocks and flows are not available. Although timely, the source data as received by the $\mathrm{CBBH}$ do not approximate the definitions, scope, and classifications required. Even though additional data are obtained and appropriate bridge tables exist to facilitate the compilation, the level of detail in the source data is not always sufficient to ensure proper classification. Data on external government debt are obtained from the State Ministry of Finance and Treasury. Data on the level of outstanding government domestic debt are still in process of

verification and legislative review, therefore the data are currently not available.

\section{Assessment of source data}

To the extent possible, automated procedures are used to facilitate the monitoring of the accuracy of data. Any data inconsistencies are discussed with the reporting institution.

Statistical techniques

Generally accepted statistical methods are used to adjust and consolidate GFS data.

\section{Assessment and validation of intermediate data and statistical} outputs

Assessment and validation of intermediate data and statistical outputs are conducted routinely. Statistical discrepancies and other potential problems are investigated and accounted for.

\section{Revision studies}

Revisions are monitored and analyzed. These are minimal due to the extensive use of accounting data as the data source to compile GFS even at the preliminary stage.

\section{Serviceability}

Periodicity and timeliness

$\mathrm{BiH}$ meets or exceeds the periodicity and timelines recommended by the GDDS for general government operations and quarterly consolidated central government operations.

However, although foreign government debt data are published quarterly, no data are yet disseminated on government domestic debt.

\section{Consistency}

General government finance data are internally consistent. No long-term time series are available, but the data are consistent for the time periods available. GFS and monetary statistics cannot be reconciled because of differences in sectorization, as well as a lack of detailed data and balance sheets. Except for projects directly financed by international donors, which are currently excluded from GFS, GFS and balance of payments use the same source data. GFS data are not reconciled with national accounts.

\section{Revision policy and practice}

Due to the recent inception of GFS, a regular and well-known timetable is not yet followed for revisions.

\section{Accessibility}

Data accessibility

The Statement of Government Operations is disseminated in a clea manner, with charts, tables, and commentaries to assist users. Although there is no Advance Release Calendar the data are released regularly by the $\mathrm{CBBH}$ on its website and in hardcopy.

\section{Metadata accessibility}

Documentation on the metadata is available on the website of the $\mathrm{CBBH}$.

\section{Assistance to users}

Assistance to users is provided through addressing users' queries and information requests. The publications of the CBBH provide comprehensive contact information. A list of CBBH publications is posted on the CBBH's website. 
Table 3d. Bosnia and Herzegovina: Assessment of Data Quality_-Dimensions 2 to 5-Monetary Statistics

\begin{tabular}{|c|c|c|c|}
\hline 2. Methodological soundness & 3. Accuracy and reliability & 4. Serviceability & 5. Accessibility \\
\hline $\begin{array}{l}\text { Concepts and definitions } \\
\text { Concepts and definitions used for } \\
\text { compiling monetary statistics are broadly } \\
\text { consistent with the framework as } \\
\text { recommended in the IMF's Monetary } \\
\text { and Financial Statistics Manual } \\
\text { (MFSM). } \\
\text { Scope } \\
\text { The scope of the monetary statistics } \\
\text { compiled by the CBBH is consistent with } \\
\text { the MFSM guidelines. The depository } \\
\text { corporation survey covers the CBBH and } \\
\text { all other depository corporations in BiH. } \\
\text { Classification/sectorization } \\
\text { Classification and sectorization used for } \\
\text { compiling monetary statistics are broadly } \\
\text { consistent with } M F S M \text { guidelines. } \\
\text { However, RS Road Fund is classified as } \\
\text { public nonfinancial corporation based on } \\
\text { legal decision instead of economic } \\
\text { classification, and some } M F S M \text { - } \\
\text { recommended categories of financial } \\
\text { assets, such as shares and other equities, } \\
\text { and insurance technical reserves are not } \\
\text { separately shown. } \\
\text { Basis for recording } \\
\text { Accounting data of CBBH and banks } \\
\text { used for compiling monetary statistics } \\
\text { are on an accrual basis. Market valuation } \\
\text { principles are applied except for } \\
\text { nontradable assets (loans and deposits), } \\
\text { which are recorded at nominal value } \\
\text { consistent with the } M F S M \text { guidelines. }\end{array}$ & $\begin{array}{l}\text { Source data } \\
\text { Source data, collected through a } \\
\text { decentralized system involving CBBH } \\
\text { Main Units, provide timely and } \\
\text { sufficient information needed for } \\
\text { classification/sectorization as } \\
\text { recommended in MFSM. } \\
\text { Assessment of source data } \\
\text { Source data, primarily generated from } \\
\text { accounting records of the banking } \\
\text { sector, are routinely reviewed to } \\
\text { ensure the accuracy and reliability. } \\
\text { Statistical techniques } \\
\text { Statistical techniques used are sound. } \\
\text { Seasonal adjustments of data series } \\
\text { use internationally accepted methods. } \\
\text { Assessment and validation of } \\
\text { intermediate data and statistical } \\
\text { outputs } \\
\text { Assessment and validation of } \\
\text { intermediate data and statistical } \\
\text { outputs are conducted routinely. } \\
\text { Statistical discrepancies and other } \\
\text { potential problems are investigated } \\
\text { and taken into account in the future } \\
\text { work program. } \\
\text { Revision studies } \\
\text { Revision studies are carried out } \\
\text { regularly to measure the direction and } \\
\text { magnitude of revisions and are used to } \\
\text { inform future statistical processes. }\end{array}$ & $\begin{array}{l}\text { Periodicity and timeliness } \\
\text { Monthly monetary statistics are } \\
\text { available } 5 \text { weeks after the end of the } \\
\text { reference month, which meet the } \\
\text { periodicity and timeliness } \\
\text { recommendations of GDDS. } \\
\text { Consistency } \\
\text { Internal data consistency of the } \\
\text { monetary statistics dataset, such as } \\
\text { inter-bank positions, is routinely } \\
\text { checked. Consistent time series over a } \\
\text { reasonable period of time are } \\
\text { maintained. While data are consistent } \\
\text { with corresponding measures of } \\
\text { balance of payments, consistency } \\
\text { checks with the GFS data are not } \\
\text { possible due to lack of sufficiently } \\
\text { detailed information. There are no } \\
\text { formal procedures in place to conduct } \\
\text { routine reconciliation between } \\
\text { monetary data and the other two } \\
\text { datasets. } \\
\text { Revision policy and practice } \\
\text { Revision policy and practice are } \\
\text { adequate. Revisions follow a regular } \\
\text { schedule. Preliminary data are clearly } \\
\text { identified. Revision studies and analysis } \\
\text { are published. }\end{array}$ & $\begin{array}{l}\text { Data accessibility } \\
\text { Data accessibility is in line with } \\
\text { internationally accepted practices. } \\
\text { Presentation of statistics is clear, } \\
\text { dissemination formats are adequate, } \\
\text { dissemination of data to all users occur } \\
\text { at the same time, and an advance } \\
\text { release calendar is published. } \\
\text { Metadata accessibility } \\
\text { Metadata accessibility is adequate. } \\
\text { Information on the underlying } \\
\text { methodology used for compiling the } \\
\text { data is available publicly. Detailed } \\
\text { supplementary data are published to } \\
\text { better meet users' needs. } \\
\text { Assistance to users } \\
\text { Assistance to users is provided through } \\
\text { addressing users' queries and } \\
\text { information requests. Detailed contact } \\
\text { information is published on CBBH } \\
\text { internet website. Listings of available } \\
\text { data and metadata are posted on the } \\
\text { CBBH's website. }\end{array}$ \\
\hline
\end{tabular}


Table 3e. Bosnia and Herzegovina: Assessment of Data Quality-Dimensions 2 to 5-Balance of Payments Statistics

\begin{tabular}{|c|c|c|c|}
\hline 2. Methodological soundness & 3. Accuracy and reliability & 4. Serviceability & 5. Accessibility \\
\hline $\begin{array}{l}\text { Concepts and definitions } \\
\text { Concepts and definitions follow } \\
\text { international standards, as stated in the } \\
\text { fifth edition of the Balance of Payments } \\
\text { Manual (BPM5), including the residence } \\
\text { concept. } \\
\text { Scope } \\
\text { In accordance with international } \\
\text { standards, the scope of balance of } \\
\text { payments statistics is defined as } \\
\text { transactions between residents and } \\
\text { nonresidents. } \\
\text { Classification/sectorization } \\
\text { Classifications and sectorization in } \\
\text { balance of payments statistics generally } \\
\text { follow international standards, with some } \\
\text { technical exceptions for components of } \\
\text { capital transfers and direct investment } \\
\text { income. } \\
\text { Basis for recording } \\
\text { CBBH adopts an accrual timing basis in } \\
\text { its surveys, in accordance with } \\
\text { international standards. However, data on } \\
\text { exports and imports use a customs } \\
\text { frontier basis as do most countries. As } \\
\text { well, some other items, such as interest, } \\
\text { are recorded on a payments basis. }\end{array}$ & $\begin{array}{l}\text { Source data } \\
\text { Source data have significant gaps. These gaps arise } \\
\text { because the BiH economy has international transactions } \\
\text { that are difficult to measure. There are many small-scale } \\
\text { cash transactions outside the banking and payment } \\
\text { systems, and other transactions, such as services, } \\
\text { compensation of employees, and remittances, which are } \\
\text { difficult to record comprehensively. Trade data may also } \\
\text { be subject to incomplete coverage and underinvoicing. } \\
\text { Assessment of source data } \\
\text { Staff regularly assess source data and have identified } \\
\text { substantial shortcomings. } \\
\text { Statistical techniques } \\
\text { Suitable statistical techniques are used to adjust the data. } \\
\text { Fixed ratio adjustments are made in several cases to take } \\
\text { account of known shortcomings in the source data. } \\
\text { While moving closer to correct values, these } \\
\text { adjustments often lack a strong quantitative foundation, } \\
\text { therefore, the estimates are subject to a high degree of } \\
\text { uncertainty. } \\
\text { Assessment and validation of intermediate data and } \\
\text { statistical outputs } \\
\text { CBBH staff review the data, identify problems during } \\
\text { processing, and determine the extent of data } \\
\text { shortcomings. } \\
\text { Revision studies } \\
\text { CBBH staff review quarter-to-quarter revisions and note } \\
\text { the causes. However, there has been no long-term study } \\
\text { to inform statistical processes. }\end{array}$ & $\begin{array}{l}\text { Periodicity and timeliness } \\
\text { Balance of payments data are } \\
\text { available quarterly within three } \\
\text { months of the end of the reference } \\
\text { quarter. Accordingly, they more } \\
\text { than satisfy GDDS } \\
\text { recommendations on periodicity } \\
\text { and timeliness. } \\
\text { Consistency } \\
\text { Data are consistent over time and } \\
\text { with monetary statistics. Data are } \\
\text { consistent with GFS, except that } \\
\text { balance of payments statistics also } \\
\text { include all donor funded projects. } \\
\text { Due to the limited scope of the } \\
\text { national accounts, reconciliation is } \\
\text { not applicable. There are large } \\
\text { inconsistencies within the dataset, } \\
\text { as evidenced by consistently } \\
\text { positive net errors and omissions. } \\
\text { These errors and omissions are } \\
\text { believed to be caused by the data } \\
\text { source shortcomings noted } \\
\text { previously. } \\
\text { Revision policy and practice } \\
\text { A revision policy is implemented } \\
\text { and available to users on request. } \\
\text { Preliminary and/or revised data are } \\
\text { clearly identified. An explanation } \\
\text { of the major revisions in } 2005 \text { was } \\
\text { published. }\end{array}$ & $\begin{array}{l}\text { Data accessibility } \\
\text { Data are made available in a } \\
\text { variety of formats (tables, } \\
\text { charts, spreadsheets, } \\
\text { commentary). The CBBH } \\
\text { website provides a wide range } \\
\text { of data free of charge. Data are } \\
\text { made available to all users at } \\
\text { the same time and in } \\
\text { accordance with the Advance } \\
\text { Release Calendar. Additional } \\
\text { data are made available on } \\
\text { request. } \\
\text { Metadata accessibility } \\
\text { Summaries of sources and } \\
\text { methods are made available on } \\
\text { the CBBH website. } \\
\text { Documentation on adjustments } \\
\text { is currently only made } \\
\text { available to selected users, } \\
\text { thereby limiting the } \\
\text { transparency about the nature } \\
\text { of adjustments made to source } \\
\text { data by CBBH. } \\
\text { Assistance to users } \\
\text { Users' queries and information } \\
\text { requests are satisfied. Contact } \\
\text { information is provided on the } \\
\text { CBBH website. A listing of } \\
\text { publications and other available } \\
\text { materials is posted on the } \\
\text { CBBH website. }\end{array}$ \\
\hline
\end{tabular}

(CInternational Monetary Fund. Not for Redistribution 


\section{STAFF's Recommendations}

14. Based on the review of BiH's statistical practices, discussions with the dataproducing agencies, and consultation (survey questionnaire) from some data users (see Appendix III of the Detailed Assessments volume), the mission has a set of recommendations. These recommendations are designed to increase further BiH's adherence to internationally accepted statistical practices and would, in the mission's view, enhance the analytical usefulness of BiH's statistics. Some additional technical suggestions are included in the Detailed Assessments volume.

\section{Cross-cutting Recommendations}

- $\quad$ Strengthen the mandate of the BHAS to coordinate a cohesive national statistical program. Consideration should be given to assigning the BHAS a substantive official role in planning and implementing the work programs of the entity statistical institutes, inclusive of budget preparation processes.

- Improve coordination and cooperation among statistical institutions that are responsible for compiling national accounts and price statistics to produce effective country-wide work programs. Establish working groups among major data producing agencies to improve data sharing and validation, thereby enhancing intersectoral consistency.

- Conduct regular (quarterly or annual) inter-sectoral data consistency checks and produce reports on the conclusions of these checks.

- $\quad$ Provide additional resources to statistical institutions responsible for compiling national accounts, prices, government finance, and balance of payments statistics.

- $\quad$ Enhance the role of the Statistical Council in setting priorities for the country's work program by enlarging its composition to include representatives of the private sector.

- $\quad$ Move forward with GDDS participation, so as to provide a framework for statistical improvements, reflecting national priorities. As a first step, appoint a GDDS country coordinator for $\mathrm{BiH}$.

- $\quad$ Prepare and disseminate detailed manuals of sources and methods used for the compilation of the national accounts and price statistics.

- $\quad$ Establish formal procedures to identify users' needs.

- Disseminate all data on the website in a format that is downloadable and userfriendly, such as Excel. 


\section{National Accounts}

- $\quad$ Finalize and publish the constant price GDP estimates and the expenditure components of GDP.

- $\quad$ Finalize the estimates of the nonobserved economy and integrate them into the national accounts.

- $\quad$ Advance the work for the construction of a business register making use of all available databases. Once the business register is available, (i) consider introducing regular business surveys and (ii) completing the identification of the institutional sectors countrywide.

- $\quad$ Request resources to fund additional projects to conduct household budget surveys and labor force surveys. Additional resources are also required for producing a country-wide producer price index in order to improve the accuracy and reliability of the GDP estimates.

- Undertake regular revision studies and publish the results.

- Include commentary on particular data developments in publications to improve assistance to users.

\section{Price Indices}

- $\quad$ Give highest priority to completing the compilation and dissemination of a countrywide CPI. When completed, discontinue production of the RPIs.

- Improve data validation at all stages to enhance the accuracy and reliability of the final results.

- $\quad$ Post monthly short- and long-term annual data series on the agencies' website in order to improve data accessibility.

\section{Government Finance Statistics}

- $\quad$ Expand the institutional coverage of the GFS to include all the road funds.

- $\quad$ Expand the data collection programs to include cash flow data (cash statement) and balance sheet data.

- $\quad$ Apply the same institutional classification for general government in all sectors.

- $\quad$ In order to assist with the inter-sectoral data consistency checks, undertake compilation of a financial balance sheet for the general government.

- $\quad$ Continue to explore data sources to gain more information on projects directly financed by international donors. 
- In cooperation with the government institutions, include the GFS classification codes in their charts of accounts to improve the quality of the source data and to facilitate the processing of the data.

- Disseminate data on domestic debt as soon as they become available.

\section{Monetary Statistics}

- $\quad$ Establish formal arrangements for backing up the single staff member working on monetary and financial statistics in each $\mathrm{CBBH}$ main unit with a view to ensuring efficient use of existing staff resources.

- $\quad$ Reclassify RS Road Fund from public nonfinancial corporation to government unit (extra-budgetary fund) based on economic classification instead of legal decision.

- Show separately all categories of financial instruments in monetary data as recommended by the MFSM.

\section{Balance of Payments Statistics}

- Develop additional data sources as resources become available, particularly surveys of household to collect data on remittances.

- Work to obtain data on international arrivals and departures data, and on surveys of travelers' expenditure patterns to improve travel credits and debits.

- Reclassify some items currently included in capital transfers to other items so as to be consistent with international definitions.

- Reclassify interest from inter-company loans as income from direct investment instead of income from other investment.

- $\quad$ Continue to review and improve adjustments based on additional information and studies and replace them with collected data, where possible. 
Table 4. Bosnia and Herzegovina: Practices Compared to the GDDS Coverage

Periodicity, and Timeliness of Data

\begin{tabular}{|c|c|c|c|c|c|}
\hline \multirow{2}{*}{ GDDS Data Category } & \multirow{2}{*}{$\begin{array}{l}\text { Coverage (meets } \\
\text { GDDS) }\end{array}$} & \multicolumn{2}{|c|}{ Periodicity } & \multicolumn{2}{|c|}{ Timeliness } \\
\hline & & GDDS & $\mathrm{BiH}$ & GDDS & $\mathrm{BiH}$ \\
\hline \multicolumn{6}{|c|}{ COMPREHENSIVE FRAMEWORK } \\
\hline Real sector: National Accounts & Yes & $\mathrm{A}$ & A & $10-14$ months & 7 months \\
\hline $\begin{aligned} \text { Fiscal sector: } & \text { Central govt. operations } \\
& \text { General govt. operations } \\
& \text { General govt. debt }\end{aligned}$ & $\begin{array}{c}\text { Yes } \\
\text { Yes } \\
\text { Foreign debt only }\end{array}$ & $\begin{array}{l}\mathrm{A} \\
A \\
\mathrm{~A}\end{array}$ & $\begin{array}{l}\mathrm{Q} \\
A \\
\mathrm{Q}\end{array}$ & $\begin{array}{l}6-9 \text { months } \\
6-9 \text { months } \\
6-9 \text { months }\end{array}$ & $\begin{array}{l}3 \text { months } \\
6 \text { months } \\
3 \text { months }\end{array}$ \\
\hline Financial sector: Depository Corporations Survey & Yes & $\mathrm{M}$ & $\mathrm{M}$ & $2-3$ months & 5 weeks \\
\hline $\begin{array}{l}\text { External sector: Balance of payments } \\
\text { International Investment Position (IIP) }\end{array}$ & $\begin{array}{l}\text { Yes } \\
\text { N/A } \\
\end{array}$ & $\begin{array}{l}\mathrm{A} \\
A\end{array}$ & $\begin{array}{c}\mathrm{Q} \\
N / A\end{array}$ & $\begin{array}{l}6-9 \text { months } \\
6-9 \text { months }\end{array}$ & $\begin{array}{c}3 \text { months } \\
N / A\end{array}$ \\
\hline \multicolumn{6}{|c|}{ DATA CATEGORIES AND INDICATORS } \\
\hline \multicolumn{6}{|l|}{ Real Sector } \\
\hline $\begin{array}{l}\text { National accounts aggregates: } \\
\text { GDP (nominal and real) } \\
\text { Gross national income, capital formation, saving }\end{array}$ & $\begin{array}{l}\text { Yes (nominal only) } \\
\text { Yes }\end{array}$ & $\begin{array}{l}\mathrm{A}(\mathrm{Q}) \\
\quad \mathrm{A}\end{array}$ & $\begin{array}{l}\text { A } \\
A\end{array}$ & $\begin{array}{l}6-9 \text { months } \\
6-9 \text { months }\end{array}$ & $\begin{array}{l}7 \text { months } \\
11 \text { months }\end{array}$ \\
\hline $\begin{array}{l}\text { Production index/indices } \\
\text { Manufacturing or industrial production index/indices } \\
\text { Primary commodity, agricultural, or other indices, as } \\
\text { relevant }\end{array}$ & $\begin{array}{l}\text { Yes } \\
\text { N/A }\end{array}$ & $\begin{array}{l}\mathrm{M} \\
\text { As relevant }\end{array}$ & $\begin{array}{c}M \\
N / A\end{array}$ & $\begin{array}{l}6-12 \text { weeks } \\
6-12 \text { weeks }\end{array}$ & $\begin{array}{l}25 \text { days (Entities) } \\
\text { N/A }\end{array}$ \\
\hline $\begin{array}{l}\text { Price indices: } \\
\text { Retail price index } \\
\text { Producer price index }\end{array}$ & $\begin{array}{l}\text { Yes } \\
\text { Yes }\end{array}$ & $\begin{array}{l}M \\
M\end{array}$ & $\begin{array}{l}M \\
M\end{array}$ & $\begin{array}{l}1-2 \text { months } \\
1-2 \text { months }\end{array}$ & $\begin{array}{l}15 \text { days (Entities) } \\
15 \text { days } \\
\text { (Federation) }\end{array}$ \\
\hline $\begin{array}{l}\text { Labor market indicators: } \\
\text { Employment } \\
\text { Unemployment } \\
\text { Wages/earnings (all sectors) }\end{array}$ & $\begin{array}{l}\text { Yes } \\
\text { Yes } \\
\text { Yes }\end{array}$ & $\begin{array}{l}\text { A } \\
\text { A } \\
\text { A }\end{array}$ & $\begin{array}{l}\text { Biannual } \\
\text { Biannual } \\
\text { M }\end{array}$ & $\begin{array}{l}6-9 \text { months } \\
6-9 \text { months } \\
6-9 \text { months } \\
\end{array}$ & $\begin{array}{c}\text { Biannual (Entities) } \\
\text { Biannual (Entities) } \\
45 \text { days (Entities) }\end{array}$ \\
\hline \multicolumn{6}{|l|}{ Fiscal Sector } \\
\hline $\begin{array}{l}\text { Central government aggregates: } \\
\text { Central govt. budgetary aggregates: revenue, } \\
\text { expenditure, balance, and financing with breakdowns } \\
\text { (debt holder, instrument, currency) } \\
\text { Interest payments }\end{array}$ & $\begin{array}{l}\text { Yes } \\
\text { Yes }\end{array}$ & Q & Q & $\begin{array}{l}1 \text { quarter } \\
1 \text { quarter }\end{array}$ & $\begin{array}{l}1 \text { quarter } \\
1 \text { quarter }\end{array}$ \\
\hline $\begin{array}{l}\text { Central government debt: } \\
\text { Central govt. debt: domestic and foreign debt, as relevant, } \\
\text { with } \\
\text { appropriate breakdowns (debt holder, instrument, } \\
\text { currency) } \\
\text { Government guaranteed debt }\end{array}$ & $\begin{array}{l}\text { Foreign debt only } \\
\qquad \text { N/A }\end{array}$ & $\begin{array}{l}A(Q) \\
A(Q)\end{array}$ & $\begin{array}{l}\mathrm{Q} \\
N / A\end{array}$ & $\begin{array}{l}\text { 1-2 quarters } \\
1-2 \text { quarters }\end{array}$ & $\begin{array}{l}1 \text { quarter } \\
N / A\end{array}$ \\
\hline \multicolumn{6}{|l|}{ Financial Sector } \\
\hline Broad money and credit aggregates & Yes & $\mathrm{M}$ & $\mathrm{M}$ & $1-3$ months & 5 weeks \\
\hline Central bank aggregates & Yes & $\mathrm{M}$ & $\mathrm{M}$ & $1-2$ months & 5 weeks \\
\hline $\begin{array}{l}\text { Interest rates: } \\
\text { Short- and long-term govt. security rates, policy variable } \\
\text { rate } \\
\text { Money or interbank market rates and a range of deposit } \\
\text { and lending rates }\end{array}$ & $\begin{array}{l}\text { N/A } \\
\text { Deposit and } \\
\text { lending rates meet } \\
\text { GDDS } \\
\text { recommendations }\end{array}$ & M & $\begin{array}{l}\mathrm{N} / \mathrm{A} \\
\mathrm{M}\end{array}$ & $1 /$ & $\begin{array}{c}\mathrm{N} / \mathrm{A} \\
5 \text { weeks }\end{array}$ \\
\hline $\begin{array}{l}\text { Stock market: } \\
\text { Share price index, as relevant }\end{array}$ & $\mathrm{N} / \mathrm{A}$ & $M$ & N/A & $1 /$ & $\mathrm{N} / \mathrm{A}$ \\
\hline \multicolumn{6}{|l|}{ External Sector } \\
\hline Balance of payments aggregates & Yes & $A(Q)$ & Q & 6 months & 3 months \\
\hline $\begin{array}{l}\text { Public and publicly guaranteed external debt outstanding, } \\
\text { with } \\
\text { maturity breakdown }\end{array}$ & $\begin{array}{l}\text { General govt. debt. } \\
\text { No maturity } \\
\text { breakdown }\end{array}$ & Q & Q & $1-2$ quarters & 1 quarter \\
\hline Public and publicly guaranteed debt service schedule & $\mathrm{N} / \mathrm{A}$ & $6 \mathrm{M}$ & $\mathrm{N} / \mathrm{A}$ & $3-6$ months & $\mathrm{N} / \mathrm{A}$ \\
\hline Private external debt not publicly guaranteed & $\mathrm{N} / \mathrm{A}$ & $A$ & $N / A$ & 6-9 months & N/A \\
\hline $\begin{array}{l}\text { International reserves: } \\
\text { Gross official reserves denominated in U.S. dollars } \\
\text { Reserve-related liabilities }\end{array}$ & $\begin{array}{l}\text { Yes, but in national } \\
\text { currency } \\
\text { Yes }\end{array}$ & M & $\begin{array}{l}\text { M (published } \\
\text { quarterly) } \\
\text { M }\end{array}$ & $\begin{array}{l}1-4 \text { months } \\
1-4 \text { months }\end{array}$ & $\begin{array}{l}5 \text { weeks } \\
5 \text { weeks }\end{array}$ \\
\hline $\begin{array}{l}\text { Merchandise trade: } \\
\text { Total exports and total imports } \\
\text { Major commodity breakdowns with longer time lapse }\end{array}$ & $\begin{array}{l}\text { Yes } \\
\text { Yes }\end{array}$ & $\begin{array}{l}\mathrm{M} \\
M\end{array}$ & $\begin{array}{l}M \\
M\end{array}$ & $\begin{array}{l}8 \text { wks }-3 \text { mths } \\
8 \text { wks }-3 \text { mths }\end{array}$ & $\begin{array}{l}3 \text { weeks } \\
3 \text { weeks }\end{array}$ \\
\hline Exchange rates: spot rates & Yes & Daily & $\mathrm{M}$ & $1 /$ & $5-6$ weeks \\
\hline
\end{tabular}

Italics indicate encouraged categories.

$D=$ daily; $W=$ weekly; $M=$ monthly; $Q=$ quarterly; $A=$ annual; $N / A=$ not applicable/not available.

$1 /$ Dissemination as part of a high-frequency (e.g. monthly) publication. 
INTERNATIONAL MONETARY FUND

BOSNIA AND HERZEGOVINA

\section{Report on the Observance of Standards and Codes (ROSC)—Data Module}

Response by the Authorities

January 7, 2008

Contents

Page

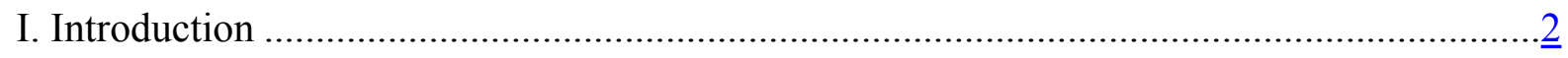

II. Status of Implementation of Recommendations …………...........................................

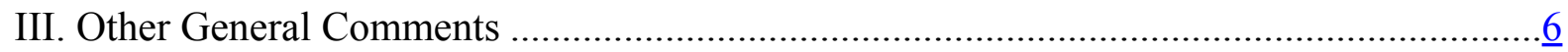

Tables

1. Cross-cutting Recommendations …………..............................................................

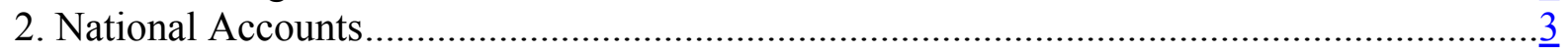

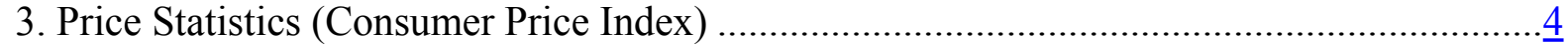

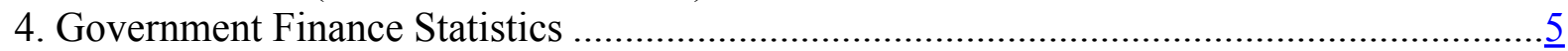

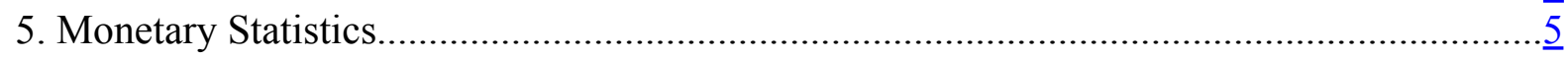

6. Balance of Payments Statistics .................................................................................... 


\section{INTRODUCTION}

1. The following is the response by the authorities to the Report on The Observance of Standards and Codes (ROSC) - Data Module mission from the International Monetary Fund (IMF) of March 13-28, 2007 based on the comments of the statistical institutions of Bosnia and Herzegovina (Bosnia and Herzegovina Agency for Statistics, Federal Institute of Statistics of the Federation of Bosnia and Herzegovina, and Republika Srpska Institute of Statistics) and the Central Bank of Bosnia and Herzegovina.

\section{STATUS OF IMPLEMENTATION OF RECOMMENDATIONS}

2. The institutions of Bosnia and Herzegovina highly appreciate the thorough assessment of the macroeconomic statistics undertaken by the IMF mission that prepared the data module of the Report on the Observance of Standards and Codes (ROSC) for Bosnia and Herzegovina. The assessment has been very useful for the concerned institutions, and they have already implemented some of its recommendations, as noted in the summary below.

Table 1. Cross-cutting Recommendations

\begin{tabular}{|c|c|}
\hline Recommendation & Comments by Institutions \\
\hline $\begin{array}{l}\text { Strengthen the mandate of the BHAS to } \\
\text { coordinate a cohesive national statistical } \\
\text { role in planning and implementing the work } \\
\text { programs of the entity statistical institutes, } \\
\text { inclusive of budget preparation processes. }\end{array}$ & \\
\hline $\begin{array}{l}\text { Improve coordination and cooperation } \\
\text { among statistical institutions that are } \\
\text { responsible for compiling national accounts } \\
\text { and price statistics to produce effective } \\
\text { country-wide work programs. Establish } \\
\text { working groups among major data } \\
\text { producing agencies to improve data sharing } \\
\text { and validation, thereby enhancing } \\
\text { intersectoral consistency. }\end{array}$ & $\begin{array}{l}\text { Work on the development of the Master Plan for the national } \\
\text { accounts is currently in progress. The main purpose of this } \\
\text { document is to define the institutional arrangements and the } \\
\text { organization of national accounts work given the fact that } \\
\text { national accounts are the main user of data from other statistical } \\
\text { departments. Also, it will be used as a tool for defining } \\
\text { responsibilities among the institutes responsible for the national } \\
\text { accounts data collection at the level of the country, as well as at } \\
\text { the level of the entities. There is a number of working groups } \\
\text { aiming at enhancing inter-sectoral consistency. }\end{array}$ \\
\hline $\begin{array}{l}\text { Conduct regular (quarterly or annual) inter- } \\
\text { sectoral data consistency checks and } \\
\text { produce reports on the conclusions of these } \\
\text { checks. }\end{array}$ & $\begin{array}{l}\text { Statistical system of Bosnia and Herzegovina is aware of certain } \\
\text { inter-sectoral data inconsistency. Statistical institutes will make } \\
\text { additional efforts to check all existing inconsistencies and to } \\
\text { gradually eliminate them. Statistical institutes are willing to } \\
\text { collaborate in this process with other relevant institutions. } \\
\text { CBBH acknowledges certain inter-sectoral data inconsistency. } \\
\text { Within the institution, there will be additional efforts to check } \\
\text { and describe all existing inconsistencies and to gradually } \\
\text { eliminate them. Collaboration on consistency checks with other } \\
\text { statistical institutions is also necessary and CBBH is willing to } \\
\text { participate in the process. }\end{array}$ \\
\hline Provide additional resources to statistical & Statistical institutes are aware of their limited resources for \\
\hline
\end{tabular}




\begin{tabular}{|c|c|}
\hline Recommendation & Comments by Institutions \\
\hline $\begin{array}{l}\text { institutions responsible for compiling } \\
\text { national accounts, prices, government } \\
\text { finance, and balance of payments statistics. }\end{array}$ & $\begin{array}{l}\text { statistical activities. The number of persons working in the } \\
\text { national accounts has already been increased. } \\
\text { Further gradual increase of staff and other resources will be } \\
\text { implemented over next years in order to increase coverage and } \\
\text { the quality of statistics. } \\
\text { Statistical institutes are preparing the new organizational } \\
\text { schemes. } \\
\text { CBBH acknowledges limited resources for statistical activities. } \\
\text { Gradual increase of staff and other resources will be } \\
\text { implemented over next years in order to increase coverage and } \\
\text { quality of the existing statistics and introduce new statistic } \\
\text { products. }\end{array}$ \\
\hline $\begin{array}{l}\text { Enhance the role of the Statistical Council } \\
\text { in setting priorities for the country's work } \\
\text { program by enlarging its composition to } \\
\text { include representatives of the private sector. }\end{array}$ & $\begin{array}{l}\text { Statistical Council should play more prominent role in } \\
\text { determining future statistical activities. } \\
\text { Inclusion of new members and more power to the Council will } \\
\text { increase its effectiveness. }\end{array}$ \\
\hline $\begin{array}{l}\text { Move forward with GDDS participation, so } \\
\text { as to provide a framework for statistical } \\
\text { improvements, reflecting national priorities. } \\
\text { As a first step, appoint a GDDS country } \\
\text { coordinator for BiH. }\end{array}$ & $\begin{array}{l}\text { The Statistical System in Bosnia and Herzegovina is determined } \\
\text { towards participation in GDDS. All activities conducted inside } \\
\text { this system are aimed towards improving the overall quality of } \\
\text { produced data in compliance with the international standards. } \\
\text { CBBH fully supports GDDS participation and will meet all } \\
\text { necessary preconditions for fulfilling GDDS criteria in } \\
\text { government finance, monetary finance, and balance of payments } \\
\text { statistics. Our expectation is Bosnia and Herzegovina may start } \\
\text { its participation to the GDDS during } 2008 \text {. }\end{array}$ \\
\hline $\begin{array}{l}\text { Prepare and disseminate detailed manuals } \\
\text { of sources and methods used for the } \\
\text { compilation of the national accounts and } \\
\text { price statistics. }\end{array}$ & $\begin{array}{l}\text { Regarding the price statistics, the comprehensive manual on data } \\
\text { collecting, processing and dissemination, as well as on data } \\
\text { sources and used methods is already published and disseminated. } \\
\text { Draft Master Plan is predicting to fulfill this task for national } \\
\text { accounts by the year 2010, with the help of international experts. }\end{array}$ \\
\hline $\begin{array}{l}\text { Establish formal procedures to identify } \\
\text { user's needs. }\end{array}$ & $\begin{array}{l}\text { The statistical institutes will work on improvement of the } \\
\text { cooperation with the users of statistical data in order to identify } \\
\text { and satisfy their needs. We consider it to be a continuous task of } \\
\text { the Statistical Institutes of Bosnia and Herzegovina. } \\
\text { CBBH will undertake measures to have more substantive } \\
\text { consultation with users in order to identify their needs in line } \\
\text { with best practices. }\end{array}$ \\
\hline $\begin{array}{l}\text { Disseminate all data on the website in a } \\
\text { format that is downloadable and user- } \\
\text { friendly, such as Excel. }\end{array}$ & $\begin{array}{l}\text { BHAS has recently undertaken a redesign of its website in order } \\
\text { to improve data access for all users. } \\
\text { CBBH has recently undertaken a redesign of its website in order } \\
\text { to improve data access for all users. Our future focus will be to } \\
\text { use IT advancement for easier data and metadata access. }\end{array}$ \\
\hline
\end{tabular}

Table 2. National Accounts

\begin{tabular}{|l|l|}
\hline Recommendation & Comments by institution \\
\hline $\begin{array}{l}\text { Finalize and publish the constant price GDP } \\
\text { estimates and the expenditure components of } \\
\text { GDP. }\end{array}$ & $\begin{array}{l}\text { In July 2007, the expenditure components of GDP estimates in } \\
\text { constant and current prices have been finalized and published for } \\
\text { the years 2004 and 2005. The same exercise has been completed } \\
\text { for the production side of GDP estimates (2004-2006). }\end{array}$ \\
\hline Finalize the estimates of the non observed & The estimates of the non-observed economy in the period 2003- \\
\hline
\end{tabular}




\begin{tabular}{|l|l|}
\hline Recommendation & Comments by institution \\
\hline $\begin{array}{l}\text { economy and integrate them into the national } \\
\text { accounts. }\end{array}$ & 2006 have been finalized and included in the national ccounts. \\
\hline $\begin{array}{l}\text { Advance the work for the construction of a } \\
\text { business register making use of all available } \\
\text { databases. Once the business register is } \\
\text { available, (i) consider introducing regular } \\
\text { business surveys and (ii) completing the } \\
\text { identification of the institutional sectors } \\
\text { countrywide. }\end{array}$ & $\begin{array}{l}\text { The activities on creation of the Business Register have been } \\
\text { undertaken using all available databases. It is planned to use the } \\
\text { Business Register as the frame for sample design and for business } \\
\text { surveys implementation. }\end{array}$ \\
\hline $\begin{array}{l}\text { Request resources to fund additional project } \\
\text { to conduct household budget surveys and } \\
\text { labor force surveys. Additional resources are } \\
\text { also required for producing a country-wide } \\
\text { producer price index in order to improve the } \\
\text { accuracy and reliability of the GDP estimates. }\end{array}$ & $\begin{array}{l}\text { Field work on the Household Budget Survey of 2007 is currently in } \\
\text { progress. Its results will be available by mid-2008. The next HBS } \\
\text { is planned for 2009. } \\
\text { The results of the Labour Force Survey of 2007 were published. } \\
\text { The next LFS is planned for 2008. } \\
\text { Both surveys are planned to become regular activities conducted in } \\
\text { the statistical system of Bosnia and Herzegovina . } \\
\text { The work on the software application design for calculating the } \\
\text { Industrial Production Index (IPI) at the state and entities level is } \\
\text { currently in progress. In the BHAS' Plan of Statistical Activities } \\
\text { for 2008 it is stipulated that the experimental calculation of state } \\
\text { level IPI should start by the middle of next year. }\end{array}$ \\
\hline $\begin{array}{l}\text { The revision procedures will be defined by the Master Plan. } \\
\text { Include commentary on particular data } \\
\text { developments in publications to improve } \\
\text { assistance to users. }\end{array}$ & $\begin{array}{l}\text { The Statistical System of Bosnia and Herzegovina acknowledges } \\
\text { the lack of additional comments necessary to improve assistance to } \\
\text { users, and it is determent to increase its efforts in order to produce } \\
\text { more user-friendly publications. }\end{array}$ \\
\hline
\end{tabular}

Table 3. Price Statistics (Consumer Price Index)

\begin{tabular}{|l|l|}
\hline Recommendation & Comments by institution \\
\hline $\begin{array}{l}\text { Give highest priority to completing the } \\
\text { compilation and dissemination of a } \\
\text { countrywide CPI. When completed, } \\
\text { discontinue production of the RPIs. }\end{array}$ & $\begin{array}{l}\text { The new methodology for producing the consumer price index } \\
\text { (CPI) in accordance with European methodologies and } \\
\text { recommendations has been introduced into the statistical system of } \\
\text { Bosnia and Herzegovina and is now being published regularly. } \\
\text { Weights have been estimated on the basis of final results of HBS of } \\
\text { 2004. A new weighting system for CPI will be estimated as soon as } \\
\text { the results of HBS 2007 will be available. There are no } \\
\text { inconsistencies in the methods of CPI data collecting and } \\
\text { publishing. CPI is considered to be of a very high priority inside } \\
\text { the Statistical System of Bosnia and Herzegovina. }\end{array}$ \\
\hline $\begin{array}{l}\text { Improve data validations at all stages to } \\
\text { enhance the accuracy and reliability of the } \\
\text { final results. }\end{array}$ & $\begin{array}{l}\text { Improvement of CPI data quality is a constant task of Price } \\
\text { Statistics Department. Commonly used software application is } \\
\text { providing the information on extreme discrepancies in prices from } \\
\text { month to month in order to make the corrections. Also field work } \\
\text { controls are made from time to time but we are determined to } \\
\text { introduce regular and more intensive controls in order to maintain } \\
\text { the representatives of the basket and collection units. }\end{array}$ \\
\hline $\begin{array}{l}\text { Post monthly short-and long-term annual data } \\
\text { series on the agencies' website in order to }\end{array}$ & $\begin{array}{l}\text { Monthly CPI from January 2005 onwards have been published in } \\
\text { September 2007. Since then, monthly CPI data are published on }\end{array}$ \\
\hline
\end{tabular}


improve data accessibility.

the $15^{\text {th }}$ day of the following month in paper form and on the website.

Table 4. Government Finance Statistics

\begin{tabular}{|c|c|}
\hline Recommendation & Comments by institution \\
\hline $\begin{array}{l}\text { Expand the institutional coverage of the GFS } \\
\text { to include all the road funds. }\end{array}$ & $\begin{array}{l}\text { Recommendation is already implemented. The institutional } \\
\text { coverage of the GFS has been already extended and now includes } \\
\text { all the road funds in the sector of general government. }\end{array}$ \\
\hline $\begin{array}{l}\text { Expand the data collection programs to } \\
\text { include cash flow data (cash statement)and } \\
\text { balance sheet data. }\end{array}$ & $\begin{array}{l}\text { This recommendation is included in the CBBH plans. Full } \\
\text { implementation of the recommendation depends on data sources } \\
\text { and, also, available resources. }\end{array}$ \\
\hline $\begin{array}{l}\text { Apply the same institutional classification for } \\
\text { general government in all sectors. }\end{array}$ & $\begin{array}{l}\text { The CBBH accepts the recommendation and it will be part of short } \\
\text { term plan activities. Reconciliation of different classifications of } \\
\text { general government units in general government sector will be } \\
\text { analyzed and we expect to resolve the issue between GFS and } \\
\text { financial sector and external sector and to discuss it with BHAS as } \\
\text { well. }\end{array}$ \\
\hline $\begin{array}{l}\text { In order to assist with the inter-sectoral data } \\
\text { consistency checks, undertake compilation of } \\
\text { a financial balance sheet for the general } \\
\text { government. }\end{array}$ & $\begin{array}{l}\text { Recommendation is already respected by the CBBH and } \\
\text { compilation of financial balance sheets for the general government } \\
\text { units is initiated. }\end{array}$ \\
\hline $\begin{array}{l}\text { Continue to explore data source to gain more } \\
\text { information on projects directly financed by } \\
\text { international donors. }\end{array}$ & $\begin{array}{l}\text { Recommendation is acceptable. CBBH continuously cooperate } \\
\text { with related government institutions and international donors on } \\
\text { the issue, but existing source data are very scarce and unreliable. } \\
\text { CBBH will try to explore additional sources and information. }\end{array}$ \\
\hline $\begin{array}{l}\text { In cooperation with the government } \\
\text { institutions, include the GFS classification } \\
\text { codes in their charts of accounts to improve } \\
\text { the quality of the sources data and to facilitate } \\
\text { the processing of the data. }\end{array}$ & $\begin{array}{l}\text { This issue depends entirely on government institutions but in a } \\
\text { short term CBBH will initiate work on the issue with } \\
\text { representatives of respected government units and provide } \\
\text { technical assistance in drafting Charts of accounts. ROSC } \\
\text { recommendations will play an important role in this work. }\end{array}$ \\
\hline $\begin{array}{l}\text { Dissemination data on domestic debt as soon } \\
\text { as they become available. }\end{array}$ & $\begin{array}{l}\text { Domestic debt statistics will be compiled and disseminated as soon } \\
\text { as source data on domestic debt are made available by respected } \\
\text { authorities. }\end{array}$ \\
\hline
\end{tabular}

\section{Table 5. Monetary Statistics}

\section{Recommendation}

Establish formal arrangements for backing up the single staff member working on monetary and financial in each CBBH main unit with a view to ensuring efficient use of existing staff resource.

Reclassify RS Road Fund from public nonfinancial corporation to government unit (extra-budgetary fund) based on economic classification instead of legal decision.

Show separately all categories of financial instruments in monetary data as recommended by the MFSM.

\section{Comments by institution}

Recommendation is acceptable and CBBH will make arrangements for backing up the single staff member in each $\mathrm{CBBH}$ unit during 2008.

Recommendation is acceptable and will be implemented very soon. Separate data for RS Road Fund were already collected and it would be easy to reclassify the Fund into government sector.

Recommendation will be fulfilled completely very soon when CBBH fully implements new methodology based on MFSM 2000. 
Table 6. Balance of Payments Statistics

\begin{tabular}{|l|l|}
\hline Recommendation & Comments by Institution \\
\hline $\begin{array}{l}\text { Develop additional data sources as resources } \\
\text { become available, particularly surveys of } \\
\text { household to collect data on remittances. }\end{array}$ & $\begin{array}{l}\text { Recommendation will be taken into account. In order to achieve } \\
\text { better coverage of balance of payments statistics data, CBBH is } \\
\text { going to cooperate with other statistical agencies on expanded and } \\
\text { more detailed surveys as soon as resources become available. }\end{array}$ \\
\hline $\begin{array}{l}\text { Work to obtain data on international arrivals } \\
\text { and departures data and on surveys of } \\
\text { travellers' expenditure patterns to improve } \\
\text { travel credits and debits. }\end{array}$ & $\begin{array}{l}\text { Recommendation will be taken into account, since existing travel } \\
\text { statistics is not sufficient. CBBH is going to work closely with } \\
\text { other statistical and government agencies in order to improve data } \\
\text { sources. }\end{array}$ \\
\hline $\begin{array}{l}\text { Reclassify some items currently included in } \\
\text { capital transfers to other items so as to be } \\
\text { consistent with international definitions. }\end{array}$ & $\begin{array}{l}\text { Recommendation is acceptable. CBBH has already been working } \\
\text { on reclassification of the items currently included in capital } \\
\text { transfers to current transfers. Reclassification will be introduced in } \\
\text { balance of payments statistics by end 2007. }\end{array}$ \\
\hline $\begin{array}{l}\text { Reclassify interest from inter-company loans } \\
\text { as income from direct investment instead on } \\
\text { income from other investment. }\end{array}$ & $\begin{array}{l}\text { Recommendation is acceptable. CBBH has already been working } \\
\text { on reclassification of the interest form inter-company loans. } \\
\text { Reclassification will be introduced in balance of payments } \\
\text { statistics by end 2007. }\end{array}$ \\
\hline $\begin{array}{l}\text { Continue to revive and improve adjustments } \\
\text { based on additional information and studies } \\
\text { and replace them with collected data, where } \\
\text { possible. }\end{array}$ & $\begin{array}{l}\text { Recommendation will be taken into account. In order to achieve } \\
\text { better coverage of balance of payments data, CBBH is going to } \\
\text { introduce these proposals where possible. }\end{array}$ \\
\hline
\end{tabular}

\section{Other General Comments}

3. It is clear that the ROSC provides a comprehensive evaluation of the quality of the data produced by the statistical institutions, but does not fully take into account the external circumstances, such as the provision of adequate data sources, in particular with regard to the national accounts. This problem has affected both entities for a long period of time. In particular, this is an issue for the Federation of Bosnia and Herzegovina and it can be traced to the lack of administrative data source for enterprises (statistical institutions have just started activities on establishing of SBS and Business registry through Cards Twinning Project). Implementation of international standards and improvements in classifications, collection, processing and dissemination of data of other relevant institutions (ministries of finance, tax administration, Funds etc.), as well as their cooperation and data exchange with statistical institutions would make a significant impact on quality of statistical data. 


\title{
INTERNATIONAL MONETARY FUND
}

BOSNIA AND HERZEGOVINA

\author{
Detailed Assessments Using the Data Quality Assessment Framework (DQAF) \\ Prepared by the Statistics Department \\ Approved by Robert W. Edwards and Michael C. Deppler
}

January 7, 2008

This document contains a detailed assessment by dataset of the elements and indicators that underlie the data quality dimensions discussed in Bosnia and Herzegovina's Report on the Observance of Standards and Codes (ROSC) Data Module. It also includes as appendices a summary of the General Data Dissemination System (GDDS), the generic framework of the Data Quality Assessment Framework (DQAF), and the results of the users' survey, which take into account questionnaire responses and discussions with users. 


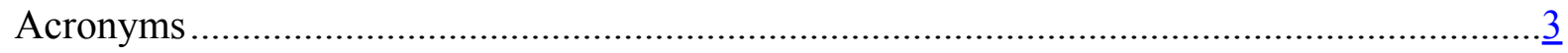

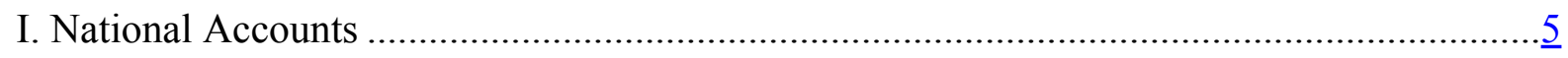

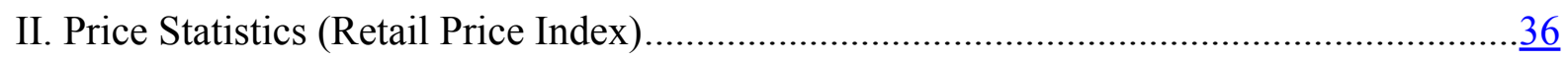

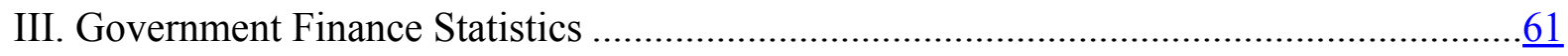

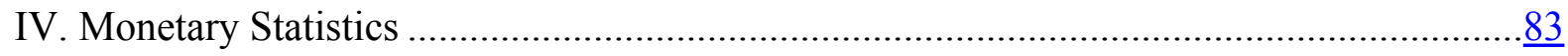

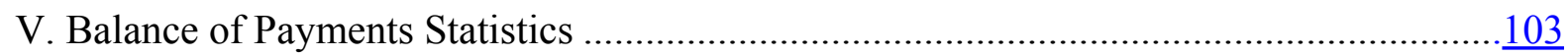

Tables

1. Summary of Results for National Accounts ..................................................................

2. Summary of Results for Price Statistics (Retail Price Index) ...........................................

3. Summary of Results for Government Finance Statistics .................................................

4. Summary of Results for Monetary Statistics …………........................................... $\frac{100}{25}$

5. Summary of Reuslts for Balance of Payments ............................................................

Appendices

I. Summary of the General Data Dissemination System (GDDS) …………………….....127

II. Data Quality Assessment Framework - Generic Framework ……….............................

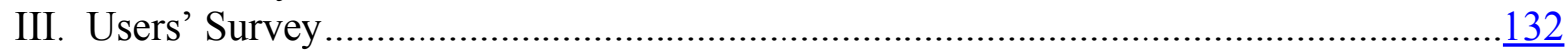

Appendix Tables

6. Questionnaire Results Anaylyzed by Type of User........................................................ 134

7. Results of Users'Survey in Percentage of Total Response...............................................135 


\section{ACRONYMS}

1995 ESA

1993 SNA

BHAS

$\mathrm{BiH}$

BIS

BOP

BPM5

$\mathrm{CBBH}$

CBS

c.i.f.

COICOP

COLI

CPA

CPI

DAC

DCS

DQAF 2003

ERSD

EU

FIS

f.o.b.

GDDS

GDP

GFS

GFSM 2001

GFSU

HBS

IMF

ISWGNA

ITRS

KM

LFS

MAU

MER

MFSM

MFSS

MOFT

$\mathrm{MoU}$

NACE

NATO

NOE
European System of Accounts 1995

System of National Accounts 1993

Bosnia and Herzegovina Agency for Statistics

Bosnia and Herzegovina

Bank for International Settlements

Balance of Payments

Balance of Payments Manual, fifth edition

Central Bank of Bosnia and Herzegovina

Central Bank Survey

cost, insurance, and freight

Classification of Individual Consumption by Purpose

Cost of Living Index

Classification of Products by Activity

Consumer Price Index

Development Assistance Committee

Depository Corporations Survey

Data Quality Assessment Framework

Economic Research and Statistics Department

European Union

Federal Institute of Statistics

free on board

General Data Dissemination System

Gross domestic product

Government Finance Statistics

Government Finance Statistics Manual 2001

Government Finance Statistics Unit

Household Budget Survey

International Monetary Fund

Intersecretariat Working Group on National Accounts

International Transactions Reporting System

Convertible Marka

Labor Force Survey

Macroeconomic Analysis Unit

Monthly Economic Review

Monetary and Financial Statistics Manual

Monetary and Financial Statistics Section

Ministry of Finance and Treasury

Memorandum of Understanding

Statistical Classification of Economic Activities in the European

Communities

North Atlantic Treaty Organization

Non-observed Economy 
ODCs

OECD

PPI

RDD

ROSC

RPI

RS

RSIS

SC

SDRs

SMOF
Other Depository Corporations

Organization for Economic Cooperation and Development

Producer Price Index

Research and Development Department

Report on the Observance of Standards and Codes

Retail Price Index

Republika Srpska

Republika Srpska Institute of Statistics

Statistical Council

Special Drawing Rights

State Ministry of Finance 


\section{Detailed Assessment Using the Data QUALITy Assessment Framework (DQAF)}

The following detailed information on statistical practices in Bosnia and Herzegovina in the areas of the national accounts, prices, government finance, money and banking, and balance of payments statistics was gathered from publicly available documents and information provided by the Bosnian officials. This information, which is organized along the lines of the generic DQAF (see Appendix II), was used to prepare the summary assessment of data quality elements, based on a four-part scale of observance, shown in Bosnia and Herzegovina's Report on the Observance of Standards and Codes (ROSC)—Data Module.

\section{National Accounts}

\section{Prerequisites of quality}

\section{$0.1 \quad$ Legal and institutional environment}

\subsubsection{The responsibility for collecting, processing, and disseminating the statistics is clearly specified}

Reflecting the administrative and political organization of the country, there are three statistical institutions representing the three main levels of government: (a) the Bosnia and Herzegovina Agency for Statistics (BHAS) at the state level, (b) the Federation of Bosnia and Herzegovina Institute of Statistics (FIS), and the Republika Srpska Institute of Statistics (RSIS). The Statistical Office of the autonomous district of Brcko has become an integral part of the BHAS since 2006 by a decision of its government.

The current Law on Statistics of Bosnia and Herzegovina (BiH) was issued in October 2002 by the High Representative with the powers vested in him under the General Framework Agreement for Peace in Bosnia and Herzegovina known as the Dayton Agreement. This decision of the High Representative came after a Law on Statistics endorsed by the Council of Ministers (executive body of BiH) on July 5, 2001 failed to be adopted by the competent authorities. The Law on Statistics was finally ratified by the BiH Parliament in October 2004.

The BiH Law on Statistics states in its Article 3 that the competent authority for the organization, production, and dissemination of the statistics at the level of Bosnia and Herzegovina shall be the Agency established in accordance with the provisions of this Law. The competent authorities in the entities shall be the bodies in the entities whose tasks are carrying out these activities ("Entity Institutes").

The legal bases for the compilation of the statistics at the entity level are the Law on statistics of the Republika Srpska (RS) and the Law on Statistics of the Federation of Bosnia and Herzegovina. Both these laws were issued during 2003 and published in the respective official gazettes of the entities. These laws assign the responsibility for the collection, compilation, and dissemination of the statistics to the respective institute of statistics. 
It should be noted that these laws have not been fully harmonized with the BiH Law on Statistics, as was agreed between the representatives of the state and the entity governments in October 2005. Although the Statistics Law attributes to the BHAS the role of coordinating the statistical work of the country and determining the methodological standards needed to meet the requirements of European Union (EU), the enforcement of the Law's provisions has been slow and hindered by obstacles. The effective harmonization of the laws continues being a pending issue. Furthermore, the Law on Statistics of the RS only has provisions to provide aggregate data to the BHAS (although it states that the confidentiality rules do not apply in providing information to the BHAS); while according to the State Law the entities' institutes of statistics should provide also the individual data, when requested. Another inconsistency found in the Law and practice relates to the period covered by the multi-annual program, which in RS covers also four years but on a rolling basis.

The BiH Law on Statistics does not specify the statistics that should be compiled and disseminated by the Agency but it states that statistics of $\mathrm{BiH}$ are those included in the statistical program of the $\mathrm{BIH}$ and/or other statistics required and/or any other statistics produced by state bodies and endorsed by the Agency. The statistical program is drawn-up for a period of four years (the present program covers the period 2005-2008) and it is being implemented in accordance with annual work plans. The statistical program of $\mathrm{BiH}$ is prepared by the Agency in consultations with the entities' institutes of statistics and endorsed by the Council of Statistics for the approval of the Council of Ministers. The annual work plan of the Agency should also be prepared in consultations with the entities institutes of statistics and submitted to the Council of Statistics for comments before being submitted to the Ministry of Treasure of the State institutions for the corresponding budgetary process.

The Statistics Law of the Federation of BiH determines in Articles 5, 6, and 7 which are the authorized bodies for the production of statistics in the Federation assigning to the Institute of Statistics the responsibility of organizing and "running the statistical research of interest for the Federation." The statistics to be produced are those included in the four-year statistical program prepared by the Institute in cooperation with the other authorized bodies. This program should be endorsed by the government and adopted by the Parliament of the Federation.

Article 4 of the Law on Statistics of the RS states that the RSIS is the authorized institution to carry out statistical activities but also lists other government agencies as authorized institutions. Article 6 of this Law states that the Institute defines the methodology and standards to be used in the implementation of the statistical work program of the entity. The Law states in its Article 3 the general scope of the statistics to be produced and leaves to the four-year annual statistical plan the determination of the detailed data to be produced.

According to Article 9 of then Law, the four-year plan is to be prepared annually. The plan is to be prepared by the Institute and adopted by the People Assembly after being endorsed by the government.

As mentioned above, the Law on Statistics does not clearly specify the statistics that should be compiled and disseminated by the Agency. However, the text explicitly mentions that 
statistics disseminated by the entities for their purposes ("Entity Statistics") shall be excluded from the BHAS program. The statistical work program of the $\mathrm{BiH}$ is equally binding on all parties involved. Given the fact that the entities' individual programs of statistics are independently set up with a view to responding to their priority needs, possible conflicts of interests may arise, a situation which has actually occurred

\subsubsection{Data sharing and coordination among data-producing agencies are adequate}

Coordination among data-producing agencies is adversely affected by the complex administrative and political structure of the country. General provisions fostering coordination and cooperation in the production of statistics are found in the statistical laws, however, with different emphasis according to the level of operation. At the State level, according to the Law on Statistics of $\mathrm{BiH}$, the BHAS is assigned the responsibility for coordination of the country's statistics, with a view of integrating the work of the entity statistical offices for the benefit of country's macroeconomic statistics. On the other hand, entity legislation broadly reflects existing work arrangements in place that promote the independence of the entities. However, in spite of their independence in undertaking certain activities, the entities have the obligation to align their programs, methods, and standards with those of the BHAS. Although there has been recent progress in the dialogue between the BHAS and the entities, more needs to be done to strengthen the cooperation among these agencies.

Another factor affecting coordination and data-sharing is related to the composition of Statistical Councils (SCs) at the levels of the state and the entities. Initially conceived as a consultative body to advise on the preparation and implementation of the statistical work program, the $\mathrm{SC}$ of $\mathrm{BiH}$ is not an effective tool in promoting inter-agency cooperation, mainly due to the conflicting interests of its membership. ${ }^{1}$ This has a direct impact on the statistical work program of the BHAS that is drawn-up for a period of four years in consultations with the entities' Institutes of Statistics, and endorsed by the Council of Statistics for the approval of the Council of Ministers. In addition, the annual work plan of the BHAS, which is also be prepared in consultations with the Entities Institutes of Statistics diverge from the work programs of the entities, which include an annual and a mid-term program due to different political priorities. Weaknesses in the harmonization and coordination of work programs of the involved institutions are reflected in the lack of timeliness in incorporating new developments and projects into the individual statistical programs.

\footnotetext{
${ }^{1}$ It covers (i) the Director of the Agency, his Deputy and directors of the Entity Institutes; (ii) the Head of the Brcko Branch and any other head of branches which the Agency may establish under this Law; (iii) the Governor of the Central Bank of $\mathrm{BiH}$ (or his representative); and (iv) the Minister of Treasury of Common Institutions (or his representative). It also includes three members amongst the users operating in the field of statistics, economics, or business.
} 
The organization of a proper statistical system at the state level would avoid duplication of efforts and also create a proper environment for a smooth and timely flow of information among various agencies in their capacity of producer and/or user of statistics. For example, with respect to national accounts statistics, an improved cooperation with ministries/agencies responsible for specific statistics would alleviate the burden of collection and processing of individual unit data by statistical agencies. In particular, in the Federation of $\mathrm{BiH}$, cooperation with the Ministry of Finance to facilitate data processing would be very beneficial to the FIS avoiding also duplication of efforts (data processing) and creating the possibility for expansion of national accounts statistics scope. Similarly, in the RS, more involvement in producing specific statistics is expected, for example, from the Ministry of Agriculture.

An example of significant efforts to secure cooperation of various agencies at the state level, is a Memorandum of Understanding (MOU) that the BHAS has signed with several institutions, most recently (January 2007) with the Central Bank of Bosnia and Herzegovina $(\mathrm{CBBH})$. These MOUs represent official agreements determining responsibilities for each party and methods for mutual exchange of information.

Recommendation: Enhance the role of the Statistical Council to support an effective implementation of the statistical work programs. Enlarge its composition to include representatives of the private sector.

Recommendation: Improve cooperation among the institutions involved in national accounts compilation by encouraging an open dialogue and a timely and adequate data flow. Improve cooperation with the agencies responsible for compilation of area-related statistics that constitute source data for national accounts compilation (see text above).

\subsubsection{Individual reporters' data are to be kept confidential and used for statistical purposes only}

The BiH Law on statistics as well as the respective entities' laws provide for the confidentiality of the individual data reported to them. All confidentially matters related to the data provided for statistical purposes are covered by Articles 23 thru 29 of the Section XI of the BiH Law "STATISTICAL CONFIDENTIALITY AND LAW ON PROTECTION OF PERSONAL DATA."

Article 23 establishes that data collected, processed and stored for the production of statistics of Bosnia and Herzegovina shall be confidential. Article 26 of this Law prevents the disclosure of individual data establishing that "Statistics of Bosnia and Herzegovina must not be disseminated to users, if they contain or reveal confidential data. Aggregates shall comprise at least three units and the share of one unit in an aggregate must not exceed 85 percent of the total." However, the second paragraph within the same article of the Law provides the Agency with discretionary rights to disseminate data in contravention of the rules mentioned in paragraph 1 , if these data are considered to be important basic information and provided that the Statistical Program foresees the dissemination of such information. 
Only the staff engaged in the statistics compilation has access to the data, and, so far, there have been no breaches of the data confidentiality. The confidentiality of the individual data is also protected when providing unit records to users (e.g., for research purposes) by making all records anonymous.

The forms used by the entities to collect data make reference to the entity's Law on Statistics. In joint projects such as the household budget survey (HBS), there is a clear statement that the data are confidential.

The BiH Law on Statistics establishes penalties for infringing the confidentiality of the data provided for statistical purposes in its Section XII, Articles 31, 32, and 33. The Law dictates a penalty of up to two years of imprisonment and/or a fine of up to five thousand Convertible Marks for any person who has access to confidential data and divulges the information in contravention of the Law.

Both entities' Laws on Statistics prescribe monetary fines in varying amounts for legal units versus physical persons. All three statistical institutions have adequate rules in place to prevent residual disclosure of individual data. Premises are also secured and cannot be accessed without due authorization.

\subsubsection{Statistical reporting is ensured through legal mandate and/or measures to encourage response}

The BiH Law on Statistics entitles the BHAS to collect data from any natural or legal person (Art. 3) needed for the compilation of the statistics included in the program or any other statistics the BHAS needed. The Law also prescribes penalties for non-compliance (Art. 31), stating "A Statistical Unit (other than the entity institutes) that knowingly provides false or misleading information in response to written requests by the Agency to meet the needs of the Program shall be guilty of an offence punishable on conviction by a fine not exceeding 5000 Convertible Marks or imprisonment not exceeding two years or both." The statistical laws of the entities have similar provisions on the obligatory nature of reporting data requested for statistical purposes and establishing penalties for noncompliance. Reference to the Law is made in the questionnaires used by the FIS.

All three statistical institutions of $\mathrm{BiH}$ monitor the response rates to their surveys and review periodically the questionnaires. Pilot surveys are conducted to test the suitability of questionnaires when new studies are carried out.

Entities' statistical offices seek to secure cooperation of responding units and reduce the response burden by providing instructions for filling the questionnaire, indicating the purpose of the data collection, etc. 


\section{$0.2 \quad$ Resources}

\subsubsection{Staff, facilities, computing resources, and financing are commensurate with statistical programs}

All statistical institutions of Bosnia and Herzegovina are funded by their respective government budgets. Funds provided annually for the implementation of the work plan on national accounts do not, however, cover ad-hoc surveys or other projects, these being funded by international donors. More resources from the budget would be needed to finance development of related statistics, such as a countrywide producer price index (PPI), or to increase frequency of undertaking surveys that would represent useful source data for the national accounts compilation (e.g., HBS and labor force survey (LFS)).

According to the Rulebook governing organization of the BHAS, the Agency is entitled to employ 74 persons as a minimum for proper operation. Currently, only 30 employees are listed (excluding the District of Brcko), out of which the Department of National Accounts lists only three staffs. With the current staff, the Agency is undertaking a fairly large number of tasks and participates in multiple projects with international and regional organizations and agencies. Given its activities, the allocation of staff resources at the agency level, in particular for national accounts, is deficient for the volume of work. There are plans to hire 11 more staffs in 2007 which should enable the agency to reach staffing levels considered a minimum requirement for proper operation.

At the entity level, the lack of human resources is accentuated by the additional workload represented by the current collection and processing of basic source data for national accounts (FIS), as well as by the involvement of these agencies in a series of projects sponsored by international donors (all agencies).

The FIS is the largest statistical institute of the country but has also proportional responsibilities in terms of data collection and processing. The agency, which operates with about 100 persons at the headquarters and about 81 in the cantons, has experienced a high turnover mainly due work pressures arising from a relatively heavy workload. In the last two years, staff have transferred to the BHAS to take advantage of better working conditions (three experienced staff), and operations have been affected by the lack of foreign-language skill and the need to dedicate resources to training. With regard to the national accounts, the staff number of the National Accounts Department in the FIS is six plus the Head, who also carries out the responsibilities of the Assistant Director of the Sector of National Accounts and Prices in the absence of a nominated person. From a broader perspective, it is envisaged that the number of staff at FIS would need to increase by about 30 in order to respond adequately to the increasing number of new statistical projects mainly proposed by international organizations. 
In the RS, human resource situation is not less constraining. Of a total of 92 persons ${ }^{2}$ employed by the RSIS, only 40 are staff qualified to undertake the large amount of activities listed in the work program (105 activities for 2007). Currently, the staff number of the National Accounts Department in the RSIS is only two persons. Due to the situation, the Assistant Director is also heavily involved in all related projects. Due to the limited resources available on the market and the higher salaries paid in the private sector, in particular in the IT sector, the prospective of hiring more staffs seems problematic.

Qualification of staff is adequate in all agencies. According to the Rulebook, the requirement for employment calls for bachelor degree. With regard to national accounts, the experience in the field and specific training are also an important factor determining employment, and this expertise can not be acquired as quickly. For example, current staff in all agencies have greatly benefited by the training sessions and on-the-job training provided by the IMF's longterm advisor.

Salary levels in all agencies are relatively comparable with those paid in other institutions of the public administration with some exceptions, such as the tax administration.

The computing equipment is sufficient to execute the current work and each person has his/her own computer. Some of the computers are donations while other were acquired with limited budgetary funds. An internal network is also servicing BHAS and the FIS. Plans are to build up an intranet, upgrade software and replace computers.

The physical facilities at the FIS are considered adequate. The offices at the RSIS are adequately equipped and furnished.

Recommendation: Provide additional human resources for national accounts compilation in the assigned departments of the statistical institutes to properly undertake the activities assigned by their mandates and participate in various related projects, as needed.

Recommendation: Request allocation of funding from budget to undertake regular surveys such as the HBS and LFS. Additional resources are also needed to produce a countrywide producer price index and improve the accuracy and reliability of the GDP estimates.

\subsubsection{Measures to ensure efficient use of resources are implemented}

In seeking improvements on resources use, the BHAS reviews the work process with regard to the conduct of the surveys, learning from past experiences to introduce improvements in most recent researches. Under the existing constraints of human and financial resources, the statistical institutions have a difficult task in establishing priorities for a more efficient use of resources, in particular human resources. Most of the employees are involved in multiple

\footnotetext{
${ }^{2} 140$ foreseen by the Rulebook.
} 
activities in order to implement the numerous ongoing projects that stretch the limited capacity of the institutions. This, in fact, is deemed to have a negative impact on the quality of the work.

As the leading institution in the prescription of methodologies, the BHAS also encourages the use of consistent concepts, classification and other methodologies across datasets. However, this has been more feasible with the introduction of new surveys and the compilation of new statistics designed to provide data for the entities and for the whole country (e.g., consumer price index (CPI) project, HBS, industrial survey, investment survey). For most of the ongoing "old" statistics produced by the entities, there are still significant differences in methodologies, classifications, and even periodicity that make their aggregation into countrywide data not feasible. There is still no consistency between classifications and concepts across datasets although progress is being achieved in implementing international standards.

The Federation Law stipulates the assessment of staff performance. Formally, superiors evaluate the immediate subordinates, although the final outcome depends on the general manager, and direct evaluation is neglected. Staff sentiment is that the process is not transparent and lacks impartiality. It is also thought that hiring is not solely based on competence.

Recommendation: Seek more efficient use of resources by establishing work priorities that are commensurate with available capacity; projects related to the core mandate of the institutions should be considered higher priorities.

\subsection{Relevance}

\subsubsection{The relevance and practical utility of existing statistics in meeting users' needs are monitored}

No established procedures are in place for consultations with users on the relevance of the statistics. The BHAS organizes on a needs basis meetings with some users and the media to present the results of new statistical surveys, like the 2004 HBS and the 2006 labor force survey (LFS). Likewise, the entities' statistical offices organize regular press releases, where they present results of frequent statistics, as well as large projects, such as LFS. The RSIS offers its publications freely to interested users to enlist their interest in statistics and in return for providing data. However, overall there is a lack of a culture that recognizes the significance of statistics. While the Statistical Council is expected to play a leading role in raising public awareness of the importance of statistics, it fell short of doing so far.

None of the statistical institutions has established advisory committees or working groups to review the relevance of the data produced and to identify emerging data needs. New statistics and improvements are mainly being introduced in order to meet the reporting requirements of the EU, much of which is supported by financial resources and technical assistance provided by the EU. 
Recommendation: Improve consultation with users in order to better identify their needs and to promote a statistical culture in the country. For example, conduct interviews or user surveys at times to get the users' feedback and also to inform the users on available data, metadata, and modalities of accessing them.

\subsection{Other quality management}

\subsubsection{Processes are in place to focus on quality}

Management of the statistical institutions is aware of the importance of the quality of the statistical products to build trust among users. However, resource constraints have limited the ability of the institutions to introduce improvements in their collecting and processing systems.

\subsubsection{Processes are in place to monitor the quality of the statistical program}

Quality of the data produced is not monitored in a comprehensive way to guide the statistical program. The results of regular internal studies performed by staff to monitor the source of errors or fluctuations in source data have a limited use, mainly related to the validation of data.

\subsubsection{Processes are in place to deal with quality considerations in planning the statistical program}

In preparing the work program and setting the work priorities, the various aspects of the quality of statistics are not fully taken into consideration. Users' feedback is not actively sought. New emerging data products that are considered when elaborating the statistical work program are generally inspired by the international community. The resulting projects are generally not commensurate with the available resources and not always relevant to the agencies' needs.

\section{Assurances of integrity}

\subsection{Professionalism}

\subsubsection{Statistics are produced on an impartial basis}

All statistical institutions of Bosnia and Herzegovina are professionally independent, and the statistics are compiled taking into account only technical considerations. The Law on Statistics of the BiH deals with the principles that underlay the technical autonomy of the statistical institutions of Bosnia and Herzegovina and includes provisions in this respect (Section VIII). Similar statements are embodied in the Law on Statistics of the entities (Law on Statistics of the Federation, Article 8 and Law on Statistics of the RS, Article 17 respectively). 
There is no government interference in the choice of techniques used to compile statistics. In the Federation, the responsibility for the NA falls exclusively on the NA Department. In the $\mathrm{RS}$, management is actively involved in the production of national accounts providing good technical guidance that improve the final estimates.

According to the Law, all appointments and dismissals in the Agency (including the Director, Deputy Director and Head of the Branch) are done in accordance with the provisions of the Law on Civil Service in the Institutions of Bosnia and Herzegovina (Law on Statistics of $\mathrm{BiH}$, Article 9).

The BHAS recruitment policy and procedures are consistent with the requirements of the Law on Civil Service of BiH. In filling each open position, the Agency follows an open bid process and candidates are selected by a recruitment commission based on their aptitudes and skills.

The recruitment process in the entities is also defined by law, although some of the staff are of the opinion that skills and competence are not always the main factors in recruiting personnel.

The statistical institutions of Bosnia and Herzegovina have benefited from the multiple statistical projects being carried out under the technical cooperation of international organizations and bilateral technical assistance projects with EU countries. These projects have an important role in transmitting know-how to the local staff, including assisting in the production of the statistics according to international standards, thus promoting professionalism within the institution. The staff of all statistical institutions have opportunities to participate in international meetings and workshop organized by the international organizations, as well as undertake working visits to other statistical institutions in the region.

\subsubsection{Choices of sources and statistical techniques as well as decisions about dissemination are informed solely by statistical considerations}

The choice of data sources and statistical techniques are solely based on measurement objectives and data requirements, subject to the constraints of resources available.

\subsubsection{The appropriate statistical entity is entitled to comment on erroneous interpretation and misuse of statistics}

The BHAS is entitled to respond to erroneous interpretation of data. However, this practice is not encouraged so as to minimize debates that may be political in nature. Both RSIS and FIS are commenting on misinterpretation of data released by them but avoid interference in politically related debates. 


\subsection{Transparency}

\subsubsection{The terms and conditions under which statistics are collected, processed, and disseminated are available to the public}

The BHAS and the RSIS publish the state and the entity respective Laws on Statistics on their website together with their multi-annual statistical programs. All three institutions make available references to the terms and conditions under which the official statistics are compiled and disseminated in publications and/on their websites. These materials are made available only in local language for now. The statistical institutions also provide a list of their publications on their respective websites.

\subsubsection{Internal governmental access to statistics prior to their release is publicly identified}

There is no government access to the data prior to its release by the BHAS and the entities.

\subsubsection{Products of statistical agencies/units are clearly identified as such}

All three statistical institutions of Bosnia and Herzegovina clearly identify themselves as the producers of the statistics they disseminate. The name and logo of the institutions are reproduced in their publications.

\subsubsection{Advance notice is given of major changes in methodology, source data, and statistical techniques}

Usually, changes are announced at the time data are released. However, the work programs provide some advance notice regarding introduction of new products. Some projects, such as the project for undertaking the 2007 household survey, are announced in advance in order to familiarize public with the survey's purpose and enlist public support and cooperation. Advance notice was also given of the implementation of the statistical classification of economic activities in the European Communities (NACE) classification in national accounts which was mentioned in a previous publication number.

There have been no major changes in the methodology in recent years. The BHAS follows the practice of informing users of the methodology implemented for the production of new statistics. For example, the 2006 publication of national accounts by BHAS, mentions in the introduction the ongoing work to prepare the GDP by expenditure and GDP at constant prices. 


\subsection{Ethical standards}

\subsubsection{Guidelines for staff behavior are in place and are well known to the staff}

Staff of all agencies of $\mathrm{BiH}$ have to observe the code of conduct specified by the Law on Civil Servants. Reference to it is also made in the Statistical Law. Moreover, a copy of the code of conduct is posted on the doors at every floor in the FIS.

Consistent with the legislation in place, the BHAS has an ethical code, including guidelines for its staff.

\section{Methodological soundness}

\subsection{Concepts and definitions}

\subsubsection{The overall structure in terms of concepts and definitions follows internationally} accepted standards, guidelines, or good practices

National accounts of Bosnia and Herzegovina are compiled following the conceptual framework of the European System of Accounts 1995 (1995 ESA)/ System of National Accounts 1993 (1993 SNA) since 1997. Compilation of accounts covering the entities is undertaken separately by the FIS and the RS, while the BHAS aggregates the data and completes the countrywide coverage with the State level units including the Central Government accounts and the Central Bank of BiH, plus the Brcko District that reports directly to BHAS.

\subsection{Scope}

2.2.1 The scope is broadly consistent with internationally accepted standards, guidelines, or good practices

The scope of national accounts produced in $\mathrm{BiH}$ is limited to annual value added (GVA) and GDP at current prices by activity. Based on GDP data and using specific aggregates ${ }^{3}$ produced by the Central Bank of $\mathrm{BiH}$, an estimate of gross national income and gross disposable income was also produced and published in the last publication number of December 2006.

However, ongoing work to produce GDP at constant prices (by FIS and RSIS) and the expenditure components of GDP (by BHAS) is at an advanced stage. In addition, the RSIS has produced experimental value added components by activity at current prices and some of the income accounts but has never published these results.

\footnotetext{
${ }^{3}$ Net primary income from the rest of the world and net transfers from the rest of the world.
} 
With regard to the delimitation of the economy boundary, the coverage is satisfactory with few departures from recommended practices. The principle of residency is observed, as applicable, by the entities. FIS is, thus, including in the estimates the territorial enclaves in the rest of the world, the free zones, as well as Bosnians who work part of the year in a foreign country. The output boundary covers elements such as own-account production of agricultural products for own final consumption, output of goods for own fixed capital formation, research and development for own needs, and mineral exploration. However, production of entertainment, software, literary or artistic originals are not included within the output boundary. For regional comparability reasons, production of illegal activities is not included, although some experimental estimates ${ }^{4}$ have been made within the non-observed economy (NOE) project.

At the State level, it should be noted that the financing of projects by foreign donors is excluded from the scope of government expenditures

The assets boundary is not clearly delineated given the limited scope of the national accounts production.

Recommendation: Finalize and publish the constant price GDP estimates and the expenditure components of GDP shortly.

Recommendation: Finalize the NOE estimates and integrate them into the national accounts estimates.

\subsection{Classification/sectorization}

\subsubsection{Classification/sectorization systems used are broadly consistent with internationally accepted standards, guidelines, or good practices}

The classification of activities NACE Rev 1 has been used for the compilation of estimates of GDP by production approach starting with the estimates of 1997 (FIS) and 2000 (RS). For the experimental calculations of GDP by expenditure underway, other classifications have been introduced, such as the classification of individual consumption by purpose (COICOP) to classify the household consumption and the classification of products by activity (CPA) to reclassify and distribute foreign trade data according to national accounts needs. However, the institutional sectors are not yet distinguished countrywide, with sectorization being based on legal status of units. In the last publication number, FIS has presented the production account by institutional sectors as well.

\footnotetext{
${ }^{4}$ For drugs and prostitution.
} 


\section{$2.4 \quad$ Basis for recording}

\subsubsection{Market prices are used to value flows and stocks}

Market prices are used to value flows and stocks. Output is valued at basic prices and the intermediate consumption is valued at purchaser's prices. With the introduction of the VAT in January 2006, the estimates underway value intermediate consumption at purchaser's prices, excluding the deductible part of VAT. Output for own use, in particular in agriculture, is valued indistinguishably with the related market sector. The FIS estimates separately the output for own use in agriculture using equivalent market prices. In the experimental expenditure-based GDP calculations, both imports and exports are valued f.o.b.

\subsubsection{Recording is done on an accrual basis}

All transactions are recorded on an accrual basis except for the government's revenues, taxes, and subsidies.

\subsubsection{Grossing/netting procedures are broadly consistent with internationally accepted standards, guidelines, or good practices}

Since the main source data for GDP compilation is based on statistical annex to the financial statements of enterprises, the transactions between establishments of the same enterprise are deemed to be recorded net. However, data for large enterprises are checked against their individual records and corrected with the information at the establishment level.

\section{Accuracy and reliability}

\subsection{Source data}

\subsubsection{Source data are obtained from comprehensive data collection programs that take into account country-specific conditions}

Data used in compiling the national accounts statistics are primarily the accounting statements of legal entities (enterprises) complemented by administrative data from various sources. There is no business register available. The production of business registers will be undertaken within the twinning project with the EU that started in 2006. Currently, each entity maintains an address book, which is used as the main frame for selecting the reporting units. However, the address books only contain the enterprises (legal entities) that are obliged to register and submit their financial statements to the Ministry of Finance and Treasury (MOFT). Although reporting is not fully observed by tax-payers, the entities' statistical offices are trying to achieve full coverage of legal entities, given their significant share in the GDP. Estimates for the unincorporated enterprises (individuals, small entrepreneurs) are based on tax returns that are submitted by entrepreneurs to the Tax administration offices. 
There are differences between the entities with regard to the modalities of data collection and processing. However, in the absence of a suitable sampling framework, no business survey or periodic censuses are conducted. The address books maintained by the entities are updated annually mainly based on the information collected from the enterprises (legal entities) and from the employment data, as applicable.

In the Federation of Bosnia and Herzegovina, the FIS collects data for all the legal entities using a form specially designed to suit the needs of the national accounts compilation - the statistical annex to the financial reports of legal units. These documents are collected by the Agency for Financial and Information on Business (AFIP), which forwards the relevant copies to the statistical offices. Data are received in hard copy form and processed by the FIS - the national accounts department. Separate information about legal enterprises may also be used to update the address book yearly. The address book contains the identification data, total revenue, number of employees, the inventories at the end of the year, and the main economic activity.

The FIS closely monitors the reporting of enterprises with a turnover of more than half a million KM (about 4,000 enterprises) to ensure a good coverage of their activities. Moreover, data is completed with information at the establishment level allowing a proper allocation of activities by NACE code at five-digit level of detail.

In accordance with the law, beginning with 2003, all legal entities and entrepreneurs are required to register with the FIS. They are assigned a 13-digit identification number, which is the same for tax purposes. Entrepreneurs may also register with municipalities, associations, and ministries (depending on their activity) but are not obliged to register with the court as legal entities do. The majority of entrepreneurs are concentrated in activities such as transport, trade, and catering. The activity code is assigned by the statistical office based on the declaration on the registration form regarding their main activity, which sometimes may differ from the actual activity undertaken. A pilot survey (visiting the premises) on the manufacturing industry to check coverage of reporting was conducted in the spring of 2005, showing that coverage was fairly good. For collection purposes, the FIS has designed a special reporting form to be used by the municipalities (the Tax Bureau within the municipality) in reporting data on the entrepreneurs (unincorporated enterprises). This form would cover aggregated data by economic activity taking into accounts that the entrepreneurs use a more simplified accounting system. It is believed that wages and salaries and income are underreported.

Non-profit institutions are subject to special regulations. They report directly to the statistical office by means of a specially designed form. The coverage of these institutions in the address book is likely to be partial. 
As with the agriculture (contributing about six percent to GDP ${ }^{5}$ ) the majority of production is undertaken by individual units, and data are collected via a special form requesting information on production (quantities and values) and associated costs (provided by experts in agriculture from the municipality offices). Special forms are also used for collecting data from municipalities for entrepreneurs and households engaged in other activities. Practically, these are indirect information, such as number of employed persons or coefficients of income/expenditure per employed person, used in the national accounts estimates.

The main sources of data ${ }^{6}$ used by the RSIS are also the financial statements of legal entities, but, unlike in the case of the FIS, these are obtained in electronic form from the Ministry of Finance (APIF-agency for collection and data processing). Reporting is increasingly enforced and a good response rate is obtained, although there may be enterprises that do not report.

Estimates for the activities of entrepreneurs are based on the number of owners and their employees, and self-employed obtained from administrative sources, i.e., the Health Insurance Fund (HIF) and the Pension Insurance Fund (PIF). ${ }^{7}$ These sources, of relative reliability, ${ }^{8}$ provide information broken down by legal category and economic activity.

Source data for the agricultural sector (about 16 percent, representing the most significant contribution to the total value added) are weak. As the greatest part of output estimates is constituted by the individual producers, source data are essentially the information provided by the municipalities for the crops (estimates of quantities produced, based on areas and yields estimates). Prices used to value the output are taken from trade statistics. There are no data available on livestock and rough estimates are included in the accounts. To improve the estimates, it is, therefore, highly recommended that a census in agriculture be undertaken.

Source data for the trade (representing about 15 percent in total value added), are the financial statements of legal enterprises and employment data.

At the State level, $\boldsymbol{B H} \boldsymbol{A S}$ aggregates the national accounts produced at the entity level and provided by the FIS and the RSIS. It completes the nation-wide coverage with the missing parts related to the state level institutions plus the information related to the District of Brcko that reports directly. For the state institutions, the BHAS is using the financial reports from the MOFT for the Central government part (covering nine ministries and 40-50 other government institutions) and from the $\mathrm{CBBH}$ for its own activity, collected via a special form.

However, source data supporting compilation of more and reliable national accounts aggregates, such as constant price estimates are not as diversified as needed nor are they

\footnotetext{
${ }^{5}$ As in 2005.

${ }^{6}$ About 60 percent of value added is estimates based on this source.

${ }^{7}$ These data are collected biannually.

${ }^{8}$ The number of owners is considered adequate but that of the employees is under-reported.
} 
robust. For example, there is a lack of an appropriate sampling frame for the population and households to be used for the HBS and other related purposes. The last census of population was undertaken in 1991 and many significant changes have taken place during the interim period as a result of the conflicts affecting the country. Consequently, different surveys use different population numbers and distribution samples.

The last HBS survey conducted in 2004 was based on a population of 3.6 million inhabitants, the adopted frame being based on equal-probability sample of selected areas and dwellings. The survey was conducted on a sample covering about 7,570 households representative of entity, in urban and rural areas. Sampling errors on population estimates ranged from 0.82 for $\mathrm{BIH}$, over 1 for the entities, ${ }^{9}$ to 3.67 for Brcko District. The non-response rate was around 16 percent.

The 2004 HBS provided a breakdown of about 400 products (goods and services) classified according to the COICOP. The survey covers household purchases and the own-consumption of goods produced by resident households. Despite the scientific design and methods used, the results of the survey are questionable, in particular with regard to services. A similar sampling frame and design with some corrections was used for the currently underway 2007. It is expected that this survey would yield more accurate results, although some pessimistic views still persist.

Both entities compile an industrial production index, a retail price index and a cost-of-living index. The PPI is only compiled by the FIS. Other statistics produced at the entity level are the statistics on manufacturing, retail trade turnover, construction, transport, and employment statistics. However, inadequate sampling methods and methods of calculation undermine their usefulness for the national accounts purposes.

Several projects related to the development of new or the improvements of existing source data are undertaken by the BHAS in collaboration with the FIS and RSIS. A uniform methodology is being used for the NOE estimates and the owner-occupied dwelling services by both entities. Work is coordinated through the BHAS.

Other ad-hoc surveys are undertaken by entities to supplement the information in certain areas. For example, a research study on the civil construction was undertaken in 2004, which provided useful information regarding the value added in construction sector.

Data on government for all agencies are appropriately covered with the exception of the data on capital stocks that have to be estimated. Due to the administrative organization, in the Federation, data are collected at the level of the cantons, ${ }^{10}$ while in the RS, data are collected from the municipalities directly by the Ministry of Finance. For the Federation of $\mathrm{BiH}$, data from government units (including municipalities) and from financial institutions are collected

\footnotetext{
${ }^{9} 1.05$ for Federation of $\mathrm{BiH}$ and 1.35 for the RS.

${ }^{10}$ There are 10 cantons, each covering a number of municipalities.
} 
directly by the FIS using special forms. These data, received in hardcopy, are also processed by the FIS (about 1,500 reporting units for government units only). Data for the RS (central and local governments) are received from the Ministry of Finance. Transfers from the entities to finance the State Government and the extra budgetary funds are also included as part of government's expenditures.

Merchandise trade statistics covering the special trade are compiled by a separate department in the BHAS based on customs documents. These data are used both for national accounts, for the experimental GDP estimates by expenditure, and the BOP. For national accounts purposes, the coverage of the estimates of imports/exports is completed with the remaining items, including the service adjustments, the estimate for smuggling made by the $\mathrm{CBBH}$, and the transactions of goods for processing.

The national accounts compilers closely monitor changes in the economic environment via media, participation in inter-sectoral working groups, etc., that could have an impact on the national accounts compilation.

Recommendation: Advance the work for the construction of a business register making use of all available databases. Once the business register is available, (i) consider introducing regular business surveys into the work plan and (ii) complete the identification of the institutional sectors countrywide.

\subsubsection{Source data reasonably approximate the definitions, scope, classifications, valuation, and time of recording required}

Most of the source data used to compile currently available estimates meet the needs of compiling national accounts but supplementary efforts need to be made in some instances to bring the data in line with the requirements. Several examples are listed by agency below:

- $\quad$ BHAS: the classifications used by the Foreign Trade Service and the National Accounts Department (NAD) are not fully harmonized with the classification used by the customs, creating additional work to manually classify the customs records by the NAD.

- $\quad$ FIS and RSIS: classification by main activity of entrepreneurs is not reliable from one year to another and the NAD of the two agencies has to spend additional time to correct the registration and allocate the activity to the right codes.

- $\quad$ Adjustments that are needed to align the GFS data with the national accounts concepts of valuation (accrual) are not undertaken due to unavailability of sufficient information.

- $\quad$ Coverage of total economic activities is good and it is possible to prepare reliable data at NACE one or two-digit level. About 90 percent of total value added is produced by the corporate sector, which is properly covered by source data. 
- However, additional source data required for the production of constant price estimates or the expenditure components of GDP are not entirely suitable (see also 3.1.1).

\subsubsection{Source data are timely}

Generally, source data are collected and processed by entities to meet the timeliness and periodicity requirements of the national accounts compilation. Deadlines for the provision of source data by reporting units are indicated in the agencies' work programs. The FIS usually receives data on enterprises (including those in agriculture) on April 30, while for the small entrepreneurs, data are received on May 30 of the year following the reference period. In the RS, data become available in April or May, allowing however the agency to prepare the preliminary results of national accounts by the end of June. In both entities, initiatives are taken to prevent late response including contacting respondents, in particular those with a significant impact on an industry's activity or by checking with complementary sources.

On the other hand, statistics compiled at entity level are in turn considered the main source data for the countrywide national accounts. Therefore, the release schedule of the FIS and RSIS should, in principle, be harmonized with that of the BHAS (July for the preliminary estimates and December for the final ones). Certain delays in data provision by the entities occur at times, in particular from the RSIS, which is carried over into the schedule for publication of the BHAS. It appears that, for some statistical activities, the timetables of the entities, in particular the RSIS, are not fully harmonized with that of the BHAS .

\subsection{Assessment of source data}

\subsubsection{Source data-including censuses, sample surveys and administrative records-are} routinely assessed, e.g., for coverage, sample error, response error, and nonsampling error; the results of the assessments are monitored and made available to guide statistical processes

Source data are regularly monitored by both entities to identify any changes in the classification and to correct for underreporting or misreporting by checking against related source data (number of employed, wages, salaries, production turnover etc.), consistency of data against previous year information, etc. Special attention is generally paid to distortions, such as outliers, and respondents may be contacted in case of need. However, coverage of the informal sector, in particular for agriculture or for certain services, remains weak. Validation of logical and inter-temporal consistency of data is not undertaken and related activities show different trends.

As for the sampling errors, these pertain mostly to the HBS or the LFS. For the last HBS survey of 2004, sampling errors were calculated at a detailed level and used to inform design process of the 2007 survey. Both surveys have been conducted with the technical assistance from the INSTAT. However, while some inadequacies noted in the first survey have been 
corrected (e.g., weights, classification of products), staff's perception is that not all problems have been properly addressed.

\subsection{Statistical techniques}

\subsubsection{Data compilation employs sound statistical techniques to deal with data sources}

Compilation techniques allow for data consistency checks. Identified outliers are verified first for possible errors of data entry and then with complementary data if possible. If necessary, the enterprise is directly contacted. Adjustments to data are made as needed.

\subsubsection{Other statistical procedures (e.g., data adjustments and transformations, and statistical analysis) employ sound statistical techniques}

Adjustments made within the NOE project (a cost approach) and for the estimation of imputed rentals of owner-occupied dwellings employ adequate procedures. Additional adjustments have been made by the RS ahead of the work undertaken within the NOE project in order to complete coverage of data in specific areas with informal activities

(entrepreneurs). These estimates have been integrated in the estimates released. However, the countrywide estimates undertaken through the NOE by the two entities have not yet been integrated into the published estimates.

\section{Production approach}

Current price estimates of GDP are produced by both entities at NACE 5-digit level and aggregated for publication at 1-digit (15 industries) or 2-digit level (FIS). Experimental constant price estimates for both entities ${ }^{11}$ and the State were prepared for 2001 and 2002 but the work was discontinued for the part covering the state (by BHAS). Work was resumed recently and improved methods making use of all available source data were applied to the 2005 estimates (and back to 2000 series). Similarly, work is ongoing to finalize the experimental estimates of GDP by expenditure for 2005.

In both entities, production accounts estimates are generally compiled separately for legal entities (corporations), the unincorporated enterprises (entrepreneurs), and the household sector as non-market producer based on information collected via the statistical annex to the financial statement (enterprises) and other relevant information as mentioned in 3.1.1. The reliance on fixed ratios in deriving the estimates is relatively low since most components of the production account at current prices are obtained yearly from the financial reports.

\footnotetext{
${ }^{11}$ In Republika Srpska, experimental GDP constant price estimates were prepared for the period 2000-2004.
} 


\section{Federation of BiH}

In agriculture, estimates for the unincorporated enterprises (representing the largest share: 80 percent of the branch activity) are based on cost of production and yield data as provided by the municipalities (see also 3.1.1.). These estimates are weak in the absence of more reliable source data. Input/output coefficients are extensively used to compile the value added and no adjustments are made to take account of fluctuations in agricultural production (big loses for example).

In manufacturing and service sector, the estimates for the unincorporated enterprises (informal sector) are based on indirect indicators provided by Tax Bureau at the municipality level (number of persons engaged and coefficients of income and expenditures per employed person). For the financial sector, the financial intermediation services indirectly measured (FISIM) are calculated as the difference between property income received and income paid by the banks. The estimate for the central bank is made by the BHAS based on the production cost approach. For insurance companies, the FIS also applies a special form to collect the required data.

\section{Republika Srpska}

The situation of the estimates for the agricultural sector is similar to that in the Federation with the legal enterprises representing only 3 percent of the branch activity. Estimates for crops are made by product without a breakdown of market and non-market, based on quantity and price data. There are no direct data on livestock stocks and production and, consequently, rough estimates are produced. Intermediate consumption and value added coefficients are based on the financial reports of agricultural enterprises adjusted for the calculations of individual farmers. Similar weaknesses can be noted as above, and the imperative need to undertake a census in agriculture.

The estimates of manufacturing and the utility sector are mainly based on the financial statements. Adjustments for NOE are being made under the special NOE project with OECD. In construction, the estimates related to the activities of entrepreneurs are based on data on employment. A rough estimate is also included for the self-construction of dwellings. Data on construction permits are undervalued, as many builders do not apply for a permit. Within NOE, an ad-hoc research was made to determine the price per square meter and the number of houses built.

In the financial sector, the financial intermediation services indirectly measured (FISIM) are calculated as the difference between property income received and income paid by the banks. For the calculation of the output for the government, data for the entity's central government and local governments are received from the Ministry of Finance. Transfer to finance the State Government are also included as part of government expenses. The extra-budgetary funds are included. In the absence of information on the stock of fixed assets for government, a rough estimate of consumption of fixed capital assumes that it is 10 percent of the 
intermediate consumption value ${ }^{12}$. This assumption has certainly its limitations and an inventory of the stock of fixed assets is needed to apply the perpetual inventory method.

For the other units of the unincorporated sector, estimates are made based on indirect information provided by existing source data (see 3.1.1). Assumptions are made to determine the number of employees, and then the wages and salaries. Coefficients relating the production account variables with wages and salaries (derived from the production accounts of enterprises) are subsequently used to determine the output and value added of the industry.

The estimates of the imputed rentals of the owner-occupied dwellings were produced by both entities for the 2004 benchmark year based on the methodology proposed by the OECD and completed with the IMF advisor assistance in agreement with the OECD expert. They are based on the cost approach as the sum of estimates of consumption of fixed capital, intermediate consumption, taxes on production, and opportunity cost of capital. The estimates have been recently incorporated and published in the official GDP data for 2005. Estimates were revised back to 2000 .

No inventory valuation adjustment (holding gains/losses) is made to the book values obtained from the financial statement data (annex) when calculating the changes in inventories for the output or the intermediate consumption.

Work in progress does not include estimates for all categories (growing crops, stock of fish, and construction of large equipment).

Preliminary GDP estimates at constant price (2004) are produced for 2005 but data are not yet released. These estimates have been prepared using generally the single indicator method, most often a volume indicator of output. A PPI is only produced in the FIS.

Recommendation: The BHAS should seek participation in the proposed project related to the estimation of government inventory of fixed assets in order to improve the government estimates of consumption of fixed capital.

Recommendation: In order to be able to produce more reliable constant price estimates, consideration should be given to the development of a countrywide PPI by the statistical offices.

\footnotetext{
${ }^{12}$ The estimation method should not be confused with the fact that the consumption of fixed capital is considered part of the gross value added.
} 


\subsection{Assessment and validation of intermediate data and statistical outputs}

\subsubsection{Intermediate results are validated against other information where applicable}

Validation of data is undertaken separately by each agency. At the entity level, the FIS and RSIS validate their estimates by comparing them with related alternative information as available. For example, suspect estimates that are based on the financial statement data are compared with other administrative sources, whenever possible. In the experimental compilations of constant prices, the implicit indices obtained are compared with the available volume and price indices. However, there are no systematic and rigorous procedures for checking the estimates.

At the country level, BHAS is mandated to verify the accuracy of data received from the entities. However, due to the tight deadlines for publishing the data combined with occasional delays in data provision and other obstacles in data collection process, a thorough assessment of data is not routinely undertaken.

\subsubsection{Statistical discrepancies in intermediate data are assessed and investigated}

Discrepancies in intermediate data are investigated when they occur and efforts are made to remove discrepancies. Other techniques for assessing results have been adopted more recently with the support of the IMF's advisor. These include assessment of data by calculating ratios such as average salary per employed, share of intermediate consumption in output, share of total wages and salaries in output, value of purchased goods against value of goods sold are used to check accuracy of data produced.

\subsubsection{Statistical discrepancies and other potential indicators of problems in statistical outputs are investigated}

GDP by expenditure is at an experimental stage. Eventual discrepancies will be considered in the context of the revisions in order to obtain consistent series of accounts. The internal consistency of GDP estimates by production is generally undertaken as part of the source data revision.

\subsection{Revision studies}

\subsubsection{Studies and analyses of revisions are carried out routinely and used internally to inform statistical processes (see also 4.3.3)}

Periodic revisions of data are made regularly following the cycle of publication of data between the preliminary and the final estimates. The resulting analyses are limited in scope and do not endeavor to ascertain biases in source data, systematic errors or direction of revision over time. However, driven by the need to improve coverage of activities and expand the scope of the national accounts estimates, several projects were undertaken with 
the support of international donors. The results of these projects, such as estimation of the imputed values of owner-occupied dwellings or the NOE entailed revisions to estimates.

Recommendation: Establish a regular well-defined revision policy including documented revision studies of source data and results and make the studies publicly available.

\section{Serviceability}

\subsection{Periodicity and timeliness}

\subsubsection{Periodicity follows dissemination standards}

Periodicity of the countrywide GDP estimates at current prices is annual, in line with the General Data Dissemination System (GDDS) recommendations. Volume measures of GDP are not yet disseminated, as recommended by the GDDS standards. There are plans to release these shortly.

\subsubsection{Timeliness follows dissemination standards}

Timeliness for all institutions follows the GDDS recommendations. Provisional nominal estimates of GDP for the country are usually published in July of the following year and final ones in December, the same year. Last provisional estimates (for 2005) were released in August $2006^{13}$ due to some delays in data collection by entities. The entities, in turn, have their schedule of release ahead of that of the BHAS. Thus, their provisional estimates are scheduled for release in June of the following year and the final estimates in December, the same year.

\subsection{Consistency}

\subsubsection{Statistics are consistent within the dataset}

Procedures for checking internal consistency of data are at basic level. In fact, internal consistency is difficult to determine in the absence of complementary GDP estimates (see also 3.4.3).

\subsubsection{Statistics are consistent or reconcilable over a reasonable period of time}

Consistent series of GDP estimates are available for the period 2000-2005. Any changes in the coverage of data, such as the introduction of the imputed rents of owner-occupied dwellings, have been incorporated into the series of estimates back to 2000 . These changes

\footnotetext{
${ }^{13}$ The RSIS has released its provisional 2005 GDP estimates on July 6, 2006 and final ones on November 30, 2006.
} 
are also mentioned in the latest publication of national accounts (December 2006) and estimates for the 2000-2005 series are included.

\subsubsection{Statistics are consistent or reconcilable with those obtained through other data sources and/or statistical frameworks}

GDP estimates are broadly consistent with other major data sources with the notable exception of government finance statistics. Government accounts are not yet reconciled with government finance statistics. Divergences in the estimates relate to the independent collection of data by the respective institutions (the entities and the BHAS on the one hand, and the $\mathrm{CBBH}$, on the other hand) and differences in classifications used. In addition, the output, as estimated in the national accounts, includes a rough estimate of the consumption of fixed capital, which is lacking in the estimates of the government finance statistics. This estimate is more of an informed guess of 6 percent and does not have a statistical basis. This estimated ratio has been maintained over a number of years in the absence of information about the stock of fixed assets in the government sector. With regard to the valuation on an accrual basis, no adjustment is made by the national accounts to the government elements recorded on a cash basis.

For the experimental GDP by expenditure, imports and exports data are consistent with the balance of payments data since they rely on the same merchandize trade data prepared by the BHAS and include the same adjustments for services and coverage (smuggling) made by the CBBH.

Recommendation: Establish formal procedures (working groups with producers of other statistics such as BOP or GFS) for regular consultation and data validation, in order to enhance intersectoral data consistency.

\subsection{Revision policy and practice}

\subsubsection{Revisions follow a regular and transparent schedule}

The revision schedule is embedded in the work program, which is posted on the Internet. The revision cycle at BHAS is, in principle, coordinated with those at the entity level, but delays occur occasionally in its implementation. In practice, the revision schedule is generally observed (see also 4.1.2.). The public is informed that the estimates released in December are final and no further revisions are expected unless methodological changes or improvements to coverage of data have intervened. These are usually highlighted in the publications with references to footnotes or mentioned on the websites.

\subsubsection{Preliminary and/or revised data are clearly identified}

Preliminary data are clearly identified in all institutions' publications with foreword remarks explaining the cause. The same presentation is available on the website. 


\subsubsection{Studies and analyses of revisions are made public (see also 3.5.1)}

The occasional revisions to data are explained to users during the regular press releases, as applicable. Causes of revisions are also mentioned in all publications but no analyses on revisions are made available to users.

\section{Accessibility}

\subsection{Data accessibility}

\subsubsection{Statistics are presented in a way that facilitates proper interpretation and meaningful comparisons (layout and clarity of text, tables, and charts)}

Annual national accounts estimates are disseminated in dedicated publications and on the websites separately by BHAS and by the entities in local languages and English. Presentation differs across the institutions. The BHAS' National Accounts publication includes time series tables and a number of charts; however, it lacks any explanatory text or analyses of released data that might facilitate understanding of the data and their trends. No charts or commentaries are included in the publications of the FIS and even less detailed information is available in the leaflet disseminated by the RSIS.

\subsubsection{Dissemination media and format are adequate}

National accounts estimates are disseminated in dedicated hardcopy publications ${ }^{14}$ and on the website of each statistical institution. There is an inconsistent level of detail in publication across institutions. The level of detail of estimates is more comprehensive in the BHAS and the FIS' publications, while the RSIS releases the GDP data in the form of a leaflet provided free of charge to the main users. GDP estimates are also released in the Statistical Yearbook by the FIS. It should be noted that the electronic format reproduces the paper one and, therefore, data are not in a data-readable format, such as excel.

\subsubsection{Statistics are released on a preannounced schedule}

Although there is no advanced release calendar, data are generally released regularly by each statistical institution. However, a preannounced schedule is not available for users to consult.

\footnotetext{
${ }^{14}$ National Accounts (BHAS), Gross Domestic Product and Gross Fixed Capital Formation (FIS), and National Accounts Statistics Release (RSIS).
} 


\subsubsection{Statistics are made available to all users at the same time}

National accounts statistics are released simultaneously to all users via the Internet and dedicated publications. The statistics are also included on the agenda of the regular press conferences, where users may receive additional explanations and documentation, as needed.

\subsubsection{Statistics not routinely disseminated are made available upon request}

Unpublished non-confidential data are made available to public upon request (usually in writing). However, this availability is not well publicized. A frequent request received by the FIS, for example, pertains to the aggregation of data my municipalities. Consideration is given to acting upon large requests and to modifying the format of publication, as applicable.

\subsection{Metadata accessibility}

5.2.1 Documentation on concepts, scope, classifications, basis of recording, data sources, and statistical techniques is available, and differences from internationally accepted standards, guidelines, or good practices are annotated

$\mathrm{BiH}$ does not participate in the GDDS. The only metadata available is found in the publications and posted on the institutions' websites. No comprehensive source and methods document is available for consultation. However, interested users may receive additional methodological explanations by addressing their requests to the respective statistical institutions.

Recommendation: Prepare and disseminate a detailed manual on sources and methods used for the compilation of the national accounts.

\subsubsection{Levels of detail are adapted to the needs of the intended audience}

Metadata summary is disseminated at one level of detail. No more detailed information is made public to interested users.

\subsection{Assistance to users}

\subsubsection{Contact points for each subject field are publicized}

Assistance to users varies from one institution to another, depending on existing capacities and arrangements in place. However, due to limited staff number and physical facilities, none of the institutions has a dedicated service to provide assistance to the users. Requests received in writing are generally monitored by all institutions and are channeled either through the publication service or directly to the responsible department. National accounts publications do not identify a contact person. In some cases (BHAS), publications do not provide sufficient contact information (website, e-mail, telephone number). All websites provide, though, general contact information on the institution. 
Recommendation: Improve content of dedicated publications and assistance to users.

5.3.2 Catalogs of publications, documents, and other services, including information on any charges, are widely available

Catalogs of publications are not available but each website includes a listing of publications and main survey results. 
Table 1. Bosnia and Herzegovina: Data Quality Assessment Framework (July 2003):

Summary of Results for National Accounts

(Compiling Agency:BHAS, FIS, RSIS)

\begin{tabular}{|c|c|c|c|c|c|c|c|}
\hline \multirow{2}{*}{ Element } & \multirow{2}{*}{ NA } & \multicolumn{4}{|c|}{ Assessment } & \multirow{2}{*}{ Comments on Assessment } & \multirow{2}{*}{ Plans for Improvement and Target Dates } \\
\hline & & $\mathrm{O}$ & LO & LNO & $\mathrm{NO}$ & & \\
\hline \multicolumn{8}{|l|}{ 0. $\quad$ Prerequisites of quality } \\
\hline 0.1 Legal and institutional environment & & & & $\mathrm{x}$ & & $\begin{array}{l}\text { Statistical Laws at state and entity level } \\
\text { are not harmonized and not fully } \\
\text { implemented. Institutional arrangements } \\
\text { do not promote data sharing activities } \\
\text { among parties involved, in particular } \\
\text { between the BHAS and the entities } \\
\text { statistical agencies. }\end{array}$ & \\
\hline 0.2 Resources & & & & (1) & & $\begin{array}{l}\text { Limited measures to ensure efficient use } \\
\text { of resources, in particular staff } \\
\text { resources. Staff and funding are } \\
\text { adequate for the regular work program } \\
\text { but not for ongoing and ad-hoc projects } \\
\text { across the agencies. }\end{array}$ & $\begin{array}{l}\text { Increase in staff number is planned (short- } \\
\text { term). }\end{array}$ \\
\hline 0.3 Relevance & & & & $\mathrm{x}$ & & $\begin{array}{l}\text { No established procedure is in place for } \\
\text { consultation with users. Lack of } \\
\text { statistical culture in the country. } \\
\text { Emphasis on the international users }\end{array}$ & \\
\hline 0.4 Other quality management & & & & $\mathrm{x}$ & & $\begin{array}{l}\text { Measures that focus on improving the } \\
\text { quality of statistical products are limited } \\
\text { in scope. New emerging data needs are } \\
\text { generally imposed by international } \\
\text { community. }\end{array}$ & \\
\hline \multicolumn{8}{|l|}{ 1. Assurances of integrity } \\
\hline 1.1 Professionalism & & $\mathrm{x}$ & & & & & \\
\hline 1.2 Transparency & & $\mathrm{x}$ & & & & & \\
\hline 1.3 Ethical standards & & $\mathrm{x}$ & & & & & \\
\hline
\end{tabular}


Table 1. Bosnia and Herzegovina: Data Quality Assessment Framework (July 2003):

Summary of Results for National Accounts

(Compiling Agency:BHAS, FIS, RSIS)

\begin{tabular}{|c|c|c|c|c|c|c|c|}
\hline \multirow{2}{*}{ Element } & \multirow{2}{*}{ NA } & \multicolumn{4}{|c|}{ Assessment } & \multirow{2}{*}{ Comments on Assessment } & \multirow{2}{*}{ Plans for Improvement and Target Dates } \\
\hline & & $\mathrm{O}$ & $\mathrm{LO}$ & LNO & NO & & \\
\hline \multicolumn{8}{|l|}{ 2. Methodological soundness } \\
\hline 2.1 Concepts and definitions & & $\mathrm{x}$ & & & & & \\
\hline 2.2 Scope & & & & $\mathrm{x}$ & & $\begin{array}{l}\text { Constant price estimates of GDP are not } \\
\text { produced. GDP by expenditure at } \\
\text { current prices is not produced. Sequence } \\
\text { of accounts is limited to production } \\
\text { account. }\end{array}$ & $\begin{array}{l}\text { Release of the constant price estimates of } \\
\text { GDP and GDP by expenditure (short-term: } \\
\text { mid-2007). } \\
\text { Compile institutional accounts (medium- } \\
\text { term). }\end{array}$ \\
\hline 2.3 Classification/sectorization & & & $\mathrm{x}$ & & & $\begin{array}{l}\text { Sectorization is based on legal status } \\
\text { rather than economic criteria. }\end{array}$ & \\
\hline 2.4 Basis for recording & & & $\mathrm{x}$ & & & $\begin{array}{l}\text { Government revenues are recorded cash } \\
\text { and not adjusted to an accrual basis. }\end{array}$ & \\
\hline \multicolumn{8}{|l|}{ 3. Accuracy and reliability } \\
\hline 3.1 Source data & & & & $\mathrm{x}$ & & $\begin{array}{l}\text { Absence of a business register. No } \\
\text { business statistics survey. Poor coverage } \\
\text { of informal activities (agriculture, trade, } \\
\text { etc.). Price and volume measures are not } \\
\text { available at the desired level of detail. } \\
\text { Data for the informal sector need some } \\
\text { adjustments for classification by activity. }\end{array}$ & \\
\hline 3.2 Assessment of source data & & & & $\mathrm{x}$ & & $\begin{array}{l}\text { Lack of validation of logical and inter- } \\
\text { temporal consistency of data. }\end{array}$ & \\
\hline 3.3 Statistical techniques & & & $\mathrm{x}$ & & & $\begin{array}{l}\text { For the published estimates of } \\
\text { consumption of fixed capital, } \\
\text { adjustments for holding gains, accrual } \\
\text { basis and NOE are not fully } \\
\text { implemented or covered. }\end{array}$ & $\begin{array}{l}\text { Finalization and integration of NOE } \\
\text { estimates into the revised GDP estimates } \\
\text { (short-term: mid-third quarter of 2007). }\end{array}$ \\
\hline $\begin{array}{l}\text { 3.4 Assessment and validation of inter- } \\
\text { mediate data and statistical outputs }\end{array}$ & & & $\mathrm{x}$ & & & $\begin{array}{l}\text { No systematic procedures of checking } \\
\text { data. Assessment of discrepancies is } \\
\text { made only when these occur. }\end{array}$ & \\
\hline
\end{tabular}


Table 1. Bosnia and Herzegovina: Data Quality Assessment Framework (July 2003):

Summary of Results for National Accounts

(Compiling Agency:BHAS, FIS, RSIS)

\begin{tabular}{|c|c|c|c|c|c|c|c|}
\hline \multicolumn{8}{|c|}{ Key to symbols: NA = Not Applicable; $\mathrm{O}=$ Practice Observed; $\mathrm{LO}=$ Practice Largely Observed; $\mathrm{LNO}=$ Practice Largely Not Observed; $\mathrm{NO}=$ Practice Not Observed; GDDS= Complies with GDDS Criteria } \\
\hline \multirow{2}{*}{ Element } & \multirow{2}{*}{ NA } & \multicolumn{4}{|c|}{ Assessment } & \multirow{2}{*}{ Comments on Assessment } & \multirow{2}{*}{ Plans for Improvement and Target Dates } \\
\hline & & $\mathrm{O}$ & LO & LNO & NO & & \\
\hline 3.5 Revision studies & & & $\mathrm{x}$ & & & $\begin{array}{l}\text { Adequate use is not made of revision } \\
\text { analyses. }\end{array}$ & \\
\hline \multicolumn{8}{|l|}{ 4. $\quad$ Serviceability } \\
\hline $\begin{array}{l}\text { 4.1 Periodicity and timeliness } \\
\text { 4.2 Consistency } \\
\text { 4.3 Revision policy and practice }\end{array}$ & & $\mathrm{x}$ & $\mathrm{x}$ & $\mathrm{x}$ & & $\begin{array}{l}\text { Consistency with GFS data is lacking. } \\
\text { Insufficient efforts to improve internal } \\
\text { consistency of statistics. } \\
\text { No revision analyses are made public. }\end{array}$ & \\
\hline \multicolumn{8}{|l|}{ 5. Accessibility } \\
\hline 5.1 Data accessibility & & & $\mathrm{x}$ & & & $\begin{array}{l}\text { No data analyses and commentaries are } \\
\text { included in the publications. Inconsistent } \\
\text { level of detail in publication of the } \\
\text { statistical institutions. }\end{array}$ & \\
\hline 5.2 Metadata accessibility & & & & $\mathrm{x}$ & & $\begin{array}{l}\text { No comprehensive source and methods } \\
\text { document is available. }\end{array}$ & $\begin{array}{l}\text { Prepare a document: source and methods and } \\
\text { publish it. Include description of any new } \\
\text { developments in national accounts data } \\
\text { compilation, such as production of constant } \\
\text { price GDP estimates or of the expenditure } \\
\text { components of GDP (short term). }\end{array}$ \\
\hline 5.3 Assistance to users & & & $\mathrm{x}$ & & & $\begin{array}{l}\text { Inadequate contact information is } \\
\text { provided for the BHAS publications. }\end{array}$ & \\
\hline
\end{tabular}




\section{Price Statistics (Retail Price Index)}

\section{Prerequisites of quality}

\subsection{Legal and institutional environment}

\subsubsection{The responsibility for collecting, processing, and disseminating the statistics is clearly specified}

Consistent with the administrative and political organization of the country, there are three statistical institutions representing the three main levels of government: (a) the Bosnia and Herzegovina Agency for Statistics (BHAS) at the state level, and (b) the Federal Institute of Statistics (FIS) which is the statistical institute of the Federation of Bosnia and Herzegovina, and the Republika Srpska Institute of Statistics (RSIS). The Statistical Office of the autonomous district of Brcko has become and integral part of the BHAS since 2006 by a decision of the High Representative.

The current Law on Statistics of Bosnia and Herzegovina (BiH) was issued in October 2002 by the High Representative under the powers vested to him under the General Framework of the Agreement for Peace in Bosnia and Herzegovina. This decision of the High Representative came after a Law on statistics endorsed by the Council of Ministers (executive body of $\mathrm{BiH}$ ) on July 5, 2001 failed to be adopted by the competent authorities. The Law on Statistics was finally ratified by the BiH Parliament in October 2004.

The BiH Law on Statistics states in its Article 3 that the competent authority for the organization, production and dissemination of the statistics at the level of $\mathrm{BiH}$ shall be the Agency established in accordance with the provisions of this law. The Competent Authorities in the entities shall be the bodies in the Entities that are tasked with carrying out these activities ("Entity Institutes").

The legal bases for the compilation of the statistics at the entity level are the Law on statistics of the Republika Srpska (RS) and the Law on Statistics of the Federation of Bosnia and Herzegovina. Both these laws were issued during 2003 and published in the respective official gazettes of the entities. These laws assign the responsibility for the collection, compilation, and dissemination of the statistics to the respective institute of statistics. It should be noted that these laws have not been fully harmonized with the BiH Law on Statistics, as was agreed between the representatives of the state and the entity governments in October 2005. Harmonization of the laws continues being a pending issue. Furthermore, the Law on Statistics of the RS only has provisions to provide aggregate data to the BHAS (although it states that the confidentiality rules do not apply in providing information to the BHAS); while according to the State Law, the entities' institutes of statistics should provide also the individual data, when requested. Another inconsistency found in the Law and practice relates to the period covered by the multi-annual program, which in RS covers also four years but on a rolling basis. 
The BiH Law on Statistics does not specify the statistics that should be compiled and disseminated by the Agency but it states that statistics of $\mathrm{BiH}$ are those included in the statistical program of the $\mathrm{BIH}$ and/or other statistics required and/or any other statistics produced by state bodies and endorsed by the Agency. The statistical program is drawn-up for a period of four years (the present program covers the period 2005-2008) and it is being implemented in accordance with annual work plans. The statistical program of $\mathrm{BiH}$ is prepared by the Agency in consultations with the entities' institutes of statistics and endorsed by the Council of Statistics for the approval of the Council of Ministers. The annual work plan of the Agency should also be prepared in consultations with the entities' institutes of statistics and submitted to the Council of Statistics for comments before being submitted to the Ministry of Treasure of the State institutions for the corresponding budgetary process.

The Statistics Law of the Federation of BiH determines in Articles 5, 6, and 7 which are the authorized bodies for the production of statistics in the Federation assigning to the Institute of Statistics the responsibility of organizing and "running the statistical research of interest for the Federation." The statistics to be produced are those included in the four-year statistical program prepared by the Institute in cooperation with the other authorized bodies. This program should be endorsed by the government and adopted by the Parliament of the Federation.

Article 4 of the Law on Statistics of the RS states that the RSIS is the authorized institution to carry out statistical activities but also lists other government agencies as authorized institutions. Article 6 of this Law states that the Institute defines the methodology and standards to be used in the implementation of the statistical work program of the entity. The Law states in its Article 3 the general scope of the statistics to be produced and leaves to the four-year annual statistical plan the determination of the detailed data to be produced. According to Article 9 of then Law, the four-year plan is to be prepared annually. The plan is to be prepared by the Institute and adopted by the People Assembly after being endorsed by the government.

In accordance with the respective legal provisions for the state and the entities, the compilation and dissemination of price indices are specified in the respective work programs of the authorized institutions. Thus, work plans of the institutes of statistics in the entities include the monthly compilation and dissemination of the retail price index (RPI) and the cost of living index (COLI), as well as the development of a consumer price index (CPI) in accordance with international standards for the respective entity. The State Agency work program includes the development of the CPI with a countrywide coverage.

\subsubsection{Data sharing and coordination among data-producing agencies are adequate}

Although the Statistics Law attributes to the BHAS the role of coordinating the statistical work of the country and determining the methodological standards needed to meet the requirements of the European Union (EU), the enforcement of the Law's provisions has been slow and full of obstacles. Nevertheless, this situation is deemed to be changing, as reflected

Price Statistics (Retail Price Index) 
by a signed agreement between all parties in October 2005, reinforcing the acceptance of the coordinating role of the BHAS, but also by better working relations between the entities, and the implementation of joint work in some of the statistical fields, such as the CPI and the household budget survey (HBS). The adoption of uniform forms and classifications for the collection and processing of some of the industrial surveys data is further evidence of some limited efforts to improve coordination.

Currently, all data required to compile the RPIs are collected directly by the Statistics Institutes in the entities.

\subsubsection{Individual reporters' data are to be kept confidential and used for statistical purposes only}

The BiH law on statistics as well as the respective entities' laws provide for the confidentiality of the individual data reported to them. All confidentially matters related to the data provided for statistical purposes are covered by the Articles 23 thru 29 of the Section XI of the BiH Law "STATISTICAL CONFIDENTIALITY AND LAW ON PROTECTION OF PERSONAL DATA.”

Article 23 establishes that data collected, processed and stored for the production of Statistics of $\mathrm{BiH}$ shall be confidential.

Article 26 of this Law prevents the disclosure of individual data establishing that "Statistics of Bosnia and Herzegovina must not be disseminated to users, if they contain or reveal Confidential Data. Aggregates shall comprise at least three units and the share of one unit in an aggregate must not exceed 85 percent of the total." However, the second paragraph within the same article of the Law provides the Agency with discretionary rights to disseminate data in contra version with the rules mentioned in paragraph 1 , if the data are considered to be important basic information and provided that the Statistical Program foresees the dissemination of such information.

The confidentiality of the individual data is protected when providing unit records to users (e.g., for research purposes) by making all records anonymous.

The Law on statistics of BiH establishes the penalties for infringing the confidentiality of the data provided for statistical purposes in its Section XII, Articles 31, 32, and 33. The Law dictates a penalty of up to two years of imprisonment and/or a fine of up to five thousand Convertible Marks for any person having access to confidential data divulges the information in contravention with the Law. The same penalties are applied to those reporting false or misleading data to the BHAS requested to fulfill the Statistical Program.

Section IX of the Law on Statistics "PENALTY PROVISIONS" establishes money fines that range from KM 500 up to KM 10000 on Article 43 as follows: 
1. "Enterprise, institution, cooperative and forms of associations if: fails to provide requested data to the statistical institute or authorized institution within given deadlines, fails to provide complete and accurate or interrupts data checkups (Articles 29 and 31.)."

2. "Responsible persons within administration, legal entity, institution that has public authority or other legal entity will also be imposed with money fine that ranges from KM 500 up to 2000 for violations stipulated in paragraph 1 of this Article."

The Law on Statistics of the Federation establishes that no individual data are to be published. The statistical Law specifies penalties for the staff. In practice there have been no breeches of the stipulations.

The forms used by the Federation to collect data make reference to the entity's Law on Statistics. In joint projects, such as the Household Budget Survey, there is a clear statement that the data are confidential.

The price survey of the Federation is conducted by personal visits to the outlets by trained enumerators. At the beginning of year the enumerators bring a presentation letter to the establishments surveyed, explaining the purposes of price collection for the production of the index as well as the confidential character of the data.

Only the staff engaged in the index compilation has access to the data. Enumerators are provided with special credentials accrediting their entitlement to collect the data on behalf of the Federation Statistical Institute.

Articles 44 of the Law on Statistics of the Federation prescribes money fines stating that "money fines that range from KM 200 up to 1500 will be imposed to reporting unit-a natural person, for violation stipulated within Article 43 paragraph 1 of this Law." Article 45 of this Law states that "Any person employed within the Federal Institute acting in capacity of representative that has access to confidential data within scope of its work that illegally and in premeditated manner reveals information to public, will be imposed with a fine that ranges from KM 30 to 2000, for such violation.”

Articles 30 and 31 of the RS Law on Statistics prescribe money fines for non-compliance with the obligation to provide data, which range from 500 to $15,000 \mathrm{KM}$ for legal entities and from 200 to $1700 \mathrm{KM}$ for the persons responsible within these institutions. These latter stated amounts also apply to natural persons requested to provide data. Article 32 of the Law prescribes money fines for the persons that having access to confidential data within the scope of their work who make unlawful use of the information.

All three statistical institutions have adequate rules in place to prevent residual disclosure of individual data. Premises are also secured and cannot be accessed without due authorization. 


\subsubsection{Statistical reporting is ensured through legal mandate and/or measures to encourage response}

The statistical Law entitles the BHAS to collect data from any natural or legal person (Art. 3) needed for the compilation of the statistics included in the program or any other statistics the BHAS needed. The Law also prescribes penalties for non-compliance (Art. 31), stating that "A Statistical Unit (other than the entity institutes) that knowingly provides false or misleading information in response to written requests by the Agency to meet the needs of the Program shall be guilty of an offence punishable on conviction by a fine not exceeding 5000 Convertible Marks or imprisonment not exceeding two years or both." The statistical laws of the entities have similar provisions on the obligatory nature of reporting data requested for statistical purposes and establishing penalties for non-compliance.

All three statistical institutions of $\mathrm{BiH}$ monitor the response rates to their surveys and review periodically the questionnaires. Pilot surveys are conducted to test the suitability of questionnaires when new studies are carried on.

In both entities' institutes of statistics price data are collected by enumerators mainly by filling the questionnaires based on the prices displayed by the outlet and, if required, through direct interview of the shop manager.

\section{$0.2 \quad$ Resources}

\subsubsection{Staff, facilities, computing resources, and financing are commensurate with statistical programs}

All statistical institutions of $\mathrm{BiH}$ are funded by their respective government budgets. Sufficient funds are provided each year for the implementation of current work plan on price statistics. However, development work, such as the CPI and the special surveys, which are mainly undertaken under the international supported projects, are dependent on their respective component of financial assistance.

The statistical agencies of $\mathrm{BiH}$ lack the necessary human resources to undertake the multiple tasks required for the compilation of the ongoing projects on price statistics. The BHAS has only two part-time employees in the department of price statistics working on the development and compilation of the new CPI. Other responsibilities of these staff include participation in designing the statistical surveys, monitoring their execution, analyzing and processing price data, and training the enumerators for carrying out the ongoing household budget survey for the year 2007. At the entities' institutes of statistics, the lack of human resources is accentuated by the additional workload represented by the current compilation of the monthly RPI together with the tasks required for the development of the new CPI.

The price department of the FIS employs four people, including the head of the unit, at its headquarters in Sarajevo. The department is responsible for the compilation of the RPI and the PPI, as well as for implementing the new CPI at the entity level. The staff is also involved 
in the work related to the household budget survey for 2007 and in an ongoing project for the compilation of purchasing power parity indices (PPP).

The FIS collects prices for the RPI in five cities using enumerators. There is one enumerator for the collection of prices in each of the cities Tuzla, Mostar, and Zenica; two enumerators for Bihac; and four enumerators in Sarajevo. The paper questionnaires are forwarded to Sarajevo for processing, although it is planned that electronically transmission of the data will be shortly implemented.

Qualifications and experience of the staff fall below acceptable standards. Most of the staff lack high education and two of the staff do not have experience on price methodology and compilation. At present, the department is also understaffed when compared with the number of positions it has allocated. The salary scale applied to the workers of the FIS is the same of other institutions in the public services but there are differences in the total benefit package due to differences in incentives and bonuses received.

In the FIS, the computing equipment is sufficient to execute the current work on the RPI. The index is compiled using Excel software in personal computers. The price department has one computer for each of the staff members. Access to all computers is secured by passwords. Backups of the data are stored on CDs only. No data are stored in the FIS server.

The physical facilities at the FIS are considered adequate except for the lack of sufficient office furniture. Each cantonal office has vehicles although price collection does not require special transportation arrangements as it is conducted only in urban areas.

The Department of Prices and Living Standards of the RSIS, currently employs three persons, of whom one person is engaged in matters related to consumer prices, including methodological training and practice, control, analyses and reporting. The other two persons are engaged on work related to the PPI and PPP. All of them have graduated from the Faculty of Economics.

In terms of fieldwork in the area of consumer prices (the RPI and COLI), the institute uses the services of trained and qualified price surveyors hired on a contractual basis. Currently, the RSIS hires seven price surveyors (due to the magnitude of the workload, two of them are allocated to the work in Banja Luka).

Within the frame of various projects, the staff have attended various courses and seminars related to the methodologies of compiling consumer price indices, but the real practice only started with the inception of HBS/CPI Project. Salary levels at the RSIS are comparable with those paid in other institutions of the public administration.

In the RSIS, the computer equipment within the Department of Prices and Living Standards is adequate and more satisfactory than in regional units, although all regional units are properly equipped to perform data entering. 
The offices at the RSIS are adequately equipped and furnished.

Recommendation: Provide additional resources to statistical institutions responsible for compiling price statistics in order to produce reliable price indices that follow the international standards.

\subsubsection{Measures to ensure efficient use of resources are implemented}

Under the existing constraints of human and financial resources, the statistical institutions have a difficult task in setting priorities that would lead to a more efficient use of resources, particularly of human resources. Most of the employees are required to be involved in multiple activities in order to implement several ongoing projects which stretches the capacity of the institutions and is deemed to have a negative impact on the quality of the work. In seeking greater efficiency in resources use, the BHAS reviews the work process for the conduct of the survey, learning from past experiences to introduce improvements in most recent researches.

As the leading institution in the prescription of methodologies, the BHAS also encourages the use of consistent concepts, classifications, and other methodological principles across datasets. However, positive results have been more easily achieved with the introduction of new surveys and the compilation of new statistical projects designed to provide data for the entities and for the whole country (e.g., CPI project, HBS, industrial survey, investment survey). For most of the existing datasets produced by the entities, there are still remarkable differences in methodologies, classifications, and even periodicity that make their aggregation into countrywide data infeasible.

The Federation Law stipulates the assessment of staff performance. Formally, the immediate superiors evaluate the subordinates, although the final outcome depends on general managers. Staff sentiment is that the process is not transparent and lacks impartiality. It is also thought that hiring is not solely based on competence.

\subsection{Relevance}

\subsubsection{The relevance and practical utility of existing statistics in meeting users' needs are monitored}

No established procedures are in place for consultations with users on the relevance of the statistics. The BHAS organizes meetings as needs arise with some users and the media to present the results of new statistical surveys, like the 2004 HBS and the 2006 Labor Force Survey.

None of the statistical institutions has established advisory committees or working groups to review the relevance of the data produced and to identify emerging data needs. New statistical products and improvements are mainly introduced to meet the requirements for joining the EU, consistent with the availability of financial resources and technical assistance 
being provided by the EU. Furthermore, the Statistical Councils do not play an important role in identifying the needs of users.

In general, $\mathrm{BiH}$ lacks a statistical culture. Interest in the statistics is mainly within a specialized professional groups and the international community. Efforts made in the past by the statistical institutions to ascertain the relevance of the statistical products have been met with indifference.

\subsection{Other quality management}

\subsubsection{Processes are in place to focus on quality}

Management of the statistical institutions is aware of the importance of the quality of the statistical products to build trust among users, however, resources constraints have limited the possibility of the institutions to introduce improvements in their collecting and processing systems at a more desirable pace. Furthermore, pressure to filing the gaps on information determines the statistical institutions to release some data even when their quality may be questionable. It is expected that the constant ongoing work in adopting international standards in the production of the statistics would bring along quality improvements.

\subsubsection{Processes are in place to monitor the quality of the statistical program}

Quality of the data produced is not monitored in a comprehensive way. There are no revision studies performed, and no systematic follow up of editing rates and response rates used to inform managers.

\subsubsection{Processes are in place to deal with quality considerations in planning the statistical program}

The statistical institutions take into account quality improvements identified during monitoring ongoing work in planning their activities. This has been recently the case during planning and execution of the CPI project, where problems faced on the quality of the data collected has led to the reexamination of the field work and the introduction of automated quality checks of the data.

\section{Assurances of integrity}

\subsection{Professionalism}

\subsubsection{Statistics are produced on an impartial basis}

All statistical institutions of $\mathrm{BiH}$ are professionally independent and the statistics are compiled taken into consideration only technical issues. There is no government interference on the outputs of the statistical work. In the Federation, the responsibility for the price index 
falls exclusively on the chief of the price department although management is informed and briefed of the results prior to dissemination.

The Law on Statistics of the BiH deals with the principles and technical autonomy of the statistical institutions of $\mathrm{BiH}$ in section VIII stating that "When implementing the Program, the staff of the Agency and entities' institutes, shall not seek or take instructions from Governments, other State's authorities, political parties or any other interest groups notably in the selection of data sources, statistical methods and procedures, in the contents, form and time of dissemination, and in the application of statistical confidentiality." Similar statements are embodied in the Law on Statistics of the entities (Law on Statistics of the Federation, Article 8 and Law on Statistics of the RS, Article 17, respectively).

Furthermore, all appointments and dismissals in the BHAS (including the Director, Deputy Director and Head of the Branch) are done in accordance with the provisions of the Law on Civil Service in the Institutions of $\mathrm{BiH}$ (Law on Statistics of BiH, Article 9). No explicit reference to the conditions governing the appointments of the head of the entities' institutes of statistics is made in their respective Laws.

The BHAS recruitment policy and procedures are consistent with the requirements of the Law on Civil Service of BiH. For each open position, the Agency fills the vacancies following an open bid process and candidates are selected by a recruitment commission based on their aptitudes and skills. The recruitment process in the entities is also defined by law although in the views of some of the staff, skills and competence are not always the main factors considered in recruiting the personnel.

The statistical institutions of $\mathrm{BiH}$ have been and are actually being benefited on a current basis with multiple statistical projects under the technical cooperation of international organizations and bilateral technical assistance projects from member countries of the EU. These projects have an important role in transmitting know-how to the local staff, besides assisting in the production of the statistics according to international standards. The staff of all statistical institutions participate on international meetings and workshop organized by the international organizations, as well as on working visits to other statistical institutions in the region. In 2006, one expert on price statistics (representing the BHAS) attended a course on price statistics organized by the IMF at the Vienna Joint Institute.

Although the BHAS promotes a culture of professionalism by encouraging staff to actively participate in activities such as lectures and conferences, only few of the staff members have been involved in such events. Furthermore, lesser attention is apparently being paid by the entities' institutes of statistics in promoting their staff work. There is a lack of methodological papers available in all statistical entities, which is clearly reflected in the scarce metadata available for the statistics. 


\subsubsection{Choices of sources and statistical techniques as well as decisions about dissemination are informed solely by statistical considerations}

The choice of source data and statistical techniques are solely based on measurement objectives and data requirements. Data on price indices are disseminated based solely on statistical considerations.

\subsubsection{The appropriate statistical entity is entitled to comment on erroneous interpretation and misuse of statistics}

Although the statistical institutions are entitled to comment on misuse of the statistics, they prefer not to exercise this right considering the sensitivity of the political situation.

\subsection{Transparency}

\subsubsection{The terms and conditions under which statistics are collected, processed, and disseminated are available to the public}

The BHAS and the RSIS publish the state and the entity respective Laws on Statistics on their website together with their multi-annual statistical programs. At present, these materials are made available only in local language. All three institutions make available references to the terms and conditions under which the official statistics are compiled and disseminated in publications and/on their websites. The statistical institutions also provide a list of their publications on their respective websites. Additionally, the Federation Year Book contains a list of publications.

\subsubsection{Internal governmental access to statistics prior to their release is publicly identified}

There is no government access to the data prior to its release in the BHAS, the FIS, and the RSIS.

\subsubsection{Products of statistical agencies/units are clearly identified as such}

All three statistical institutions of BiH clearly identify themselves as the producers of the statistics that they disseminate. The name and logo of the institutions is reproduced in their publications.

\subsubsection{Advance notice is given of major changes in methodology, source data, and statistical techniques}

There have been no major changes in the methodology in recent years, as most of the regular statistics being produced are based on the methodology inherited from the former Yugoslav statistics system. The work programs provide some advance notice regarding introduction of new products. Some projects, such as the project for undertaking the 2007 household survey, are announced in advance in order to familiarize the public with the survey's purpose and 
enlist their cooperation. The introduction of the new international classifications of activities in recent years has also been announced in advance.

\subsection{Ethical standards}

\subsubsection{Guidelines for staff behavior are in place and are well known to the staff}

Employees of all statistical institutions of $\mathrm{BiH}$ are subject to the rules of conduct as specified in the respective laws on civil servants and the rule book of their institutions. Employees are made aware of the ethical code.

\section{Methodological soundness}

\subsection{Concepts and definitions}

\subsubsection{The overall structure in terms of concepts and definitions follows internationally accepted standards, guidelines, or good practices}

The RPI, which is produced by the entities and by the district of Brcko, separately, is used as their official indicator of inflation. No countrywide RPI exists. In addition to the RPI, a COLI is compiled and disseminated by the entities and by the district of Brcko. The COLI has a more limited use than the RPI and it is based on a subset of products included in the RPI.

Both indices, the RPI and the COLI, were established in the late 1980s based on the methodology inherited from the former Yugoslavia, thus implying the use of a conceptual framework that predates the current international standards.

The concept underlying the weights for the RPI corresponds to the retail trade turnover, including services, as this index is designed to measure changes in prices of goods and services sold by the retail trade industry. The concept of price used is the market prices including taxes. Product specifications do not consider the terms of transactions as a characteristic determining the price.

The source data for the determination of weights of the RPI is the retail trade turnover in 1986, based on surveys of enterprises and estimates of sales in the green markets. The basket has been updated (expanded) since then with the introduction of new products and adjustments that have been made in accordance to the product weights within the groups to which they belong by reallocating the base period weights. No changes have been introduced on the weights of the groups of products. Obviously, the 1986 weights base year period is too old to properly reflect the structure of weights in most recent periods.

The basket of the RPI in the Federation consists of 600 products for which weights are available. In RS, the basket includes 420 products. The classification of products corresponds to the old Yugoslavian classification. 
The COLI derives its weights from household expenditures obtained from the household budget survey of 1987, based on a sample of 3,030 households with national coverage.

Both types of weights are based on fairly old data series, given that they were inherited from the former statistical system.

That was one of the main criteria for starting up the implementation of HBS/CPI project in the $\mathrm{BiH}$ in 2004. Work is in progress for compiling the CPI at the level of the entities and the country as a whole following the international standards and recommendations. For instance, the concept of household consumption expenditure used in determining the index weights corresponds to the recommendations of the 1993 SNA/1995 ESA.

Product specifications for the collection of prices within the CPI compilation framework are generally in accordance with the standard practices. Transaction characteristics that may affect the price are not strictly considered in the compilation of the index.

Recommendation: Give highest priority to completing the compilation and dissemination of a countrywide CPI. When completed, replace the RPIS with the CPI.

\subsection{Scope}

\subsubsection{The scope is broadly consistent with internationally accepted standards, guidelines, or good practices}

No countrywide price index is available. Separate RPIs are compiled at entity level and for the District of Brcko. Work is ongoing with the technical assistance of the Italian Statistical Office to produce a countrywide CPI.

In each entity, the scope of the RPI is the turnover of the trade industry. The product coverage of the RPI is broader than consumption of households in that it relates to total sales of goods and services by the trade and service industries, without distinction between the final destinations of the products.

The scope of the new CPI being compiled with the technical assistance provided by ISTAT conforms to the methodological standards recommended by the EU. The index measures the changes in price of goods and services purchased by all resident households to satisfy their consumption needs. The concept of expenditure used is the monetary consumption expenditures only; therefore, the consumption of own-produced goods by households and the imputation of the services of owners-occupied dwellings are rightly excluded from the index. Weights have been derived form the Household Survey Budget of 2004 (2004 HBS), which has full geographical and household coverage. Both rural and urban households are included in the survey. Only transactions related to consumption are included in the scope of the CPI; therefore, expenditures related to the purchases of goods and services for the activities of 
unincorporated enterprises of households are excluded. Excluded as well are the expenditures of households on residential structures.

\subsection{Classification/sectorization}

\subsubsection{Classification/sectorization systems used are broadly consistent with internationally accepted standards, guidelines, or good practices}

The old classification of products of the former Yugoslavia is used in the price surveys and the compilation of the RPI. On the compilation of the CPI the classification of households and transactions correspond to the recommendations provided by the 1993 SNA/1995 ESA. The COICOP classification is being used for the classification of consumption on goods and services and the compilation of the CPI.

With the development of the compilation system for a CPI, each product included in the price surveys has been assigned the correspondent COICOP code although the compilation of the RPIs continue to be based on the old classification as the corresponding codes are necessary for applying the RPI current processing systems.

\subsection{Basis for recording}

\subsubsection{Market prices are used to value flows and stocks}

Market prices paid by buyers are used both for the valuation of the trade turnover and in the price survey used for the compilation of the RPI.

It should be noted that as a consequence of the procedures established for the price survey needed for the CPI, the price data for the RPI and the COLI improved considerable starting from January 2005.

In previous years, price collection for RPI and COLI in the entities was also based on narrow product specifications, which were easier to apply during the times of the Former Yugoslavia, when the variety of products was more restricted and mainly composed by locally produced products. With the higher diversification of supply in the most recent years, the statisticians have had to handle frequent changes in the products specifications, which has implied that products lightly different have been considered to be the same, thus likely undermining the accuracy of the index.

The valuation of consumption expenditures used for the determination of weights of the CPI is based on the actual market prices paid for the transactions. Therefore, the prices include the distribution margins and taxes paid by consumers.

Product specifications used for the collection of prices are very detailed. However, no special attention was given to the terms of the sales (whether cash or credit). 


\subsubsection{Recording is done on an accrual basis}

Prices collected are the prices paid by consumers at the time the transactions take place. Prices for agriculture products are collected twice in a month, on the first and third week. Prices for other food products, non-food products, and for services are colleted once in a month (during the first half of the month).

\subsubsection{Grossing/netting procedures are broadly consistent with internationally accepted standards, guidelines, or good practices}

The concept of retail trade turnover is used for the derivation of the weights of the RPI, therefore no distinction is made between used and new goods. Gross purchases instead of acquisitions less disposals of goods are used in the compilation of the CPI, thus deviating from the correspondent international recommendations.

\section{Accuracy and reliability}

\subsection{Source data}

\subsubsection{Source data are obtained from comprehensive data collection programs that take into account country-specific conditions}

The source data for the determination of weights of the RPI in the retail trade turnover of 1986, based on surveys of enterprises and estimates of sales in the green markets. Obviously, the 1986 weights base year period is too old (more than 15 years) to properly reflect the structure of weights in most recent periods. Moreover, the underlying source data are no longer available, neither any comprehensive documentation on how these data were obtained; only general methodological notes prepared by the former Yugoslav office for statistics are available. Furthermore, the statistical institutions of $\mathrm{BiH}$ have no regular program for the conduct of regular surveys that could allow for the updating of the RPI weights.

For the collection of prices, the entities conduct monthly surveys with direct observations of prices at the selling points by enumerators especially trained for this purpose. The regular price collection conducted by the entities' institutes of statistics and the Brcko branch of the BHAS equally serve compilation of the three different indices currently available (RPI, COLI, and CPI). All types of outlets are included in the surveys, which are conducted in supermarkets, hypermarkets, specialized shops, markets, and different types of service providers. Tariffs of the utility services are collected directly from the respective enterprises.

In the Federation, the list of products used to compile the RPI is composed of about 600 items. The list of goods and services used in the RS within the framework of RPI cover around 420 items. The choice of the products and the outlets is based on a purposive sampling approach. The criteria have been to include the biggest establishment in term of their shares in total turnover and the most important products based on judgment of the compilers. 
Prices for most of the products in the RPI basket are collected once a month except for fresh agriculture products for which the collection is bi-monthly ( $1^{\text {st }}$ and $3^{\text {rd }}$ weeks).

Purposive sampling methods were used for the selection of geographical areas, items, outlets, and product varieties.

New products are identified through the current price surveys. The list of products is reviewed at the beginning of each year.

At present there is no regular program for the conduct of household budget surveys. The first household budget survey after independence was conducted in 2004. At present, there is in place an ongoing income and expenditure household survey for the year 2007. Although the aim of the statistical institutions is to conduct this kind of survey with an annual periodicity, the achievement of this goal is highly dependant on resources available.

The CPI under development derives its weights from the HSB 2004. This survey is based on a two-stage random sampling method. The primary sampling units are the Enumeration Areas (areas with a certain number of dwellings), whose number is 19,423 for the whole country. In the selected EA a complete enumeration of dwellings was done in order to establish the framework from which the sample of dwellings to be included in the survey was selected. The survey was conducted during the 12 months of the year. Due to the lack of appropriate sampling framework, the results have often been questioned within and outside the statistical institutions. In particular, there is a sense that the expenditures of households are overstated. Expenditures are broken down to about 400 items, which has not been enough to determine the weights for the new CPI, raising additional methodological problems faced on the design of the index methodology.

The CPI basket consists of 646 items, and 580 representative positions for which estimates of weights are available. Each item has assigned the COICOP code extended to 12 digits. About 20,000 prices are collected every month. The HBS 2004 only provided detailed expenditure data at the level of about 400 product groups. Further breakdown was obtained using other source data and expert judgments, depending on the commodity group and data sources available. The inadequate item coverage from the HBS is one of the main shortcomings of the weight source data for the compilation of the CPI.

\subsubsection{Source data reasonably approximate the definitions, scope, classifications, valuation, and time of recording required}

The source data for the compilation of the RPI and the CPI approximate the requirements for the indices compilation in terms of prices definition, scope, classifications, valuation, and time of recording. As previously described, detailed specifications are used to collect prices paid by consumers during the reference month of the index. 


\subsubsection{Source data are timely}

Prices are collected monthly (twice a month for agriculture products) on a timely basis. The only exception documented refers to the index of January 2006 in the Federation, which was tardily published in March 2006 after problems were identified on the price data collected. Data were improperly collected given rise to the recalculation of the index for the whole year 2005. In the RS, all data collected in the field are delivered/transferred to the RSIS on a timely basis every month through the regional statistical offices. Respondents are made aware of the deadlines set for reporting.

\subsection{Assessment of source data}

\subsubsection{Source data-including censuses, sample surveys and administrative records-are} routinely assessed, e.g., for coverage, sample error, response error, and nonsampling error; the results of the assessments are monitored and made available to guide statistical processes

In the past, there were no adequate measures for monitoring the quality of the data collected in the price surveys. Now the quality of the data collected has improved by the introduction of regular random control procedures including revisiting the surveyed outlets as well as automated quality check procedures introduced within the project for the development of the CPI. In case of doubts, data are verified with the source of information.

The HBS 2004 is based on a random sample method. Sampling errors were calculated at detailed level providing satisfactory results at aggregated levels. The CPI survey is based on a purposive sampling approach.

Different procedures to assure accuracy were applied to the HBS. The price surveys now include (with the introduction of the CPI) automated quality control procedures like the identification of outliers, missing data, non-response, etc.. Extreme values are confirmed with respondents.

\subsection{Statistical techniques}

\subsubsection{Data compilation employs sound statistical techniques to deal with data sources}

The quality of the RPI data has benefited with the introduction of automated editing processes. Field-work check-ups were not common in the entities because the lack of human resources.

The statistical institutions are controlling all data provided in terms of coverage/exhaustiveness, accuracy, reliability, consistency, and comparability with previous data prior to any further data processing and dissemination. Check-ups of the data are also made in regard to detailed specifications for individual products. 
Imputations for missing prices are similar in both entities. Usually the same price of previous month is carried forward, or in some cases, by extrapolation of the last price observed by using the price change of a close product. When a product is not available in a surveyed outlet, the manager is asked whether the product is temporarily or permanently unavailable. For the former, the last observed price is imputed while for the latter another outlet is looked out to find the same product or substitute the product for a close related one. It should be noted that a price is not carried forward for more than two months, when a replacement has to be found. No adjustment for quality is made when introducing new replacement products although the effect in the index is expected not to be significant as efforts are made to find similar products. In cases when an outlet is closed, the same product is sought in other outlets, which is a sound practice.

The Federation RPI treats seasonal products in two different ways: (i) the last available price is usually brought forward to the following months, or in some cases, (ii) the average price of the last five months for which the product was available is carried forward until the product reappears. In contrast, the RS only carries forward the last observed price until the beginning of the next season. It should be noted that the procedures followed produce a bias in the index of the respective group.

Compilation of the CPI is based on software especially devised by ISTAT for the compilation of the Italian CPI, adapted to Bosnia. The software handles the data from entry up to compilation and generation of the output tables. Imputations for non-response in the CPI are done by carrying forward the last price observed; if these occur for more than two months, the item is replaced. Within the compilation of the CPI, quality adjustments are made when introducing new products by applying the ratios between the price of the new replacement product and the old product in an overlapping period as an estimate of the quality difference.

\subsubsection{Other statistical procedures (e.g., data adjustments and transformations, and statistical analysis) employ sound statistical techniques}

For the compilation of the RPI, the elementary indices are calculated as the ratios of average prices. For each entity, average prices are calculated as weighted arithmetic means of prices collected in the cities covered. For each city, the price is the simple average of all observations. At the entity level, the average price is calculated as the average of the cities' prices weighted by their shares in the population of the respective entity.

Short-term price relatives (relative to previous year and not relative to the weight base year) are used both in the Federation and in the RS as the ratio between the average price in the current month to the average price in previous year.

The Laspeyres formula is used to aggregate the indices in both entities. In the Federation, the base weights used in the index compilation were price updated (by price indices) but in the last three years it has not been done on the assumption that a relatively low inflation rate does not justify such adjustment. The RS does not currently update the weights every year by price 
changes. Failing to update the weights by annual price changes along with the change of the price reference period (of the price relatives used in the calculation of such an index) actually introduces a bias in the index. Updating the weights when using-term short price relatives is equivalent to maintaining the fixed weights of the base year when using long-term relatives. Failing to do so implies that the resulting indices deviate from the intended index based on fixed weights.

For the CPI, the elementary indices are compiled as the geometrical means of the price ratios. Long-term ratios from the current month to December of 2004 (price reference period of the index) as well as short-term ratios (to December of previous year) are being used. It should be noted that the weights obtained from the HBS 2004 have been adjusted by price changes from the average of 2004 to the price reference period used in the calculations (December of previous year).

The CPI is being compiled by product at the level of city (or town), entity and the state. Weights for the aggregate index at the town level are the products' expenditure shares in the entity to which the town belongs. The entity product index is obtained as a weighted average of the town indices, using their shares in the entity's population as weights. The overall index for the entity is being obtained as a weighted average of the respective entity's product indices using their respective expenditure shares in the entity as weights. The state (countrywide) index is the weighted average of the product indices of the entities using the shares of expenditures of the entities in the total for the country.

\subsection{Assessment and validation of intermediate data and statistical outputs}

\subsubsection{Intermediate results are validated against other information where applicable}

In the Federation, retail prices and producer prices are compared when feasible. There is also a special focus in following up on the tariffs of public utilities and telecom services, for which the basis for pricing has been subject to frequent changes. The RS lacks a producer price index and therefore validation of intermediate results is more limited.

Recommendation: Improve data validation at all stages to enhance the accuracy and reliability of the final results.

\subsubsection{Statistical discrepancies in intermediate data are assessed and investigated}

Unusual movements of the index in specific sectors are investigated by sector and by outlet. It is a common procedure in both entities to compare prices with previous month for each outlet and product to assure the consistency of the data. 


\subsubsection{Statistical discrepancies and other potential indicators of problems in statistical outputs are investigated}

The RPI is compiled only at the entity level by aggregation of the respective product indices. No index is compiled for the cities; therefore no inconsistencies can arise due to different typologies of aggregation.

\subsection{Revision studies}

\subsubsection{Studies and analyses of revisions are carried out routinely and used internally to inform statistical processes (see also 4.3.3)}

No major revisions (such as updating weights) have been made to the RPIs since their inception in the late 1980s and, therefore, no revision studies have been carried out. The index is usually final when disseminated, except if errors would occur. However, problems found in data collection have been addressed by improving procedures in conducting the price survey.

\section{Serviceability}

\subsection{Periodicity and timeliness}

\subsubsection{Periodicity follows dissemination standards}

The RPI is compiled and disseminated monthly by the entities and the district of Brcko, thus complying with the GDDS recommendations on periodicity.

\subsubsection{Timeliness follows dissemination standards}

The RPI exceeds the GDDS recommendations on timeliness for the dissemination of price indices. The RS publishes the RPI no later than the $12^{\text {th }}$ day after the end of the reference month. The Federation publishes the RPI before the $15^{\text {th }}$ of the month that follows the reference period.

\subsection{Consistency}

\subsubsection{Statistics are consistent within the dataset}

The RPI is internally consistent. The overall index is the weighted average mean of the product indices. There is only one system of weights; therefore no inconsistencies can arise from different forms of aggregation. The index is calculated only at the entity level. 


\subsubsection{Statistics are consistent or reconcilable over a reasonable period of time}

The RPIs produced by the entities and the district of Brcko are consistent for long periods. Consistent data series exist from 1989.

\subsubsection{Statistics are consistent or reconcilable with those obtained through other data sources and/or statistical frameworks}

Where possible, the consistency of the RPIs with other indicators of price changes is monitored. Unusual changes in prices are explained like with the introduction of the VAT in January of 2006. Every month, the entities provide a brief summary of main findings together with the data.

\subsection{Revision policy and practice}

\subsubsection{Revisions follow a regular and transparent schedule}

There is no revision policy established for updating the weights and/or the methodology of the RPIs. No regular revisions are introduced to the published data as the RPIs are final when published. However, the internal policy of the statistical institutions is to revise the data if errors are found.

\subsubsection{Preliminary and/or revised data are clearly identified}

The statistical institutions of the BiH clearly identify the preliminary character of their statistical products, as applicable. This is not the case of the RPI, however, for which the indices are considered final when published.

\subsubsection{Studies and analyses of revisions are made public (see also 3.5.1)}

No major revisions have been implemented with the RPI and revision studies are not applicable.

\section{Accessibility}

\subsection{Data accessibility}

\subsubsection{Statistics are presented in a way that facilitates proper interpretation and meaningful} comparisons (layout and clarity of text, tables, and charts)

The entities' institute of statistics disseminates the RPIs by means of press releases, press conferences and the Internet on fixed dates each month. Monthly data on the RPIs are first disseminated through the websites of the entities' institutes of statistics. 
The RS presents the data for the current month with various reference periods, as follows: (i) the average of previous year, (ii) the previous month, and (iii) the same month of previous year, as well as the indices of cumulative changes from the beginning of the year relatives to the same cumulative period in previous year. The release also includes a short description of main findings but no charts are included. The same information, except for the addition of a chart, is published later on the "Monthly Statistical Review," which is also posted on the Internet. A "Quarterly Statistical Review" provides monthly series for the last two years having as reference periods (i) the average of previous year (the year preceding the current reference period of the data) and (ii) the previous month. This publication also contains detailed monthly series for the last three months of the current year and December of the preceding year.

The Federation firstly publishes the RPI data in the "Monthly Statistical Review," also posted on the website. It presents the RPI for the current month in a similar fashion as the RS. In addition, year-to-year average annual indices for a period covering the last three years and monthly indices on a fixed- price-reference period for the months of the current year and the twelve months of the preceding year are included. A brief description of main findings is also provided. No charts are provided. The Federation's Yearbook provides longer annual series and more detailed data than the monthly publication. It also includes a chart.

None of the statistical institutions disseminate seasonally adjusted series of the RPI. The data are posted in the websites of the statistical institutions at the time of release, although no long term-annual and/or monthly series are available. The Federation provides long-term annual series in its Yearbook. No charts are disseminated together with the data and no seasonally adjusted series are made available to the public. However, the quarterly bulletins provide graphs and more detailed data accompanied with text.

Recommendation: Post monthly and long-term, annual data series on the agencies' website in order to improve data accessibility.

\subsubsection{Dissemination media and format are adequate}

Both entities published the RPI data in electronic and paper form. The electronic format reproduces the paper one and, therefore, data are not in a data-readable format, such as Excel. The entities' statistical institutions do not maintain an electronic database that can be accessed by users to obtain longer and/or more detailed series. However, these data series can be obtained, free of charge, through a written request to the institutions.

\subsubsection{Statistics are released on a preannounced schedule}

The statistical institutions do not have a preannounced release schedule, although the indices are published punctually on the dates stipulated on their annual work plans, which are posted in their websites. 


\subsubsection{Statistics are made available to all users at the same time}

The RPIs are made available to all users at the same time by posting the data on the institutions' websites.

\subsubsection{Statistics not routinely disseminated are made available upon request}

Long-term series and more detailed data are made available to users upon written request to the statistical institutions. The information is provided free of charge.

\subsection{Metadata accessibility}

5.2.1 Documentation on concepts, scope, classifications, basis of recording, data sources, and statistical techniques is available, and differences from internationally accepted standards, guidelines, or good practices are annotated

There is no comprehensive metadata for the RPI. Only a very general and short description of methods and sources is made available to the public. The entities also lack internal detailed documentation on sources and methods for the compilation of the index.

Recommendation: Prepare and disseminate detailed manuals of sources and methods used for the compilation of the price statistics.

\subsubsection{Levels of detail are adapted to the needs of the intended audience}

There is only one level of metadata available.

\subsection{Assistance to users}

\subsubsection{Contact points for each subject field are publicized}

No specific names are provided to the public as contacts for inquiries on the RPI. However, the publications, which are also posted on the Internet, provide all contact details for addressing inquiries, which are promptly handled by the institutions. Assistance to users is to some extent monitored and used to improve the contents and forms of publications.

\subsubsection{Catalogs of publications, documents, and other services, including information on} any charges, are widely available

There are no specific catalogs published by the statistical institutions but all publications can be found on the respective websites of the statistical institutions. Moreover, the Federation also provides a list of publications on its website. 
Table 2. Bosnia and Herzegovina: Data Quality Assessment Framework (July 2003):

Summary of Results for Price Statistics (Retail Price Index)

(Compiling Agency: BHAS, FIS, RSIS)

\begin{tabular}{|c|c|c|c|c|c|c|c|}
\hline \multirow{2}{*}{ Element } & \multirow{2}{*}{ NA } & \multicolumn{4}{|c|}{ Assessment } & \multirow{2}{*}{ Comments on Assessment } & \multirow{2}{*}{$\begin{array}{c}\text { Plans for Improvement and Target } \\
\text { Dates }\end{array}$} \\
\hline & & $\mathrm{O}$ & $\mathrm{LO}$ & LNO & $\mathrm{NO}$ & & \\
\hline \multicolumn{8}{|l|}{ 0. $\quad$ Prerequisites of quality } \\
\hline 0.1 Legal and institutional environment & & & & $\mathrm{X}$ & & $\begin{array}{l}\text { Statistical Laws of the entities and the state are } \\
\text { not harmonized and not fully implemented, thus } \\
\text { undermining coordination among the three } \\
\text { institutions. Data sharing, although mandatory by } \\
\text { law, is problematic as well as the implementation } \\
\text { of a common work program. }\end{array}$ & \\
\hline 0.2 Resources & & & & $\mathrm{X}$ & & $\begin{array}{l}\text { The statistical institutions lack adequate human } \\
\text { resources. Budgetary allocations are only enough } \\
\text { to cover operational costs of regular activities. } \\
\text { Financial resources allocated for capital expenses } \\
\text { are very modest. Difficulties to recruit skilled } \\
\text { personnel, particularly on IT area where the } \\
\text { Institutes face a high turnover. }\end{array}$ & \\
\hline 0.3 Relevance & & & & $\mathrm{X}$ & & $\begin{array}{l}\text { There are no established procedures for } \\
\text { consultation with users. New activities are } \\
\text { mostly driven by commitments toward } \\
\text { integration in the EU. }\end{array}$ & \\
\hline 0.4 Other quality management & & & & $\mathrm{X}$ & & $\begin{array}{l}\text { There are almost no formal procedures across the } \\
\text { statistical activities to monitor and ensure quality } \\
\text { of the outputs. }\end{array}$ & \\
\hline \multicolumn{8}{|l|}{ 1. Assurances of integrity } \\
\hline 1.1 Professionalism & & $\mathrm{X}$ & & & & & \\
\hline 1.2 Transparency & & $\mathrm{X}$ & & & & & \\
\hline 1.3 Ethical standards & & $\mathrm{X}$ & & & & & \\
\hline
\end{tabular}


Table 2. Bosnia and Herzegovina: Data Quality Assessment Framework (July 2003):

Summary of Results for Price Statistics (Retail Price Index)

(Compiling Agency: BHAS, FIS, RSIS )

\begin{tabular}{|c|c|c|c|c|c|c|c|}
\hline \multirow{2}{*}{ Element } & \multirow{2}{*}{ NA } & \multicolumn{4}{|c|}{ Assessment } & \multirow{2}{*}{ Comments on Assessment } & \multirow{2}{*}{$\begin{array}{c}\text { Plans for Improvement and Target } \\
\text { Dates }\end{array}$} \\
\hline & & $\mathrm{O}$ & $\mathrm{LO}$ & $\mathrm{LNO}$ & $\mathrm{NO}$ & & \\
\hline \multicolumn{8}{|l|}{ 2. Methodological soundness } \\
\hline 2.1 Concepts and definitions & & & & $\mathrm{X}$ & & $\begin{array}{l}\text { The RPI and not the CPI is used as the official } \\
\text { indicator of inflation. The concept underlying the } \\
\text { RPI is the trade turnover, including services. The } \\
\text { RPI is based on an outdated methodology that } \\
\text { predates current international standards. }\end{array}$ & $\begin{array}{l}\text { A nation-wide CPI that follows the } \\
\text { international standards is under } \\
\text { development (short term: by end- } \\
\text { 2007). }\end{array}$ \\
\hline 2.2 Scope & & & & & $\mathrm{X}$ & $\begin{array}{l}\text { The RPI is not produced for the country as a } \\
\text { whole. Separate indices are prepared for the } \\
\text { entities and the district of Brcko. }\end{array}$ & \\
\hline 2.3 Classification/sectorization & & & & $\mathrm{X}$ & & $\begin{array}{l}\text { The old Yugoslav system of product } \\
\text { classification is used, which does not meet } \\
\text { international standards. }\end{array}$ & \\
\hline 2.4 Basis for recording & & & $\mathrm{X}$ & & & $\begin{array}{l}\text { Actual prices paid by purchasers are recorded. } \\
\text { However, product specifications do not consider } \\
\text { terms of transactions such as discounts and } \\
\text { surcharges for credit as a distinctive property of a } \\
\text { product. }\end{array}$ & \\
\hline \multicolumn{8}{|l|}{ 3. Accuracy and reliability } \\
\hline 3.1 Source data & & & & $\mathrm{X}$ & & $\begin{array}{l}\text { There is no comprehensive data collection } \\
\text { program for compiling the source data needed to } \\
\text { update the weights of the RPIs. The present } \\
\text { system of weights is more than fifteen years old } \\
\text { and the underlying source data are no longer } \\
\text { available. }\end{array}$ & \\
\hline $\begin{array}{l}\text { 3.2 Assessment of source data } \\
3.3 \text { Statistical techniques }\end{array}$ & & & $\mathrm{X}$ & $\mathrm{X}$ & & $\begin{array}{l}\text { Price data are regularly assessed by compilers but } \\
\text { field inspection checks are limited. } \\
\text { No adjustments are made for quality changes. } \\
\text { Weights are not aligned to the price reference } \\
\text { period thus introducing a bias in the index,. }\end{array}$ & \\
\hline
\end{tabular}


Table 2. Bosnia and Herzegovina: Data Quality Assessment Framework (July 2003):

Summary of Results for Price Statistics (Retail Price Index)

(Compiling Agency: BHAS, FIS, RSIS)

\begin{tabular}{|c|c|c|c|c|c|c|c|}
\hline \multirow{2}{*}{ Element } & \multirow{2}{*}{ NA } & \multicolumn{4}{|c|}{ Assessment } & \multirow{2}{*}{ Comments on Assessment } & \multirow{2}{*}{$\begin{array}{c}\text { Plans for Improvement and Target } \\
\text { Dates }\end{array}$} \\
\hline & & $\mathrm{O}$ & LO & LNO & $\mathrm{NO}$ & & \\
\hline $\begin{array}{l}\text { 3.4 Assessment and validation of inter- } \\
\text { mediate data and statistical outputs } \\
\text { 3.5 Revision studies }\end{array}$ & & & $X$ & & & $\begin{array}{l}\text { Validation of intermediate results is limited and } \\
\text { not systematic. A major shortcoming is the lack } \\
\text { of other price indices to be compared with. } \\
\text { No major revisions and studies have been made } \\
\text { to the RPI since its introduction. }\end{array}$ & \\
\hline \multicolumn{8}{|l|}{ 4. Serviceability } \\
\hline $\begin{array}{l}\text { 4.1 Periodicity and timeliness } \\
\text { 4.2 } \text { Consistency } \\
4.3 \text { Revision policy and practice }\end{array}$ & & $\begin{array}{l}X \\
X\end{array}$ & & $X$ & & $\begin{array}{l}\text { No revision policy has been established for } \\
\text { updating weights or changing methodology for } \\
\text { the RPI. }\end{array}$ & \\
\hline \multicolumn{8}{|l|}{ 5. Accessibility } \\
\hline $\begin{array}{l}\text { 5.1 Data accessibility } \\
\text { 5.2 Metadata accessibility } \\
\text { 5.3 Assistance to users }\end{array}$ & & & $\mathrm{X}$ & $\mathrm{X}$ & & $\begin{array}{l}\text { Data accessibility is in general good although } \\
\text { long-term series are not disseminated. Data are } \\
\text { not seasonally adjusted and not in a data-readable } \\
\text { format. } \\
\text { There is no detailed metadata available on the } \\
\text { compilation of the RPIs. Only a very limited } \\
\text { description of methods and sources is made } \\
\text { available to the public. } \\
\text { No contact information (names) in the } \\
\text { publications.. }\end{array}$ & \\
\hline
\end{tabular}




\section{Government FinanCE Statistics}

Notwithstanding the fact that the compilation of government finance statistics (GFS) is a relative new development in $\mathrm{BiH}$, GFS compiled by the Central Bank of Bosnia and Herzegovina (CBBH) and based on the methodology recommended in the GFSM 2001 is currently available for all levels of government. Data were first compiled in 2003 for the consolidated central government and in 2005 for the general government. However, despite this notable progress, the coverage of the central and general governments stocks and flows are not consistent with international standards and limits the strength of the analytical conclusions that can be drawn from the fiscal data.

\section{Prerequisites of quality}

\subsection{Legal and institutional environment}

\subsubsection{The responsibility for collecting, processing, and disseminating the statistics is clearly specified}

The CBBH By-law, which was established in 2006 and published in the Official Gazette of $B i H$, specified the scope of the responsibility of the $C B B H$ for collecting, compiling and disseminating monetary statistics, balance of payments statistics, and government finance statistics. The assignment of the responsibility for collecting, compiling, and disseminating GFS solely to the CBBH was confirmed by an agreement reached between the $\mathrm{CBBH}$ and the Ministries of Finance in July 2003. The authority of the $\mathrm{CBBH}$ to request data and information from government units is granted by the CBBH Law (Article 68) and the By$L a w$. The $C B B H B y$-Law also specified that in its implementation, guidance provided in two CBBH official documents should be followed: Terms of Reference for Data Reporting and Statistical Methodology Framework.

The responsibility for compiling GFS resides with the CBBH's Economic Research and Statistics Department (ERSD). The ERSD was reorganized in November 2002 and now comprises a Research Division and a Statistics Division. The Statistics Division further consists of three sections, responsible for (i) monetary and financial statistics, (ii) government finance and external debt statistics, and (iii) balance of payments statistics, respectively. The re-organization reflected the increased importance that the $\mathrm{CBBH}$ management attached to its statistics work and has resulted in better defined responsibilities of each unit within the ERSD. 


\subsubsection{Data sharing and coordination among data-producing agencies are adequate}

There are no formal arrangements for data sharing with other statistical institutions, but some coordination does exist. The Memorandum of Understanding (MoU), which was signed in January 2007 between the BHAS and the CBBH, provides the basic framework for data sharing. In addition, good cooperation on data sharing exists between the $\mathrm{CBBH}$ and the Ministries of Finance at the state and entity levels. Occasional contacts are also maintained with other data producing agencies to promote a proper understanding of data requirements, to avoid duplication of effort, and to take into account the reporting burden. However, the Macroeconomic Analysis Unit (MAU), an unit of the Indirect Taxation Authority is also compiling government data for operational purposes. Although these data are not official statistics, they are available to users on the website of the MAU and are currently not consistent with the GFS data that are compiled by the CBBH. As the MAU is a fairly new institution, established in 2005, its coverage of the general government sector still excludes some local authorities. However, it may be confusing for users if two different sets of government finance data, compiled by government agencies, are available.

Recommendation: If both sets of data continue to be available to users, the CBBH and MAU should at a minimum coordinate to ensure that the two sets of data on the general government statistics made available to users are consistent.

\subsubsection{Individual reporters' data are to be kept confidential and used for statistical purposes only}

Ensuring confidentiality is not an issue since GFS data are obtained as a by-product of budget and treasury systems. Adequate procedures are, however, in place to protect the confidentiality of any data. CBBH staff are guided by the CBBH Book of Rules relating to the disclosure of confidential data. Access to confidential data requires clearance and is tightly supervised.

\subsubsection{Statistical reporting is ensured through legal mandate and/or measures to encourage response}

The CBBH carefully considers the response burden and assists respondents by including detailed written explanations. Reporting of data to $\mathrm{CBBH}$ is supported by good procedures for assistance and follow-up (see also 0.1.1 and 0.1.2).

\section{$0.2 \quad$ Resources}

\subsubsection{Staff, facilities, computing resources, and financing are commensurate with statistical} programs

In the ERSD of the CBBH, four employees compile the macroeconomic statistics in the government finance area on a full-time basis. These employees are currently not considered as sufficient in number to carry out the existing mandate; therefore there is also no capacity 
available for any additional development work. The CBBH has no difficulty in recruiting new staff as salaries are seen to be competitive. One position is currently vacant in the Unit, which is placing an additional burden on the existing staff. In March 2007, the average experience in the Unit amounted to three years in the field of GFS. This lack of experience in the compilation of GFS can be ascribed to the recent establishment of the unit and the turn over of staff which causes problems for further improvements of the data. The staff of the GFS unit do participate in international statistical conferences and attend courses on government finance statistics. However, staff members do not participate in any international or regional working groups.

Although all staff in the GFSU are equipped with a computer, the software available for compiling GFS is not adequate to perform the required tasks. The whole process of data transmission, compiling, and tabulation is not computerized. The Information Technology Department has systems in place to protect the CBBH's computer resources and maintain operation in the events of an emergency.

There are established processes for budgeting for the coming year's work program. Proposals for departments' needs for ongoing programs and developmental work are submitted to $\mathrm{CBBH}$ 's management for approval. However, the funding of the GFS needs is not secure as funding is not based on statistical program needs.

Recommendation: Strengthen and increase resources for the compilation of GFS.

\subsubsection{Measures to ensure efficient use of resources are implemented}

The efficient use of existing resources is promoted by the ERSD through (i) periodic performance reviews for staff for Governor Rewards, (ii) staff training in relevant areas to enhance their technical knowledge and skills, and (iii) periodic reviews of work processes when needs arise and adjustments to improve work processes.

The annual work plan of the $\mathrm{CBBH}$ provides details on the allocation of resources to ensure the efficient use of all available resources. The $\mathrm{CBBH}$ evaluates statistical methodologies and compilation systems using outside expert assistance financed by donors, on a regular basis.

\subsection{Relevance}

\subsubsection{The relevance and practical utility of existing statistics in meeting users' needs are monitored}

The CBBH seeks to monitor the relevance of GFS in meeting user needs in various ways. Internally, consultation with the management and other relevant departments of the $\mathrm{CBBH}$ is in place to periodically address issues of concern related to data usefulness for monetary policy purposes. Externally, informal consultations take place periodically with other government agencies, the media, and other data users. 
Although no formal monitoring of user needs (such as a survey) has been undertaken, the CBBH publications of GFS and its internet website (http://www.cbbh.gov.ba) provide detailed contact information to data users for sending comments, queries, and requests, which are usually accommodated to the extent possible.

Recommendation: Establish formal procedures to identify users' needs.

\subsection{Other quality management}

\subsubsection{Processes are in place to focus on quality}

The CBBH management attaches importance to its work on statistics and is sensitive to data quality issues and takes initiatives to improve data flows between the $\mathrm{CBBH}$ and other agencies. The re-organization of the ERSD in 2002 highlighted the increased importance of statistics at the $\mathrm{CBBH}$.

The GFSU verifies that data reporting practices followed by government units are consistent with the guidelines and regulations established by the $\mathrm{CBBH}$ and reviews the reported data for accuracy. Validation procedures for assessing the plausibility or reasonability of reported data are undertaken by checking accounting relationships and development trends. Should unusual movements in data be identified, in-depth investigations are carried out for possible misclassifications or other errors.

\subsubsection{Processes are in place to monitor the quality of the statistical program}

The ERSD has internal processes to identify and resolve issues at various stages of the collection, compilation, and dissemination of GFS. The data compilers also monitor new regulations and developments in the area of GFS.

Detailed contact information is provided for sending comments or requests to the CBBH. Comments or requests from data users are important feedback for monitoring the quality of GFS.

\subsubsection{Processes are in place to deal with quality considerations in planning the statistical program}

The CBBH management and staff recognize the tradeoffs among the dimensions of data quality. In formulating its statistical work programs, the $\mathrm{CBBH}$ takes into account user needs, data priorities, and trade-offs. Increased attention has been given to improving coverage, timeliness, and other data quality aspects.

Although there are no user surveys to obtain feedback on data quality issues, new data requests from the $\mathrm{CBBH}$ Governing Board have guided the planning for meeting emerging data needs. In addition, comments that the $\mathrm{CBBH}$ has received from outside data users have provided useful guidance for improving the data compilation and dissemination practices. 
Implementation of some of these comments in recent years has resulted in significant improvements in the comprehensiveness of GFS and metadata published in the CBBH's Annual Report, Quarterly Bulletin, and Monthly Economic Review.

\section{Assurances of integrity}

\subsection{Professionalism}

\subsubsection{Statistics are produced on an impartial basis}

The independence of the CBBH is established in the CBBH Law (Article 3), which grants the $\mathrm{CBBH}$ the powers to carry out the duties for which it is responsible. The governing body of the $\mathrm{CBBH}$ is the $\mathrm{CBBH}$ Governing Board consisting of $\mathrm{CBBH}$ Governor, three vice governors, and other members. The Governor is appointed for a six-year term. The CBBH has an established tradition of professional independence and other agencies recognize the importance of the statistical independence of the $\mathrm{CBBH}$.

The CBBH Act provides the $\mathrm{CBBH}$ with autonomy and professional independence in carrying out its statistical functions. The Governor of the $\mathrm{CBBH}$ shall decide, on the basis of professional and ethical considerations, the scope and purpose of the statistics produced, as well as on the methods and procedures for data collection, production, and publication.

Professional competence plays a key role in recruitment and promotion policies. Recruitment and promotion are based on relevant aptitude and/or expertise. Minimum requirements for potential recruits include educational background. After a year's probation period, for staff with previous work experience, a recruitment decision is finalized based on the new staff member's performance.

New staff receive on-the-job training during their first months on the job. In addition, the $\mathrm{CBBH}$ encourages staff to pursue advanced studies in work-related fields by providing funds for part-time college courses. Professionalism is further promoted through the active encouragement of staff participation in training opportunities, workshops, meetings, and seminars, to ensure awareness and understanding of statistical standards and good statistical practices. Staff have free, unlimited access to a wide range of international academic journals and research databases through the internet and in the CBBH's library. CBBH staff participate in regional and international conferences. 


\subsubsection{Choices of sources and statistical techniques as well as decisions about dissemination are informed solely by statistical considerations}

The choice of sources and statistical techniques for the compilation of government finance statistics is based solely on statistical considerations made by the CBBH staff; however, these decisions are influenced by cost considerations and the resource constraints facing the $\mathrm{CBBH}$. Staff are encouraged to present the reasons for the choice of methodologies in documents that are made public.

Decisions about dissemination are informed solely by statistical considerations. The CBBH publishes quarterly and annual GFS and detailed metadata to aid users in understanding the published data.

\subsubsection{The appropriate statistical entity is entitled to comment on erroneous interpretation and misuse of statistics}

If there is erroneous interpretation or misuse of the GFS in the media or other fora, the CBBH's Public Relation Department comments and provides clarification in the media and publishes statements on its website. If needed, the $\mathrm{CBBH}$ contacts the reporters and other interested parties to have the erroneous interpretation corrected. The $\mathrm{CBBH}$ maintains a cordial working relationship with the media and journalists. Divisions monitor news reports on the statistics following the dissemination of official publications.

\subsection{Transparency}

\subsubsection{The terms and conditions under which statistics are collected, processed, and disseminated are available to the public}

The CBBH's publications and its website provide explanations of the basis for the compilation of statistics in order to improve user understanding and reduce the likelihood of any misinterpretation. The laws and regulations under which statistics are collected, processed, and disseminated by the $\mathrm{CBBH}$ are available to the public. The CBBH Law and the $C B B H$ By-Law are available on the CBBH's website. These laws clearly state CBBH's policies on (i) treatment of confidential data and (ii) transparency of its operations and information.

The CBBH's publications always indicate the address of the CBBH's internet website, where more information about the $\mathrm{CBBH}$, other macroeconomic statistics, and related working papers are disseminated. 


\subsubsection{Internal governmental access to statistics prior to their release is publicly identified}

The CBBH does not provide GFS data to any external person or institution before it is officially released. Access to GFS is provided simultaneously to all users when the data are posted on the CBBH website (http://www.cbbh.ba).

\subsubsection{Products of statistical agencies/units are clearly identified as such}

All products of the $\mathrm{CBBH}$ are clearly identified as such with the CBBH's name and logo appearing on the front page of all its publications and on the website. The publications also advise users to specify the source of the information when quoting from the agency's publications.

\subsubsection{Advanced notice is given of major changes in methodology, source data, and statistical techniques}

The CBBH provides advance notice of changes in methodology, where appropriate. For instance, in a Press release on 10/7/2003 and in the monthly Newsletter for October 2003 the $\mathrm{CBBH}$ provided advance notice of its decision to start compiling government finance statistics using the methodology as set out in GFSM 2001.

\subsection{Ethical standards}

\subsubsection{Guidelines for staff behavior are in place and are well known to the staff}

The Code of Conduct for Employees of the CBBH (Code of Conduct) provides comprehensive ethical guidelines for the staff of the CBBH. These guidelines, well known to CBBH staff, establish the main principles and rules for staff integrity, objectivity, efficiency, professional independence, maintaining confidentiality of data, and avoiding conflict of interest, among others. New staff are informed of the Code of Conduct when they join the $\mathrm{CBBH}$ and are also required to sign an official document to certify that they have read and understand these guidelines.

\section{Methodological soundness}

\section{$2.1 \quad$ Concepts and definitions}

2.1.1 The overall structure in terms of concepts and definitions follows internationally accepted standards, guidelines, or good practices

Since the development of GFS in $\mathrm{BiH}$ the $\mathrm{CBBH}$ compiles government statistics following the definitions and concepts of the IMF's GFSM 2001. 


\section{$2.2 \quad$ Scope}

\subsubsection{The scope is broadly consistent with internationally accepted standards, guidelines,} or good practices

The scope of government institutions covered in GFS in $\mathrm{BiH}$ is broadly consistent with the GFSM 2001 and other international accepted standards and guidelines. In the compilation of annual GFS, the CBBH covers all government institutions excluding only the Road Fund of the Republic of Srpska. In 2006 the legal status of the Road Funds at entity level in the $\mathrm{FBiH}$ has changed and both entity road funds are now legally classified as public enterprises. ${ }^{15}$

The consolidated central government of $\mathrm{BiH}$ is defined to include the state government, entity governments, cantons, Brcko District, all the road funds, except the Road Fund of the Republic of Srpska, and all the social security funds. General government in the $\mathrm{BiH}$ comprises of the consolidated central government and the local governments. Consolidated data on the operations of local governments are obtained from the ministries of finance at the entity level.

However, the scope of GFS does not cover all economic stocks (balance sheet data) and flows (cash flow data) of the units of the general government. Furthermore, the transactions for projects directly financed by international donors are also excluded. The CBBH is in the process of investigating data sources to obtaining more information on these projects. These projects need to be researched and classified, and those applicable to the general government sector should be included in the revenue and expense of the government unit.

The GFS Unit is currently only compiling the Statement of Government Operations as recommended in Table 4.1 of the GFSM2001. However, in both the quarterly and annual Statements of Government Operations the net operating balances are not compiled as data on government's consumption of its own fixed capital are not available.

The Statement of Government Operations, which is currently compiled on a quarterly basis for the consolidated central government, excludes all transactions in financial assets and liabilities due to incomplete quarterly source data. However, the annual Statement of Government Operations for the general government includes these transactions.

The other statements recommended in the GFSM 2001-Statement of Sources and Uses of Cash (Table 4.2), Statement of Other Economic Flows (Table 4.3), and Balance Sheet and detailed components (Tables 7.1, 7.2, 7.3, and 7.4)—are not compiled due to a lack of adequate source data and staff resources.

\footnotetext{
${ }^{15}$ For the purposes of consistency and fiscal analysis the road funds should be classified as extrabudgetary institutions and included in the institutional coverage of the general government.
} 
Although the CBBH disseminates data on the outstanding foreign debt of the central government on a quarterly basis, data on the level of outstanding domestic government debt are still in process of verification and legislative review.

Recommendation: Expand the coverage of the GFS to include all the road funds.

Recommendation: Expand the reporting of accounts to include cash flow data, and balance sheet data on financial and nonfinancial stock positions.

Recommendation: Continue the process of investigating data sources to obtain more information on projects directly financed by international donors.

Recommendation: In cooperation with the National Accounts Unit of the BHAS compile data on government's consumption of its own fixed capital to be included in the Statement of Government Operations.

Recommendation: Disseminate data on domestic debt as soon as possible.

\subsection{Classification/sectorization}

2.3.1 Classification/sectorization systems used are broadly consistent with internationally accepted standards, guidelines, or good practices

The CBBH compiles general government statistics according to the GFSM 2001.

Consequently, the classification of the revenue, expense, transactions in nonfinancial assets, and financial assets and liabilities of the government are consistent with the GFSM 2001.

Annual data for the general government and its subsectors are compiled for revenue and expense by economic type and the main balances and gross lending/borrowing are compiled. Data on expense by function are not available due to the differences in the level of detail data available in the functional classification that are used in the entities. However, by using the current source data a limited functional classification can be compiled.

Financing data distinguish between domestic and foreign financing, and between types of instruments.

Recommendation: Improve the functional classification of the source data by using uniform COFOG classification in all the accounting systems. 


\subsection{Basis for recording}

\subsubsection{Market prices are used to value flows and stocks}

Most flows are valued at market prices and goods in kind are valued at the monetary value estimated and attributed by the receiving government institution. As indicated earlier, the $\mathrm{CBBH}$ does not compile a balance sheet for the government and outstanding domestic debt is not yet available, therefore all domestic financial assets, liabilities and non-financial assets can not yet be valued at market prices.

Identified outstanding central government debt is recorded at face value. Central government foreign currency debt is revalued for exchange rate changes. Regarding foreign currency assets/liabilities of the governments the mid-point exchange rates in the market, at the end of each period, are used to convert these liabilities/assets to local currency.

\subsubsection{Recording is done on an accrual basis}

Recording is currently done on a mixed basis Not all government institutions have introduced accrual accounting. Therefore, the data obtained by the GFS Unit included accrual and cash data.

Recommendation: Introduce full accrual accounting in all government entities.

\subsubsection{Grossing/netting procedures are broadly consistent with internationally accepted} standards, guidelines, or good practices

Government finance statistics are compiled on a gross basis in line with GFSM 2001. Financing is compiled on a gross basis but recorded on a net basis (e.g., loans minus repayments, purchase of shares minus sale, etc.). Corrective transactions are netted against the original source data transactions during the compilation process.

\section{Accuracy and reliability}

\subsection{Source data}

\subsubsection{Source data are obtained from comprehensive data collection programs that take into} account country-specific conditions

In order to compile government statistics the $\mathrm{CBBH}$ make use of data obtained from the state government, entity governments, cantons, Brcko District, and social security funds

(43 reports on an annual basis and 41 reports on a quarterly basis - excluding the two consolidated local government reports obtained from the ministries of finance at the entity level). These source data are obtained from administrative records, budget information, and final accounts. Further additional information, particularly special annual reports from the Oracle Treasury computer system, are also obtained by the CBBH to produce the Statement 
of Government Operations. However, due to limited staff resources, differences in the accounting systems used by the different government institutions, the aggregated level of the data sources, and the lack of all-inclusive data collection programs, the full range of economic stocks and flows is not available. Therefore, the other statements recommended in the GFSM 2001 - Statement of Sources and Uses of Cash (Table 4.2), Statement of Other Economic Flows (Table 4.3), and Balance Sheet and detailed components (Tables 7.1, 7.2, 7.3, and 7.4)_-are not compiled.

Approximately 60 percent of the data are received in a format which does not allow for an electronic download and needs to be entered into the system by the staff of the GFS Unit.

Additional to the data on revenue obtained from the different levels of government, data are also obtained from the Indirect Taxation Authority. These data from the Indirect Taxation Authority allow the GFSU to validate the data received from the different government institutions. The data received from the Indirect Taxation Authority incorporate enough detail to classify the data appropriately.

Data are collected on external government debt from the State Ministry of Finance. These data are available with breakdowns by currency and creditors. Lags between the time of the transaction and the entry of the data into the MOF's databank are, however, experienced which led to problems in explaining the changes in outstanding debt and the financing of government operations. Data on the level of outstanding domestic debt are still in process of verification and legislative review; therefore they are currently not available.

Recommendation: Expand the data collection programs to obtain data on the full range of economic stocks and flows.

Recommendation: In cooperation with the reporting institutions improve the format of reports to allow for electronic downloads.

\subsubsection{Source data reasonably approximate the definitions, scope, classifications, valuation, and time of recording required}

The source data as received by the GFSU do not approximate the definitions, scope, and classifications required to compile GFS. The level of detail in the source data is not sufficient to ensure proper classification. The GFSU of the $\mathrm{CBBH}$, therefore, has to request a large amount of additional data from the providers of the source data in order to reclassify the data appropriately. Appropriate bridge tables exist to facilitate the compilation of GFS. However, due to the continuous changes in the different charts of accounts these bridge tables are subject to constant revisions. These revisions to the bridge tables are done after consultation with the institutions supplying the source data.

Recommendation: In cooperation with the government institutions include the GFS classification codes in the charts of accounts to improve the quality of the source data and to reduce the current workload. 


\subsubsection{Source data are timely}

Source data are provided with sufficient timeliness and periodicity from all the reporting units of the government in order to compile consolidated central government data with a lag of not more than one quarter. However, in some cases a significant amount of effort and follow-up procedures are needed to ensure the timely availability of the source data. Source data on the operations of the central government units are received 45 days after the end of each quarter.

Source data on external government debt are available on a monthly basis.

\subsection{Assessment of source data}

3.2.1 Source data-including censuses, sample surveys and administrative records-are routinely assessed, e.g., for coverage, sample error, response error, and nonsampling error; the results of the assessments are monitored and made available to guide statistical processes

To the extent possible, automated procedures are used to facilitate the monitoring of the accuracy of data reported by individual government sector units. Any data inconsistencies and out-of-trend values are discussed with the reporting institution and the reasons documented. Source data are also checked across different sources for example, the transfers made by one government entity to another government entity are checked against the amount received by the receiving entity.

\subsection{Statistical techniques}

\subsubsection{Data compilation employs sound statistical techniques to deal with data sources}

All data come from administrative and accounting sources. As a result, procedures requiring estimation are not needed, and no surveys or imputations are employed. Preliminary data are routinely replaced by final data. As a result of the extensive checks applied to the data, such as multiple item-by-item checks, few changes take place between preliminary and final data.

\subsubsection{Other statistical procedures (e.g., data adjustments and transformations, and statistical analysis) employ sound statistical techniques}

Generally accepted methods are used to adjust and consolidate GFS data derived from administrative and accounting records. Suspect submissions or data discrepancies identified in the consolidation are investigated and resolved, frequently through direct contacts. $\mathrm{CBBH}$ staff reported that significant further refinements are being tested to permit greater accuracy in consolidating stock and flow statistics. No other statistical procedures are employed. 


\section{$3.4 \quad$ Assessment and validation of intermediate data and statistical outputs}

\subsubsection{Intermediate results are validated against other information where applicable}

Before the publication of the data, all tables are checked for internal consistency. Comparisons can, however, not be made between net lending/borrowing (derived from the non-financial accounts) and changes in net financial assets/liabilities on a quarterly basis as the $\mathrm{CBBH}$ has not yet compiled a quarterly financial account.

\subsubsection{Statistical discrepancies in intermediate data are assessed and investigated}

All discrepancies between GFS and intermediate budgetary data, and those between the intermediate budgetary and accounting data, are investigated. Expenditure data are crosschecked for consistency with other ad-hoc data obtained from government institutions, and fiscal revenue data are cross-checked against all other intermediate data, such as information from the Indirect Taxation Authority and the transactions for the government executed by the $\mathrm{CBBH}$.

3.4.3 Statistical discrepancies and other potential indicators of problems in statistical outputs are investigated

Data on selected external public debt stocks and related flows are compared with creditor information for the biggest creditors.

\subsection{Revision studies}

3.5.1 Studies and analyses of revisions are carried out routinely and used internally to inform statistical processes (see also 4.3.3)

Although no formal revision studies are carried out routinely, the reasons for revisions are accounted for and analyzed. These are minimal due to the extensive use of accounting data as the data source to compile GFS, even at the preliminary stage.

\section{Serviceability}

\subsection{Periodicity and timeliness}

\subsubsection{Periodicity follows dissemination standards}

$\mathrm{BiH}$ meets the periodicity recommended by the GDDS, as follows:

- General government operations data, which are encouraged by the GDDS, meet the GDDS encouraged periodicity. 
- $\quad$ Consolidated central government operations data excluding financing are published quarterly, which more than meet the GDDS recommendation for annual consolidated central government operations data.

- $\quad$ Although no data are disseminated for the domestic debt of government, government foreign debt data are published quarterly with a breakdown by creditors and annually with breakdowns by creditors and by currencies.

\subsubsection{Timeliness follows dissemination standards}

$\mathrm{BiH}$ meets the timeliness requirements of the GDDS as follows:

- $\quad$ The general government operations data, which are disseminated within six months after the end of the reference period, more than meet the GDDS encouraged timeliness of 6-9 months.

- $\quad$ Central government operations data excluding financing data are disseminated within one quarter after the reference period, which more than meet the timeliness recommended by the GDDS of 6-9 months.

- Central government debt data, foreign debt only, meet the timeliness recommended by the GDDS.

\subsection{Consistency}

\subsubsection{Statistics are consistent within the dataset}

General government finance data are internally consistent as well as the GFS accounts for the other levels of government. On the revenue and expense sides, the aggregates are consistent with their components, and balances are consistent with these aggregates. The sum of the transaction data for the subsectors of the general government, after consolidation, is consistent with data on the consolidated general government.

\subsubsection{Statistics are consistent or reconcilable over a reasonable period of time}

No long term time series on GFS is currently available for any level of government as the CBBH started compiling data in 2003 for the consolidated central government and in 2005 for the general government. However, over the short period of time the available data are consistent for those levels of government. 


\subsubsection{Statistics are consistent or reconcilable with those obtained through other data sources and/or statistical frameworks}

Due to differences in the sectoral classification of general government in GFS and in the monetary statistics, as well as a lack of detailed data and balance sheets in the GFS, it is not possible to reconcile the GFS data with the monetary statistics.

All foreign grants, loans, loan repayments, and interest payments for, which the state government has assumed responsibility, are consistent with the balance of payments data, as the same source data are used for the compilation of GFS and the balance of payments. However, the balance of payments data also include directly foreign financed projects which are currently excluded from GFS.

GFS data are not consistent with national accounts data and need to be further developed.

Recommendation: Use the same sectoral classification for general government in real sector, financial sector, and external sector statistics.

Recommendation: Start by compiling a financial balance sheet for the general government. ${ }^{16}$

Recommendation: Institutionalize the regular reconciliation of GFS, monetary, balance of payments, and national accounts.

\subsection{Revision policy and practice}

\subsubsection{Revisions follow a regular and transparent schedule}

Due to the recent start in the compilation and publication of GFS for the general government the $\mathrm{CBBH}$ took a decision to revise the data as soon as more accurate data are obtained. The $\mathrm{CBBH}$ does, however, plan as soon as the data and data sources become more dependable to issue information on a revision policy and practices.

\subsubsection{Preliminary and/or revised data are clearly identified}

Preliminary data are clearly indicated in the publications and a distinction is made between previously disseminated data and significantly revised data in the $\mathrm{CBBH}$ 's publications.

\footnotetext{
${ }^{16}$ Also see the recommendations under 3.1.1 and 3.1.2.
} 


\subsubsection{Studies and analyses of revisions are made public (see also 3.5.1)}

As GFS is mainly using accounting data and the coverage of the general government sector is good, no specific studies or analyses of routine revisions are made public. However, if major revisions are undertaken, their results are made public in the publication.

\section{Accessibility}

\subsection{Data accessibility}

\subsubsection{Statistics are presented in a way that facilitates proper interpretation and meaningful} comparisons (layout and clarity of text, tables, and charts)

GFS for the general government and its subsectors, following the analytical presentation recommended in GFSM 2001, are at present disseminated for the Statement of Government Operations on a quarterly and annual basis. The Statement of Government Operations is disseminated in a clear manner, with charts, tables, and text to assist the user. However, in order to facilitate proper interpretation and meaningful comparisons the $\mathrm{CBBH}$ needs to publish data on the sources and uses of cash, other economic flows, and the balance sheet.

The $\mathrm{CBBH}$ is currently disseminating data on the outstanding foreign debt only. No data on the outstanding domestic debt of the government are currently available, which precludes debt sustainability analysis.

\subsubsection{Dissemination media and format are adequate}

All the data are released by the $\mathrm{CBBH}$ on its websites. This information can also be obtained in a hardcopy format.

\subsubsection{Statistics are released on a preannounced schedule}

An advance release calendar is not available on the CBBH's website for GFS.

Recommendation: Include release dates for the GFS in the advance release calendar of the $\mathrm{CBBH}$.

\subsubsection{Statistics are made available to all users at the same time}

Statistics are made available to all the users at the same time, and are widely disseminated on the CBBH's website (http://www.cbbh.ba).

\subsubsection{Statistics not routinely disseminated are made available upon request}

Statistics not routinely disseminated are made available to users upon request. 


\subsection{Metadata accessibility}

5.2.1 Documentation on concepts, scope, classifications, basis of recording, data sources, and statistical techniques is available, and differences from internationally accepted standards, guidelines, or good practices are annotated

Documentation explaining the concepts, scope, classifications, basis of recording, data sources, and statistical techniques used in compiling GFS, as well as differences from internationally accepted standards and guidelines are available on the CBBH' website.

\subsubsection{Levels of detail are adapted to the needs of the intended audience}

The level of detail is adequate to satisfy the needs of most users of the data.

\subsection{Assistance to users}

\subsubsection{Contact points for each subject field are publicized}

The hardcopy publications and the website of the $\mathrm{CBBH}$ provide comprehensive information on how users can contact the CBBH. Assistance to users is provided through addressing users' queries and information requests.

5.3.2 Catalogs of publications, documents, and other services, including information on any charges, are widely available

A list of publications is updated regularly and posted on the CBBH's website. 


\begin{tabular}{|c|c|c|c|c|c|c|c|}
\hline \multicolumn{8}{|c|}{$\begin{array}{c}\text { Table 3. Bosnia and Herzegovina: Data Quality Assessment Framework (July 2003): } \\
\text { Summary of Results for Government Finance Statistics }\end{array}$} \\
\hline \multicolumn{8}{|c|}{ (Compiling Agency: Central Bank of Bosnia and Herzegovina) } \\
\hline \multicolumn{8}{|c|}{ Key to symbols: NA = Not Applicable; O = Practice Observed; LO = Practice Largely Observed; LNO = Practice Largely Not Observed; NO = Practice Not Observed; GDDS = Complies with GDDS Criteria } \\
\hline \multirow{2}{*}{ Element } & \multirow{2}{*}{ NA } & \multicolumn{4}{|c|}{ Assessment } & \multirow{2}{*}{ Comments on Assessment } & \multirow{2}{*}{ Plans for Improvement and Target Dates } \\
\hline & & $\mathrm{O}$ & LO & LNO & $\mathrm{NO}$ & & \\
\hline \multicolumn{8}{|l|}{ 0. Prerequisites of quality } \\
\hline 0.1 Legal and institutional environment & & & $\mathrm{X}$ & & & $\begin{array}{l}\text { The Macroeconomic Analysis Unit } \\
\text { (MAU) is also compiling government } \\
\text { data for operational purposes. Although } \\
\text { these data are not official statistics, they } \\
\text { are available to users on the website of } \\
\text { the MAU and are currently not } \\
\text { consistent with the GFS data that are } \\
\text { compiled by the CBBH. }\end{array}$ & $\begin{array}{l}\text { If both sets of data continue to be available to } \\
\text { users, the CBBH and MAU should at a } \\
\text { minimum coordinate to ensure that the two } \\
\text { sets of data on the general government } \\
\text { statistics made available to users are } \\
\text { reconciled (short-term). }\end{array}$ \\
\hline 0.2 Resources & & & $\mathrm{X}$ & & & $\begin{array}{l}\text { Employees are currently not considered } \\
\text { as sufficient in number to carry out the } \\
\text { existing mandate; therefore there is also } \\
\text { no capacity available for any additional } \\
\text { development work. The process of data } \\
\text { transmission, compiling, and tabulation } \\
\text { is not completely computerized. }\end{array}$ & $\begin{array}{l}\text { Strengthen and increase resources for work } \\
\text { on GFS (medium-term). }\end{array}$ \\
\hline 0.3 Relevance & & & $\mathrm{X}$ & & & $\begin{array}{l}\text { No formal monitoring of user needs } \\
\text { (such as a survey) has been undertaken. }\end{array}$ & $\begin{array}{l}\text { Establish formal procedures to identify users' } \\
\text { needs (short-term). }\end{array}$ \\
\hline 0.4 Other quality management & & $\mathrm{X}$ & & & & & \\
\hline \multicolumn{8}{|l|}{ 1. Assurances of integrity } \\
\hline 1.1 Professionalism & & $\mathrm{X}$ & & & & & \\
\hline 1.2 Transparency & & $\mathrm{X}$ & & & & & \\
\hline 1.3 Ethical standards & & $\mathrm{X}$ & & & & & \\
\hline
\end{tabular}




\begin{tabular}{|c|c|c|c|c|c|c|c|}
\hline \multicolumn{8}{|c|}{$\begin{array}{l}\text { Table 3. Bosnia and Herzegovina: Data Quality Assessment Framework (July 2003): } \\
\text { Summary of Results for Government Finance Statistics }\end{array}$} \\
\hline \multicolumn{8}{|c|}{ Key to symbols: $\mathrm{NA}=$ Not Applicable; $\mathrm{O}=$ Practice Observed; $\mathrm{LO}=$ Practice Largely Observed; LNO = Practice Largely Not Observed; $\mathrm{NO}=$ Practice Not Observed; GDDS = Complies with GDDS Criteria } \\
\hline \multirow{2}{*}{ 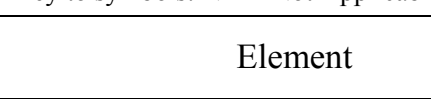 } & & \multicolumn{4}{|c|}{ Assessment } & \multirow{2}{*}{ Comments on Assessment } & \multirow{2}{*}{ Plans for Improvement and Target Dates } \\
\hline & NA & $\mathrm{O}$ & LO & LNO & $\mathrm{NO}$ & & \\
\hline \multicolumn{8}{|l|}{ 2. Methodological soundness } \\
\hline 2.1 Concepts and definitions & & $\mathrm{X}$ & & & & & \\
\hline 2.2 Scope & & & & $\mathrm{X}$ & & $\begin{array}{l}\text { GFS covers all government institutions } \\
\text { excluding the Road Fund of the } \\
\text { Republic of Srpska. } \\
\text { Statement of Sources and Uses of Cash, } \\
\text { Statement of Other Economic Flows, } \\
\text { and Balance Sheet and detailed } \\
\text { components are not compiled. Capital } \\
\text { projects directly financed by } \\
\text { international donors are also excluded. }\end{array}$ & $\begin{array}{l}\text { Expand the coverage on transactions to } \\
\text { include cash flow data, balance sheet data on } \\
\text { financial and nonfinancial stock positions. } \\
\text { Continue with the process of investigating } \\
\text { data sources to obtain more information on } \\
\text { projects directly financed by international } \\
\text { donors (medium to long-term). }\end{array}$ \\
\hline & & & & & & $\begin{array}{l}\text { In both the quarterly and annual } \\
\text { Statements of Government Operations } \\
\text { the net operating balances are not } \\
\text { compiled as data on government's } \\
\text { consumption of fixed capital are not } \\
\text { available. }\end{array}$ & $\begin{array}{l}\text { In cooperation with the National Accounts } \\
\text { Unit of the BHAS compile data on } \\
\text { government's consumption of fixed capital to } \\
\text { be included in the Statement of Government } \\
\text { Operations (short-term). }\end{array}$ \\
\hline & & & & & & $\begin{array}{l}\text { Data on the level of outstanding } \\
\text { domestic debt are currently not } \\
\text { available. The data are still in a process } \\
\text { of verification and legislative review. }\end{array}$ & $\begin{array}{l}\text { Disseminate data on domestic debt (as soon } \\
\text { as possible). }\end{array}$ \\
\hline
\end{tabular}




\begin{tabular}{|c|c|c|c|c|c|c|c|}
\hline \multicolumn{8}{|c|}{$\begin{array}{l}\text { Table 3. Bosnia and Herzegovina: Data Quality Assessment Framework (July 2003): } \\
\text { Summary of Results for Government Finance Statistics }\end{array}$} \\
\hline \multicolumn{8}{|c|}{ (Compiling Agency: Central Bank of Bosnia and Herzegovina) } \\
\hline \multicolumn{8}{|c|}{ Key to symbols: NA = Not Applicable; $\mathrm{O}=$ Practice Observed; LO = Practice Largely Observed; LNO = Practice Largely Not Observed; NO = Practice Not Observed; GDDS = Complies with GDDS Criteria } \\
\hline \multirow{2}{*}{ Element } & \multirow{2}{*}{ NA } & \multicolumn{4}{|c|}{ Assessment } & \multirow{2}{*}{ Comments on Assessment } & \multirow{2}{*}{ Plans for Improvement and Target Dates } \\
\hline & & $\mathrm{O}$ & LO & LNO & $\mathrm{NO}$ & & \\
\hline 2.3 Classification/sectorization & & & $\mathrm{X}$ & & & $\begin{array}{l}\text { Data on expense by function are not } \\
\text { available due to the differences in the } \\
\text { detailed information on classification } \\
\text { that are used in the entities. However, by } \\
\text { using the current source data a limited } \\
\text { functional classification can be } \\
\text { compiled. }\end{array}$ & $\begin{array}{l}\text { Improve the functional classification of the } \\
\text { source data by using the standard COFOG } \\
\text { classification in all the accounting systems } \\
\text { (medium-term). }\end{array}$ \\
\hline 2.4 Basis for recording & & & $\mathrm{X}$ & & & $\begin{array}{l}\text { Recording is currently done on a mixed } \\
\text { cash and accrual basis. }\end{array}$ & $\begin{array}{l}\text { Continue to introduce full accrual accounting } \\
\text { in all government entities. }\end{array}$ \\
\hline \multicolumn{8}{|l|}{ 3. Accuracy and reliability } \\
\hline 3.1 Source data & & & & $\mathrm{X}$ & & $\begin{array}{l}\text { Due to the differences in the accounting } \\
\text { systems used by the different } \\
\text { government institutions and the } \\
\text { aggregated level of the data sources, all- } \\
\text { inclusive data collection programs to } \\
\text { cover the full range of economic stocks } \\
\text { and flows are not in place. } \\
\text { Approximately } 60 \text { percent of the data are } \\
\text { received in a format which does not } \\
\text { allow for an electronic download and } \\
\text { needs to be entered into the system by } \\
\text { the staff of the GFS Unit. } \\
\text { The level of detail in the source data is } \\
\text { not sufficient to ensure proper } \\
\text { classification. }\end{array}$ & 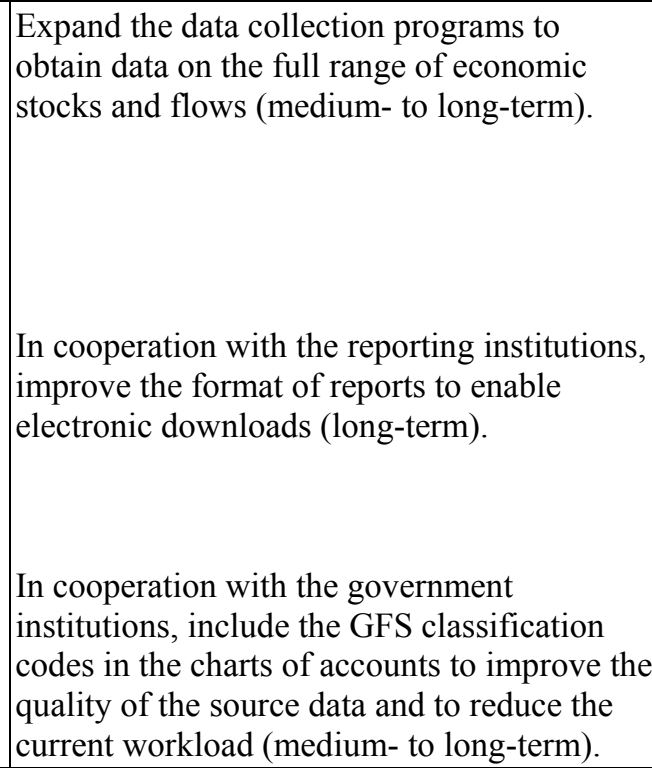 \\
\hline
\end{tabular}




\begin{tabular}{|c|c|c|c|c|c|c|c|}
\hline \multicolumn{8}{|c|}{$\begin{array}{l}\text { Table 3. Bosnia and Herzegovina: Data Quality Assessment Framework (July 2003): } \\
\text { Summary of Results for Government Finance Statistics }\end{array}$} \\
\hline \multicolumn{8}{|c|}{ (Compiling Agency: Central Bank of Bosnia and Herzegovina) } \\
\hline \multicolumn{8}{|c|}{ Key to symbols: $\mathrm{NA}=$ Not Applicable; $\mathrm{O}=$ Practice Observed; $\mathrm{LO}=$ Practice Largely Observed; $\mathrm{LNO}=$ Practice Largely Not Observed; $\mathrm{NO}=$ Practice Not Observed; GDDS $=$ Complies with GDDS Criteria } \\
\hline \multirow{2}{*}{ Element } & \multirow{2}{*}{ NA } & \multicolumn{4}{|c|}{ Assessment } & \multirow{2}{*}{ Comments on Assessment } & \multirow{2}{*}{ Plans for Improvement and Target Dates } \\
\hline & & $\mathrm{O}$ & LO & LNO & NO & & \\
\hline 3.2 Assessment of source data & & $\mathrm{X}$ & & & & & \\
\hline 3.3 Statistical techniques & & $\mathrm{X}$ & & & & & \\
\hline $\begin{array}{l}\text { 3.4 Assessment and validation of inter- } \\
\text { mediate data and statistical outputs }\end{array}$ & & $\mathrm{X}$ & & & & & \\
\hline 3.5 Revision studies & & $\mathrm{X}$ & & & & & \\
\hline \multicolumn{8}{|l|}{ 4. Serviceability } \\
\hline 4.1 Periodicity and timeliness & & $\mathrm{X}$ & & & & & \\
\hline 4.2 Consistency & & & & $X$ & & $\begin{array}{l}\text { Due to the differences in the definitions } \\
\text { of general government in GFS and in the } \\
\text { monetary statistics and the lack of } \\
\text { detailed data, it is not possible to } \\
\text { reconcile the GFS data with the } \\
\text { monetary statistics. } \\
\text { Directly foreign financed projects are } \\
\text { currently excluded from GFS but } \\
\text { included in the balance of payments } \\
\text { data. } \\
\text { GFS data are not consistent with } \\
\text { national accounts data and need to be } \\
\text { further developed. }\end{array}$ & $\begin{array}{l}\text { Use the same sectoral classification for } \\
\text { general government in real sector, financial } \\
\text { sector, and external sector statistics. } \\
\text { Start by compiling a financial balance sheet } \\
\text { for the general government. } \\
\text { Institutionalize the regular reconciliation of } \\
\text { GFS, monetary, balance of payments, and } \\
\text { national accounts (short-term). }\end{array}$ \\
\hline 4.3 Revision policy and practice & & $\mathrm{X}$ & & & & & \\
\hline \multicolumn{8}{|l|}{ 5. Accessibility } \\
\hline 5.1 Data accessibility & & & $\mathrm{X}$ & & & $\begin{array}{l}\text { An advance release calendar for GFS is } \\
\text { not available on the CBBH's website. }\end{array}$ & $\begin{array}{l}\text { Include release dates for the GFS in the } \\
\text { advance release calendar of the CBBH } \\
\text { (immediately). }\end{array}$ \\
\hline 5.2 Metadata accessibility & & $\mathrm{X}$ & & & & & \\
\hline 5.3 Assistance to users & & $\mathrm{X}$ & & & & & \\
\hline
\end{tabular}


This page intentionally left blank

(C)International Monetary Fund. Not for Redistribution 


\section{Monetary Statistics}

During 1996 and 2004, CBBH made major efforts to implement recommendations of a number of STA's monetary and financial statistics missions that were intended to improve procedures for collecting, compiling, and disseminating monetary and financial statistics. These efforts enhanced considerably CBBH's capacity to produce country-wide monetary and financial statistics. However, new statistical issues have arisen from ongoing institutional changes and accounting developments in the financial sector which have posed new challenges for the compilation systems used by the CBBH.

\section{Prerequisites of quality}

\subsection{Legal and institutional environment}

\subsubsection{The responsibility for collecting, processing, and disseminating the statistics is clearly specified}

The Central Bank of Bosnia and Herzegovina (CBBH) is the sole official agency responsible for collecting, compiling, and disseminating monetary statistics. The authority of the $\mathrm{CBBH}$ to request data and information from banks is granted by the $C B B H$ Law (Article 68) and the $B y$-Law. The CBBH By-law, which was enacted in 2002 and amended in 2006 and published in the Official Gazette of BiH further specifies the scope of the responsibility of the $C B B H$ for collecting, compiling, and disseminating monetary, balance of payments, and government finance statistics. The $C B B H B y-L a w$ also specifies that in implementing this $B y-L a w$, guidance provided in two CBBH official documents should be followed: Terms of Reference for Data Reporting and Statistical Methodology Framework.

The responsibility for compiling monetary statistics resides with the CBBH's Economic Research and Statistics Department (ERSD). The ERSD, as a result of the re-organization in November 2002 of the former Research and Development Department (RDD) responsible for statistics work, comprises the Research Division and the Statistics Division. The Statistics Division further consists of three sections, responsible for (i) monetary and financial statistics, (ii) government finance, external debt, and real sector statistics, and (iii) balance of payments statistics, respectively. The re-organization reflected the increased importance that the $\mathrm{CBBH}$ management attached to its statistical work and has resulted in better defined responsibilities assigned to each unit within the ERSD.

\subsubsection{Data sharing and coordination among data producing agencies are adequate}

The data reporting and compilation system in $\mathrm{BiH}$ is a decentralized one with the CBBH's Monetary and Financial Statistics Section (MFSS) of ERSD charged with the primary responsibility of collecting and compiling monetary statistics, and CBBH's Main Units in 
Sarajevo, Mostar, and Banja Luka sharing the responsibilities. Although this arrangement within CBBH has worked well and has ensured the efficient and timely flow of source data to the MFSS for compiling monetary statistics, there is room for improvements in coordination between $\mathrm{CBBH}$ and its Main Units through provisions of increased training to and meetings with staff in the Main Units.

The monthly balance sheet data of the $\mathrm{CBBH}$ is produced and provided by the Accounting Department to the MFSS in a timely manner. The MFSS coordinates with CBBH Accounting Departments, commercial banks, and the Banking Agency of the Federation and the Banking Agencies of the RS to ensure that new data requirements are appropriately incorporated into the existing data reporting system to meet emerging needs for the compilation of monetary statistics.

\subsubsection{Individual respondents' data are to be kept confidential and used for statistical purposes only}

Monetary statistics do not disclose data on individual units. The CBBH Law (Article 68) states that the $\mathrm{CBBH}$ Governing Board defines the confidentiality regime for statistical information provided to the $\mathrm{CBBH}$. Under such regime, individual data collected for statistical purposes shall be utilized only for statistical purposes. Disclosure of confidential data is prohibited.

The reporting banks and other financial institutions are well aware of their rights and obligation with regard to the provision of information as stated in the $C B B H L a w$ (Article 68), which is posted in CBBH's internet website (http://www.cbbh.ba).

Although there are no specific provisions in CBBH Law and CBBH By-Law on penalties in case of violation of confidentiality rules, the $\mathrm{CBBH}$ takes several measures for preventing disclosure of individual data, including (i) application of coding-system to prevent revealing information on individual institutions, (ii) restricting access to the database containing individual data to authorized staff only, and (iii) periodic renewal of password for accessing to database containing individual data.

\subsubsection{Statistical reporting is ensured through legal mandate and/or measures to encourage response}

The CBBH By-Law (Article 68) states that all banks must provide the CBBH with reports on their financial statements and other financial data in the format and by the date prescribed by $\mathrm{CBBH}$. Currently banks are required to report monthly balance sheet data to the CBBH Main Units within 15 days after the end of the reference month. The Decision (UV\#240/06) published in Official Gazette of BIH in November 2006 specifies that in case of noncompliance with reporting requirements, the non-reporting institution will be made known to general public and in serious case, it will be reported to the Statistics Council of $\mathrm{BiH}$ for appropriate action. 
The CBBH provides reporting banks with written instructions for completing their monthly report. When revisions are introduced to the report forms, the $\mathrm{CBBH}$ provides training to reporting banks via seminars or meetings. The monetary data compilers maintain regular contact with reporting banks via email or telephone to discuss or clarify identified data issues.

\section{$0.2 \quad$ Resources}

\subsubsection{Staff, facilities, computing resources, and financing are commensurate with statistical programs}

The overall number and qualification of staff working on monetary statistics are generally adequate. There are seven staff working on monetary statistics, of whom, four are located in the CBBH and one in each of the three CBBH Main Units. The majority of them have college degrees in economics or related areas. In addition to on-the-job training, three staff members have participated in the Monetary and Financial Statistics Course conducted by the IMF in the Joint Vienna Institute. However, in the past several years, a high turnover of qualified staff has hindered MFSS's developmental work in monetary statistics. In addition, there is only one staff member working on monetary statistics in each Main Unit of the $\mathrm{CBBH}$ and formal supporting arrangements for these staff are not in place to prevent any disruption of the work in the absence of the staff working on monetary statistics.

Recommendation: Take measures to ensure that a core staff with adequate qualification is maintained in ERSD of CBBH for monetary statistics work.

Recommendation: Establish formal arrangements for backing up the single staff member working on monetary statistics in each CBBH Main Unit with a view to ensuring efficient use of existing staff resources.

Computing resources provided for compiling monetary statistics are adequate to perform required tasks. All staff in the MFSS are equipped with a computer. The whole process of data transmission, compiling, and tabulation is computerized. In addition, the Information Technology Department has systems in place to protect the CBBH's computer resources and maintain operation in the events of an emergency.

Adequate financial resources are allocated to the ERSD for the work on monetary statistics. There are established processes for budgeting for the coming year's work program. Proposals for departments' needs for ongoing programs and developmental work are submitted to CBBH's management for approval. 


\subsubsection{Measures to ensure efficient use of resources are implemented}

The efficient use of existing resources is promoted by the ERSD through (i) periodic performance reviews for staff for Governor Rewards, (ii) staff training in relevant areas to enhance their technical knowledge and skills, (iii) periodic review of work processes when needs arise and adjustments to improve work processes, and (iv) extensive computerization of the monetary statistics production process.

\subsection{Relevance}

\subsubsection{The relevance and practical utility of existing statistics in meeting users' needs are monitored}

The CBBH seeks to monitor the relevance of monetary statistics in meeting user needs in various ways. Internally, consultation with the management and other relevant departments of the CBBH is in place to address issues of concern related to data usefulness for monetary policy purposes. Externally, an established process of consultation takes place periodically with other government agencies, the media, and other data users. When the need arises, such as data requests from World Bank, IMF, European Central Bank, and BiH Council of Ministers, Unit for Economic Policy and Implementation of $\mathrm{BiH}$, the ERSD undertakes studies to help identify new and emerging data requirements and coordinate with relevant departments to incorporate these new requirements in the existing data reporting and compilation procedures. Also, CBBH staff participate in international and regional statistical meetings and seminars to keep abreast of new developments in statistical standards and best practices that may be applied in the monetary statistics. In addition, the CBBH publications of monetary statistics and its internet website (http://www.cbbh.ba) provide detailed contact information to data users for sending comments, queries, and requests, which are usually addressed promptly. However, most of the actions taken for monitoring the relevance of monetary statistics are on an ad hoc basis. No proactive measures are taken to identify data users' needs, such as formal survey.

Recommendation: Take proactive measures, such as formal surveys, to identify data users' needs.

\subsection{Other quality management}

\subsubsection{Processes are in place to focus on quality}

The CBBH management attaches importance to its work on statistics and is sensitive to data quality issues and takes measures to improve data flows between the $\mathrm{CBBH}$ and other agencies. The re-organization of the RDD into ERSD in 2002 highlighted the increased importance of statistics at the $\mathrm{CBBH}$.

The MFSS, in collaboration with CBBH Main Units, verifies that data reporting practices followed by banks are consistent with the guidelines and regulations established by the 
$\mathrm{CBBH}$ and reviews the reported data for accuracy. Validation procedures for assessing the plausibility or reasonability of reported data are undertaken by checking accounting relationships and development trends. Should unusual movements in data be identified, indepth investigations are carried out for possible misclassifications or other errors.

\subsubsection{Processes are in place to monitor the quality of the statistical program.}

The ERSD has internal processes to identify and resolve issues at various stages of the collection, compilation, and dissemination of monetary statistics. The data compilers also monitor new regulations and developments in the area of monetary and financial statistics.

Detailed contact information is provided for sending comments or requests to the $\mathrm{CBBH}$. Comments or requests from data users provide important feedback for monitoring the quality of monetary statistics.

\subsubsection{Processes are in place to deal with quality considerations in planning the statistical program}

The CBBH management and staff recognize the tradeoffs among the dimensions of data quality. In formulating its statistical work programs, the CBBH takes into account user needs, data priorities, and trade-offs. Increased attention has been given to improving timeliness and quality. The $\mathrm{CBBH}$ has formulated plans for improving monetary statistics as described in $\mathrm{CBBH}$ 's metadata for the financial sector prepared in accordance with the IMF's GDDS framework.

Although there are no formal user surveys to obtain feedback on data quality issues, new data requests from the $\mathrm{CBBH}$ Governing Board for monetary policy purposes have guided the planning for meeting emerging data needs. In addition, comments that the $\mathrm{CBBH}$ has received from outside data users have provided useful guidance for improving the data compilation and dissemination. Implementation of some of these comments in recent years has resulted in significant improvements in the comprehensiveness of monetary data and metadata published in the CBBH's Quarterly Bulletin and Monthly Economic Review.

\section{Assurances of Integrity}

\subsection{Professionalism}

\subsubsection{Statistics are compiled on an impartial basis}

The independence of the CBBH is established in the CBBH Law (Article 3), which grants the $\mathrm{CBBH}$ the powers to carry out the duties under its own responsibility. The governing body of the $\mathrm{CBBH}$ is the $\mathrm{CBBH}$ Governing Board consisting of $\mathrm{CBBH}$ Governor, three vice governors, and members from outside the $\mathrm{CBBH}$. During the first years of the operation of the $\mathrm{CBBH}$, the Governor was appointed for a six-year term by the IMF. No governor shall be 
removed during his six-year term, other than as a result of removal from the Governing Board in accordance with Article 11 of the CBBH Law.

The terms and conditions under which the monetary statistics are produced promote the professional independence of the $\mathrm{CBBH}$.

Professional competence plays a key role in recruitment and promotion policies. Recruitment and promotion are based on relevant aptitude and/or expertise. Minimum requirements for potential recruits include education background in economic and other related areas. After a one-year probation period, a recruitment decision is finalized based on new hires' performance.

New staff receive on-the-job training during their first months on the job. CBBH staff participate in regional and international conferences. In addition, the $\mathrm{CBBH}$ encourages staff to pursue advanced studies in work-related fields by providing funds for part-time college courses.

\subsubsection{Choices of sources and statistical techniques as well as decisions about dissemination are informed solely by statistical considerations}

The choice of sources and statistical techniques for the compilation of monetary statistics is based solely on statistical considerations made by the CBBH staff. Staff are encouraged to present their reasoning for the choice of methodologies in documents that are made public.

Decisions about dissemination are informed solely by statistical considerations. $\mathrm{CBBH}$ publishes a wide range of monetary statistics and detailed metadata to aid users in understanding the published data.

\subsubsection{The appropriate statistical entity is entitled to comment on erroneous interpretation and misuse of statistics}

If there is erroneous interpretation or misuse of the monetary statistics in the media or other fora, the CBBH's Public Relation Department comments and provides clarification in the media and publishes statements on its website. If needed, the CBBH contacts the reporters and other parties involved to have the erroneous interpretation corrected.

\subsection{Transparency}

\subsubsection{The terms and conditions under which statistics are collected, processed, and disseminated are available to the public}

The laws and regulations under which statistics are collected, processed, and disseminated by the $\mathrm{CBBH}$ are available to the public. The $C B B H$ Law is available on CBBH's internet website and the $C B B H B y-L a w$ is available on $C B B H$ 's intranet website. These laws clearly 
state CBBH's policies on (i) treatment of confidential data and (ii) transparency of its operations and information.

\subsubsection{Internal governmental access to statistics prior to their release is publicly identified}

Access to monetary statistics is provided simultaneously to all users when the data are posted on the CBBH website (http://www.cbbh.ba). There is no internal governmental access to monetary statistics prior to its publication.

\subsubsection{Products of statistical agencies/units are clearly identified as such}

Monetary statistics are clearly identified as a $\mathrm{CBBH}$ product and include the $\mathrm{CBBH}$ name and logo. When data produced by other agencies are published, the source is identified in the footnotes. The $\mathrm{CBBH}$ requests attribution when its statistics are used for reproduction or redissemination.

\subsubsection{Advance notice is given of major changes in methodology, source data, and statistical} techniques

Advance notice is given when major changes in methodology, source data, and statistical techniques are introduced. Usually MFSS prepares the information on major changes to be released in advance. Such information is usually published in $\mathrm{CBBH}$ News Letter.

\subsection{Ethical standards}

\subsubsection{Guidelines for staff behavior are in place and are well known to the staff}

The Code of Conduct for Employees of the CBBH (Code of Conduct) provides comprehensive ethical guidelines for the staff of the $\mathrm{CBBH}$. These guidelines, well known to CBBH staff, establish the main principles and rules for staff integrity, objectivity, professional competence, efficiency, professional independence, maintaining confidentiality of data, and avoiding conflict of interest, among others. New staff are informed of the Code of Conduct when they join the $\mathrm{CBBH}$ and are also required to sign an official document to certify that they have read and understand these guidelines.

\section{Methodological soundness}

\subsection{Concepts and definitions}

\subsubsection{The overall structure in terms of concepts and definitions follows internationally} accepted standards, guidelines, or good practices

The analytical framework used by the $\mathrm{CBBH}$ in compiling monetary statistics reflects concepts and principles that are internationally accepted and are based on the IMF's draft, A Guide to Money and Banking Statistics in International Financial Statistics (1984). With 
implementation of major recommendations of a number of STA missions since 1996, CBBH's monetary statistics are moving towards full adoption of the guidelines outlined in the Monetary and Financial Statistics Manual (MFSM). The Depository Corporation Survey (DCS) or monetary survey is derived by consolidating the analytical accounts of the CBBH and all registered domestic and foreign banks in $\mathrm{BiH}$. The CBBH's analytical accounts$C B B H$ Survey - is equivalent to the central bank survey as recommended in the MFSM. Since the end of 1999, analytical accounts of the CBBH include only the accounts of $\mathrm{CBBH}$, whereas prior to that time appropriate accounts of Payments Bureaus on deposits in foreigncurrency were also included.

Key aggregates identified in the DCS are net foreign assets, net claims on central government, claims on non-central governments, claims on nonbank financial institutions, claims on nonfinancial corporations, and claims on households, currency in circulation outside banking system, demand deposits and other deposits of residents broken-down by national currency and foreign-currency and by domestic sectors, and other items (net).

The DCS provides two liquidity-based measures of money: Money (M1) and Broad Money (M2). M1 comprises currency in circulation plus demand deposits in national currency of resident sectors other than the central government. M2 is defined as M1 plus time and savings deposits in national currency, demand and time and savings deposits in foreigncurrency of all resident sectors other than the central government.

\subsection{Scope}

2.2.1 The scope is broadly consistent with internationally accepted standards, guidelines, or good practices

The depository corporations sector in $\mathrm{BiH}$ consists of the $\mathrm{CBBH}$ and all 32 banks (other depository corporations) operating in $\mathrm{BiH}$ as of March 2007.

For analytical purposes, the depository corporations subsector as defined in $M F S M$ cover central bank and Other Depository Corporations (ODCs). According to MFSM, the ODCs consists of all resident financial corporations (except the central bank) and quasi-corporations mainly engaged in financial intermediation, whose liabilities consist of deposits or financial instruments considered as deposit substitutes that are included in the national definition of money. In $\mathrm{BiH}$, all commercial banks are included in ODCs subsector and the scope of the currently compiled broad money survey is consistent with the MFSM recommendations. 


\subsection{Classification/sectorization}

\subsubsection{Classification/sectorization systems used are broadly consistent with internationally accepted standards, guidelines, or good practices}

The sectorization adopted for monetary statistics conforms with the MFSM. Distinction between nonresident and resident sectors is based on the residency criterion as described in the Balance of Payments Manual, fifth edition (BPM5).

The resident sector is divided into five subsectors: (i) government, which are disaggregated into central government (including state and entity government units) and government units at canton, municipal, and local levels and various government funds, (ii) banks, (iii) nonbank financial institutions, (iv) nonfinancial enterprises, which are disaggregated into public and private, (v) nonprofit institutions, and (vi) households and others. However, the Road Fund in RS is classified by the authorities as a public nonfinancial corporation based on the Court Decision of March 2004 instead of a government unit based on economic classification.

Recommendation: Reclassify the RS Road Fund from public nonfinancial corporations to government unit (extra-budgetary funds) based on the economic classification.

The classification of financial instruments used for monetary statistics is in broad conformity with MFSM guidelines. The monetary data separately identify monetary gold and Special Drawing Rights (SDRs), currency and deposits, and loans. Securities other than shares, insurance technical reserves, financial derivatives, and other accounts receivable/payable are not separately shown as recommended in MFSM, of which, financial derivatives and securities other than shares do not exist while insurance technical reserves and other accounts receivable/payable are included in other items (net).

The banking sector in $\mathrm{BiH}$ does not engage in transactions of securities repurchase agreements.

Recommendation: Show separately all financial asset categories in monetary statistics as recommended by the MFSM to further improve the analytical usefulness of monetary data.

\section{$2.4 \quad$ Basis for recording}

\subsubsection{Market prices are used to value flows and stocks}

The general recommendation of the MFSM is that the valuation of financial assets and liabilities be carried out on the basis of market prices or market price equivalents. The only exception to this rule is that loans should be valued at their book value without adjustment for expected losses. These principles are followed in BiH's monetary statistics. 
Monetary gold is valued monthly using the market price quoted on the London Stock Exchange; traded financial instruments are valued monthly using market prices, albeit such instruments make up significant portion in banks' portfolios due to the imposed cap on banks' holdings of shares of nonfinancial corporations; and loans are valued at the book value without adjustment for provisions.

Conversion of foreign-currency-denominated assets and liabilities into local currency is carried out using the mid-point of end-of-period buying and selling rates prevailing in the market as quoted by the CBBH. The national currency-Convertible Marka (KM) was directly linked to the Euro since January 2002 (previously to the Deutsche Mark at par).

Likewise, SDR-denominated accounts are also converted into local currency using the endof-period market exchange rate.

Valuation adjustments are presented under capital accounts (or shares and other equities) in the analytical accounts of the $\mathrm{CBBH}$ and banks.

\subsubsection{Recording is done on accrual basis}

In BiH's monetary statistics, financial transactions are recorded on an accrual basis. Interest on financial assets or liabilities is accrued at the end of each month and accrued interest is recorded under the underlying financial instruments consistent with MFSM recommendations.

The MFSM also recommends that interest arrears be included with the underlying instruments. The current practice of the $\mathrm{CBBH}$ is consistent with the MFSM.

Financial transactions are recorded simultaneously by the counterparties to a transaction in conformity with MFSM guidelines.

\subsubsection{Grossing/netting procedures are broadly consistent with internationally accepted standards, guidelines, or good practices}

A general principle in macroeconomic statistics is that data should be collected and compiled on a gross basis. For data presented on a net basis, the underlying gross data should also be shown.

In BiH's monetary statistics, assets and liabilities are presented on a gross or net basis in conformity with the MFSM guidelines. In particular, claims on a particular transactor or group of transactors are not netted against liabilities to that transactor or group. Also, provisions against loans are shown on a gross basis on the liability side and loans are included in domestic credit on a gross basis on the asset side. The broad money survey shows underlying gross data for net foreign assets and net claims on central government. 
In the monetary survey, claims and liabilities between depository corporations are appropriately cancelled out, while preserving the presentation of data on claims on and liabilities to other domestic sectors and nonresidents.

\section{Accuracy and Reliability}

\subsection{Source data}

\subsubsection{Source data are obtained from comprehensive data collection programs that take into account country-specific conditions}

The source data used in compiling the central bank survey (CBS) are monthly call reports generated from CBBH's accounting balance sheet. In addition, the IMF-related accounts recorded separately under the arrangement of a Trust Account of $\mathrm{CBBH}$ - the fiscal agent responsible for financial relationship with the IMF since September 2000 - also provide input data for the central bank survey.

In generating the call report form, the CBBH's Accounting Department follows a classification scheme established by STA missions in accordance with the IMF methodology. The Accounting Department is able to update the classification scheme as new accounts are introduced in the accounting books of $\mathrm{CBBH}$.

The source data used for compiling data for the other depository corporations (ODCs) continue to be gathered based on a decentralized data collection arrangements. These data, generated from different accounting systems used by the Federation and the RS and presented in a uniform call report form, are reported to CBBH Main Unit in Banja Luka by all banks in Republika Srpksa and in Brcko and to CBBH Main Unit Sarajevo by all banks in the Federation. After compiling a ODCS for their respective regions, the CBBH Main Units transmit electronically these data along with all individual call reports to the ERSD for use in compiling countrywide ODCS.

With implementation of ongoing revisions to the charts of accounts for the CBBH and banks to conform to the International Accounting Standards, the reporting format, by and large, provides sufficient detail to compile monetary statistics in consistent with the MFSM guidelines.

The source data are kept under continuous review to ensure that the data collection system remains comprehensive, reflects recent developments, and meets new data demands. These reviews take into account (i) ongoing revisions to the charts of accounts, (ii) developments in the financial sector and institutional arrangements, and (iii) issues raised by other government agencies and other data users. 


\subsubsection{Source data reasonably approximate the definitions, scope, classifications, valuation, and time of recording required}

The source data, reported in accordance with $\mathrm{CBBH}$ requirements, provide a reasonable approximation to the definitions, scope, classification, valuation, and timing of reporting needed for monetary statistics.

The CBBH provides banks with guidance in the form of reporting instructions and ad-hoc consultation in completing the report forms. The $\mathrm{CBBH}$ also provides training to banks through seminars or workshops if major revisions are introduced to call report forms. The CBBH's monetary data compilers, in particular, those in CBBH Main Units maintain regular contact with reporting banks to resolve data issues that have important implications for the accuracy of the classification of accounting data for use in monetary statistics.

\subsubsection{Source data are timely}

The balance sheet data of the CBBH become available 20 days after the end of the reference month and the reporting date for monthly balance sheet data is the $15^{\text {th }}$ day of each month after the end of the reference month. These source data are provided on a sufficiently timely basis to allow for timely compilation of monetary statistics.

\subsection{Assessment of source data}

3.2.1 Source data-including censuses, sample surveys, and administrative records-are routinely assessed, e.g., for coverage, sample error, response error, and nonsampling error; the results of the assessments are monitored and made available to guide statistical processes

The CBBH monetary data compilers, in collaboration with CBBH Accounting Department and the Banking Agencies in the Federation and RS, review the reporting system for its adequacy for providing reliable source data. Automated data validation procedures are employed to check the internal consistency of reported data. In addition, source data are also reviewed against those of previous periods to identify out-of-trend items. The identified data inconsistencies are investigated with the reporting units.

\subsection{Statistical techniques}

\subsubsection{Data compilation employs sound statistical techniques to deal with data sources}

The forms for reporting source data are designed to encourage use of computer programs, which enable prompt and accurate data processing. The potential for processing errors is minimized by the use of electronic reporting and processing procedures. 


\subsubsection{Other statistical procedures (e.g., data adjustments and transformations, and statistical analysis) employ sound statistical techniques}

The procedure for late reporting of data by banks is to carry forward the balance sheet of the last month of the particular reporting bank into the current month's statistics. However, reporting delays occur very rarely.

Seasonally adjusted monetary aggregates are compiled using Census X-12, an internationally accepted method. However, these adjusted data series are only available internally.

\subsection{Assessment and validation of intermediate data and statistical outputs}

\subsubsection{Intermediate data are validated against other information where applicable}

The accuracy and reliability of the reported source data for the $\mathrm{CBBH}$ and banks are checked against other sources or information, for instance, data on banks' main categories of assets and liabilities are checked against individual bank's data published in their web sites. In addition, data on loans to households in banks' balance sheet are checked against flow data on household loans collected from banks for other analytical purposes.

\subsubsection{Statistical discrepancies in intermediate data are assessed and investigated}

The $\mathrm{CBBH}$ monetary data compilers identify statistical discrepancies, e.g. discrepancies in interbank positions and, in collaboration with the Accounting Departments and Banking Agencies, investigate their causes, and make revisions to the relevant data as appropriate.

\subsubsection{Statistical discrepancies and other potential indicators of problems in statistical outputs are investigated}

Procedures are in place to investigate large and unexplained movements in monetary and credit aggregates to detect possible classification and sectorization errors. Such investigation is usually carried out jointly by ERSD and CBBH Main Units with banks in their respective regions.

\subsection{Revision studies}

\subsubsection{Studies and analyses of revisions are carried out routinely and used internally to inform statistical processes (see also 4.3.3)}

Studies and analyses of revisions are carried out as part of the CBBH's data quality control process. Such studies and analysis follow the regular major review for CBBH data annually and for banks' data semi-annually for revisions as needed to reflect in monetary statistics recent developments in the financial sector and institutional arrangements in addition to revisions in accounting data. The $\mathrm{CBBH}$ data compilers cross-check preliminary data with final data, and significant discrepancies are investigated. The results of investigations and 
adjustments made in the data compiling process are taken into account in subsequent periods. For example, the differences between preliminary data and final are mainly due to accounting data revisions. So the monetary data revisions cycle is planned in such way to follow the main revision cycles of accounting data. In general, revisions tend to be small in magnitude.

\section{Serviceability}

\subsection{Periodicity and timeliness}

\subsubsection{Periodicity follows dissemination standards}

The periodicity for both the $\mathrm{CBBH}$ and the banking sector is monthly, thus meeting the monthly periodicity recommendation of the GDDS.

\subsubsection{Timeliness follows dissemination standards}

The CBBH publishes monthly data for CBS, ODCs, and DCS five weeks after the end of the reference month on its internet website (http://www.cbbh.ba), thus meeting the timeliness recommendation of the GDDS of 1-3 months. Selected indicators, such as those needed for monitoring the operation of $\mathrm{CBBH}$ as a currency board, are available internally with daily or weekly frequency and higher timeliness.

\subsection{Consistency}

\subsubsection{Statistics are consistent within the dataset}

The CBBH's monetary statistics are internally consistent. No significant discrepancy exists between the central bank's and banks' data on interbank positions as recorded in monetary statistics. If a discrepancy on banks' reserve deposits at the $\mathrm{CBBH}$ between $\mathrm{CBBH}$ data and banks' data is identified, an investigation on the causes of the discrepancy will be undertaken. Automated error-checking systems are in place to check the consistency of the reported data. Other internal consistency checks are also used to ensure accuracy of the information used in the compilation of monetary statistics. In particular, changes in stocks over time are consistent with the flow data currently available.

\subsubsection{Statistics are consistent or reconcilable over a reasonable period of time}

Consistent time series data are available since August 1997. This reflects the practice that whenever major changes in source data, methodology, and statistical techniques are introduced, historical data are reconstructed as far back as possible. For minor changes, brief notes are introduced to the published data describing the main breaks in the time series. Unusual changes in economic trends are also explained in the analytical text included in the publication. 


\subsubsection{Statistics are consistent or reconcilable with those obtained through other data sources and/or statistical frameworks}

The monetary data compilers communicate with the CBBH Balance of Payments Section and Government Finance Statistics (GFS) Section for checking the consistency of the monetary statistics with flow data from the balance of payments and government finance statistics. The net foreign assets in monetary statistics are generally consistent with foreign assets and foreign liabilities of the banking sector in the corresponding measure of the BOP. Major efforts have been made on an ad hoc basis in checking data consistency with GFS. However, consistency checks with GFS data are currently not possible due to lack of sufficiently detailed information on GFS.

Recommendation: The CBBH MFSS, in coordination with the GFS section, establish formal procedures for reviewing regularly the consistency of monetary data with corresponding measures in the GFS dataset and for investigating sources of any discrepancies.

\subsection{Revision policy and practice}

\subsubsection{Revisions follow a regular and transparent schedule}

The monthly monetary data are final after release with the exception of year-end data. Preliminary annual data for $\mathrm{CBBH}$ and banks are disseminated before final data are available. This practice is in place as annual accounting data take longer to become available. This revision practice follows a predictable pattern of which data users are informed. Key revisions are explained in the text or footnotes to the published data.

\subsubsection{Preliminary and/or revised data are clearly identified}

Preliminary data are identified in all $\mathrm{CBBH}$ publications. Users are alerted that the initially published data are preliminary and subject to revision.

\subsubsection{Studies and analyses of revisions are made public (see also 3.5.1)}

Studies and analysis of revisions are undertaken following each round of revisions to measure, assess, and explain the source of revisions made to the data. These studies are published in CBBH's Monthly Economic Review. 


\section{Accessibility}

\subsection{Data accessibility}

\subsubsection{Statistics are presented in a way that facilitates proper interpretation and meaningful comparisons (layout and clarity of text, tables, and charts)}

The CBBH publishes monetary data in a format that is easily understandable in its Quarterly Bulletin containing monthly data and Annual Report. In 2002, the CBBH began posting on its internet website (http://www.cbbh.ba) monetary data on a monthly rather than quarterly basis, which improved significantly the timeliness of monetary data. Longer-time series with data beginning from 1997 are also posted on CBBH websites. These publications contain datasets with various levels of details and annual data series since 1997 and monthly data series for the latest several years. In addition, the CBBH began in 2004 a Monthly Economic Review (MER) for the months between the issuance of the Quarterly Bulletin. The MER, compiled by CBBH's Economic Research Division under ERSD, contain an analytical commentary on current economic and financial developments, trends, and accompanying charts and tables. These publications contain datasets with various levels of detail and annual data series for five years and monthly data for the latest two years. Currently, MER is not published on $\mathrm{CBBH}$ internet due to resources constraints; the publication is required by law to be presented in four languages (Bosnian, Croatian, Serbian, and English). Nevertheless, the authorities indicated that consideration may be given to the publication of $M E R$ when resources condition has improved in the future so as to further enhance data accessibility.

\subsubsection{Dissemination media and formats are adequate}

The CBBH releases monetary data through a variety of publication formats as indicated in 5.1.1. Most data included in these publications are also available on CBBH's internet website (http://www.cbbh.ba). Data in Monthly Economic Review are not posted on the website.

\subsubsection{Statistics are released on a preannounced schedule}

An advance release calendar for monetary statistics is published on the CBBH's internet website (http://www.cbbh.ba). Release of monetary statistics follows the dates announced.

\subsubsection{Statistics are made available to all users at the same time}

The data are released simultaneously to all users through dissemination on CBBH's internet website (http://www.cbbh.ba) and through various CBBH publications. The press is not briefed in advance.

\subsubsection{Statistics not routinely disseminated are made available upon request}

Statistics not regularly published are made available to interested users upon their request. 


\subsection{Metadata accessibility}

5.2.1 Documentation on concepts, scope, classifications, basis of recording, data sources, and statistical techniques is available, and differences from internationally accepted standards, guidelines, or good practices are annotated

All CBBH publications in which monetary statistics are published contain explanatory notes and/or footnotes on the data. In particular, the CBBH Quarterly Bulletin contains comprehensive information to aide users in meaningful interpretation of the data in terms of scope, concept, definitions, classification, and sectorization used in the compilation of the data. Such information is also posted on the CBBH's internet website (http://www.cbbh.ba) and regularly reviewed and updated.

\subsubsection{Levels of detail are adapted to the needs of the intended audience}

The CBBH's publications and website provide datasets for CBS, ODCS, and the depository corporations survey, which show separately all economic sectors and most categories of financial instruments as recommended in the MFSM. Metadata on monetary statistics disseminated through CBBH internet website (http://www.cbbh.ba) provide various levels of detail for the intended audience.

\subsection{Assistance to users}

\subsubsection{Contact points for each subject field is publicized}

Information on specific contact persons are posted on the CBBH internet website (http://www.cbbh.ba) for users to send comments, queries, and requests concerning any category of monetary data published by the CBBH. Users frequently request assistance in the form of clarification and explanation of data mainly through email, telephone, or facsimile, and the assistance is in general promptly provided. Although no formal monitoring of assistance to users has been carried out through comprehensive user surveys, the CBBH reviews closely comments, queries, and requests from general data users as well as from the CBBH Governing Board to obtain users' feedback.

\subsubsection{Catalogs of publications, documents, and other services, including information on any charges, are widely available}

The CBBH publishes a list of publications on its internet website (http://www.cbbh.ba). The $\mathrm{CBBH}$ maintains and updates a list of regular recipients of its publications, and publications are sent to them on a regular basis. CBBH publications are also provided to users upon request free of charge. 
Table 4. Bosnia and Herzegovina: Data Quality Assessment Framework (July 2003): Summary of Results for Monetary Statistics (Compiling Agency: Central Bank of Bosnia and Herzegovina)

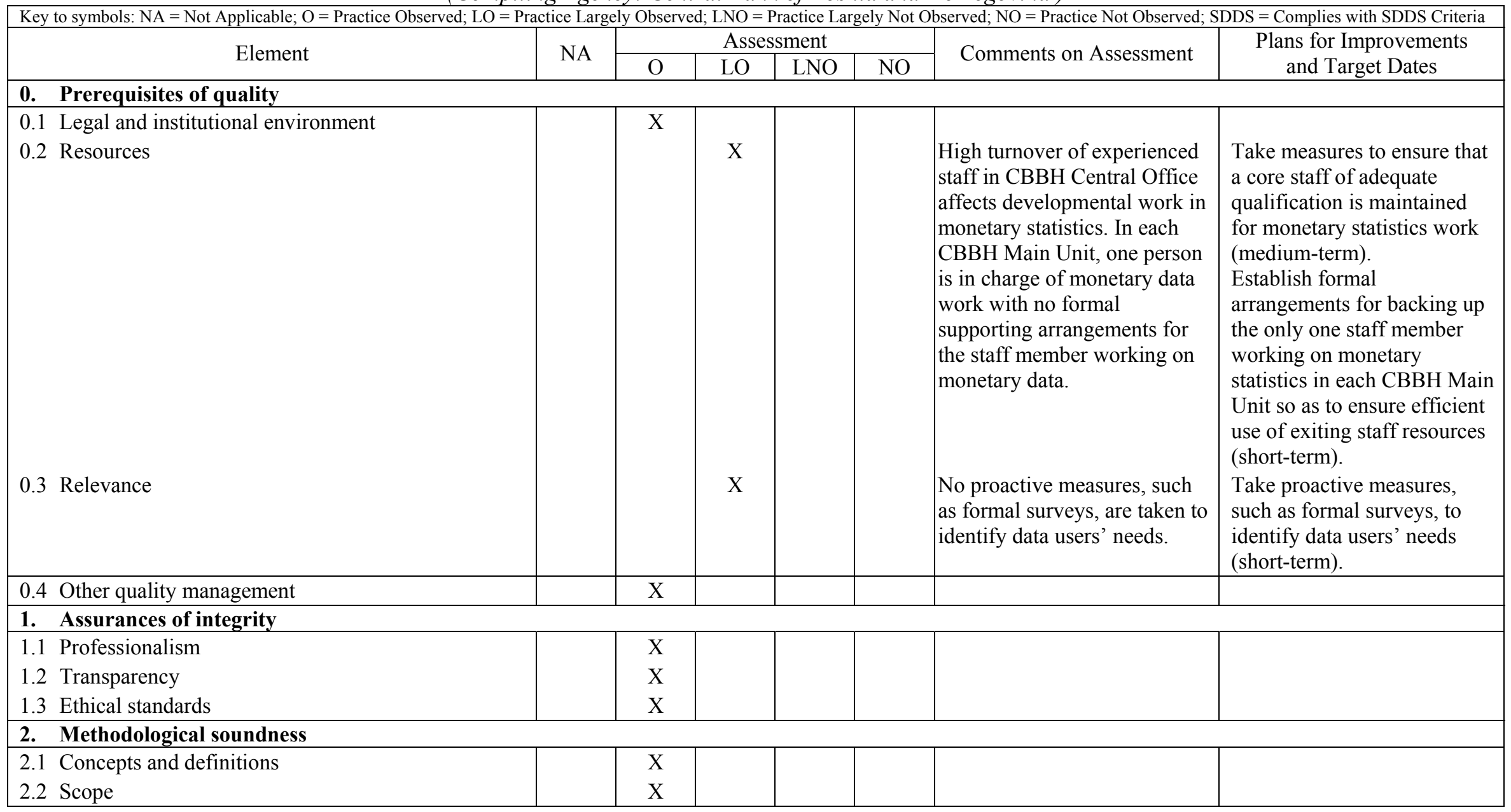


Table 4. Bosnia and Herzegovina: Data Quality Assessment Framework (July 2003): Summary of Results for Monetary Statistics (Compiling Agency: Central Bank of Bosnia and Herzegovina)

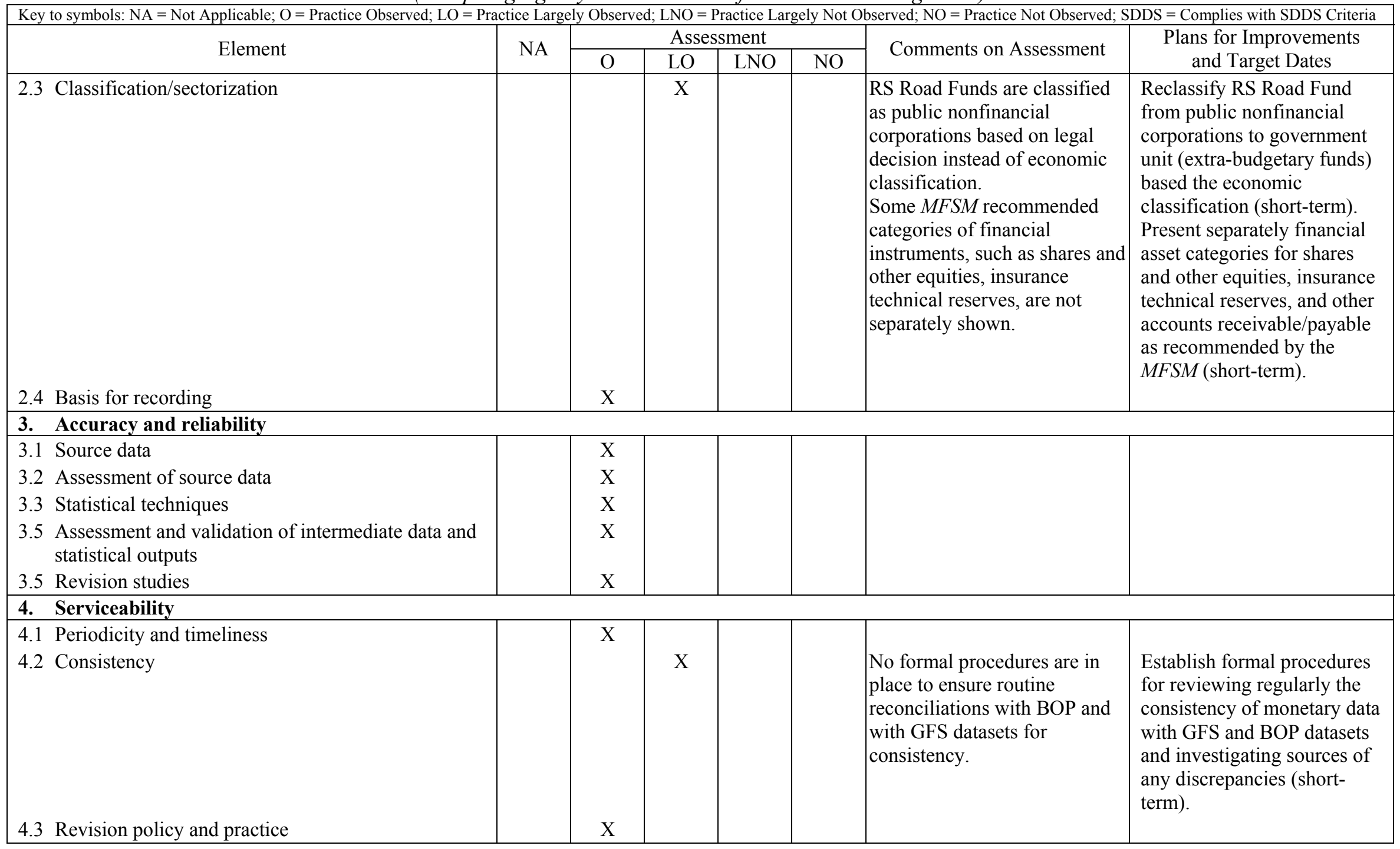


Table 4. Bosnia and Herzegovina: Data Quality Assessment Framework (July 2003): Summary of Results for Monetary Statistics (Compiling Agency: Central Bank of Bosnia and Herzegovina)

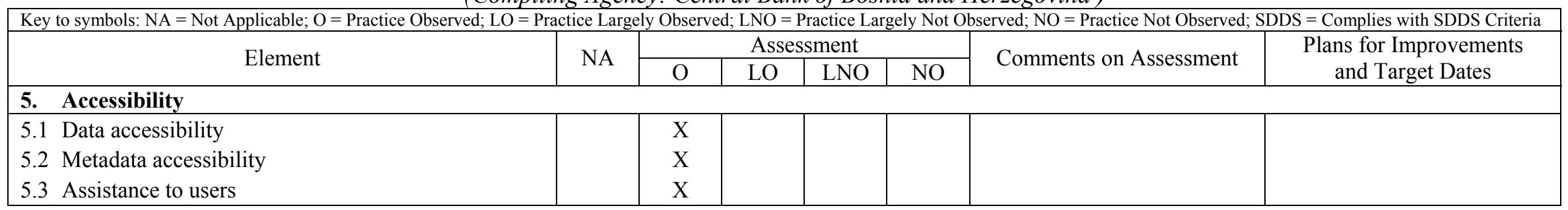




\section{Balance of Payments Statistics}

Since 1998, BiH has gone from having no balance of payments statistics to having a complete set on an annual and quarterly basis as well as producing experimental annual international investment position data. Despite resource constraints, continuing improvements have been made to the statistics. Nevertheless, as noted below, many shortcomings remain. Some of these shortcomings arise from intrinsic measurement difficulties, such as the frequent small transactions typical of cross-border service activities and workers' remittances. As a result, a degree of uncertainty remains about several important components of the balance of payments.

\section{Prerequisites of quality}

\subsection{Legal and institutional environment}

\subsubsection{The responsibility for collecting, processing, and disseminating the statistics is clearly specified}

The CBBH by-law entitled The Decision on Collecting of Data for Monetary and Financial Sector Statistics, Balance of Payments, Government Finance Statistics, and External Debt of Bosnia and Herzegovina Statistics was adopted by the CBBH Governing Board in 2006 and published in the Official Gazette of BiH 81/2006 of December 27, 2006. It is published in local languages (although not in English) and is available to the public by subscription. The by-law specifies the scope of the responsibility of the $\mathrm{CBBH}$ for collecting, compiling, and disseminating balance of payments and other statistics. The authority of the CBBH to compile statistics related to its functions is stated in Article 68 of the $C B B H$ Law (sometimes also translated as the $C B B H A c t$ ) but without specific reference to balance of payments or other types of statistics. The by-law on statistics also includes as supplements two $\mathrm{CBBH}$ official documents to be followed: Guidelines on Manners and Terms for Data Collection and Statistical Data Dissemination for Monetary and Financial Sector Statistics, Balance of Payments, Government Finance Statistics, and External Debt Statistics, and The Decision on Collecting of Data for Monetary and Financial Sector Statistics, Balance of Payments, Government Finance Statistics, and External Debt of Bosnia and Herzegovina Statistics.

The authority of $\mathrm{CBBH}$ to collect balance of payments statistics was reinforced by the Memorandum of Understanding between BHAS and CBBH, adopted in January 2007. In that memorandum, the two agencies agreed that $\mathrm{CBBH}$ would be responsible for balance of payments, while BHAS would assist by supplying trade and other data to CBBH. CBBH staff consider the legislative and institutional framework adequate to carry out their duties for the preparation of balance of payments statistics. 
The exclusive responsibility for compiling balance of payments statistics resides with the CBBH's Economic Research and Statistics Department (ERSD). The ERSD consists of Research Division and Statistics Division. The Statistics Division further consists of three sections, responsible for (i) monetary and financial statistics, (ii) real sector, government finance and public external debt statistics, and (iii) balance of payments statistics, respectively.

\subsubsection{Data sharing and coordination among data-producing agencies are adequate}

As well as its own data collections, $\mathrm{CBBH}$ uses data supplied by other agencies, such as BHAS and the Ministry of Finance and Treasury (MOFT). The supply of data from the MOFT on government debt and associated transactions works effectively.

There has been improvement in coordination with BHAS since 2005, but there is still potential for additional data supply. However, the capacity for improvement is constrained by some of the institutional issues identified for BHAS, as identified elsewhere in this report. The previous duplication of tabulation of international merchandise trade data by BHAS and $\mathrm{CBBH}$ has now been resolved. Up to 2005, both BHAS and CBBH compiled international merchandise trade data, with duplication and some small but unresolved inconsistencies. However, it has now been arranged that BHAS supplies $\mathrm{CBBH}$ with data on a special trade basis (i.e., excluding the exports and imports to bonded warehouses and similar customs-free areas). In addition, the Indirect Taxation Authority of Bosnia and Herzegovina allows direct access by $\mathrm{CBBH}$ to a database on exports and imports according to the general trade system (which covers the whole territory, including bonded warehouses etc., as required for balance of payments statistics). Nevertheless, there is some potential for improvement if additional data were made available, namely, goods for repair, goods for processing, and indicators of the freight and insurance component included in the price of imports (derived from those declarations where both free on board and cost, insurance, and freight values were reported).

To the extent that household and individual surveys are needed to improve data, notably for travel and remittances, cooperation with other agencies may be considered. This is because, so far, $\mathrm{CBBH}$ only has experience in conducting business surveys. For estimates of travel credits and debits, data on numbers of international arrivals and departures in conjunction with data on length of stay would be helpful and are provided in many countries. Despite some attempts being made by $\mathrm{CBBH}$, the border service is unwilling to supply these data. (Different data would be available for airports and roads, as the procedures at road checkpoints are limited.) Interviews or questionnaires of travelers at airports and other exit points are used as methods of collecting data for travel services in many countries, but would need to be undertaken by an agency with specialist expertise in collecting data from individuals.

Cooperation with BHAS and the statistical institutes is also an option to improve coverage of data on workers' remittances as part of the household budget survey, where they are one of the major sources of household income. The large size of remittances and their importance as a driver of the $\mathrm{BiH}$ economy means that there is a particular need for up-to-date data on 
trends. While data on remittances through the banks are up-to-date, changes in the banks' share of remittances would make this an inadequate indicator of trends. There is also an option that BHAS and the statistical institutes could assist with collecting continuing and upto-date measures of remittances by including additional questions as part of the new regular labor force survey or in conjunction with other household surveys. Another possibility is that data on export and import of services could be collected as part of a comprehensive business survey program, however BHAS and the statistical institutes do not yet have such a program.

Recommendations: Encourage border service to assist in meeting statistical needs including travel and workers' remittances.

In view of their particular importance to the BiH economy, consider the possibility of working with BHAS to improve data on workers' remittances, including data on channel of payment in the household budget survey (cash, in kind, through banks, other) and, in the longer term, in short-term surveys (such as part of the household survey used to collect labor force data).

\subsubsection{Individual reporters' data are to be kept confidential and used for statistical purposes only}

Published balance of payments statistics do not disclose data on individual enterprises. The CBBH Law Article 24 states that staff must not disclose or publicize nonpublic material information which they have obtained in the performance of their Central Bank duties or use such information, or allow such information to be used, for personal gain. A figure can be published even though it contains data from only one or two enterprises, provided that the enterprise is not identified.

Reporting enterprises are aware of their rights to confidentiality as stated in the CBBH Law, which is stated at the top of forms and is posted in CBBH's internet website (http://www.cbbh.ba).

The CBBH takes several measures for preventing disclosure of individual data, including (i) application of a coding system to avoid revealing information on individual institutions,

(ii) restricting access to the database containing individual data to authorized staff only, and

(iii) periodic renewal of passwords for accessing databases containing individual data.

Questionnaires are stored with restricted access. CBBH staff have always refused requests for information that could be used to identify a particular respondent.

\subsubsection{Statistical reporting is ensured through legal mandate and/or measures to encourage response}

The CBBH By-Law entitled The Decision on Collecting of Data Monetary and Financial Sector Statistics, Balance of Payments, Government Finance Statistics, and External Debt of Bosnia and Herzegovina Statistics, Article 3, states that any surveyed enterprise has to provide the $\mathrm{CBBH}$ with requested data for its purposes in the format and by the date 
prescribed by $\mathrm{CBBH}$. Penalty measures for noncompliance with reporting requirements are in place.

Other data collection practices have been developed to encourage cooperation from data suppliers. The $\mathrm{CBBH}$ carefully considers the response burden. The $\mathrm{CBBH}$ assists respondents by including detailed written explanations, support by telephone, fax, and e-mail for completing questionnaires. As well, follow-up visits to data reporters are undertaken on their special request. However, staff do not have enough time to visit all the non-responding companies and more emphasis is thus placed on the other communication means.

For resident commercial banks, postal and telecommunication operators, as well as insurance and reinsurance companies, response is complete. Other enterprises' survey response rate is about 80 percent in terms of numbers (and more in terms of value, as the largest enterprises are followed up more intensely), which is considered acceptable.

\section{$0.2 \quad$ Resources}

\subsubsection{Staff, facilities, computing resources, and financing are commensurate with statistical programs}

The balance of payments section of the CBBH comprises five staff members. These are all professional staff who undertake a wide range of tasks from survey collection to methodological work. In addition, a staff member in each of the three $\mathrm{CBBH}$ main units carries out additional data collection functions with regard to the commercial banks. These staff in the main offices also work on banking supervision and monetary statistics, and balance of payments needs represent only a small part of their workload.

The number of staff is relatively small in comparison with other countries in the Balkan region that have recently undertaken ROSCs. Staff have indicated a number of areas where there is room for improvement that could be undertaken with additional staff. These projects include the improvement of data on the freight and insurance components of the value of imports, resident transport operators, travel, direct investment abroad, and portfolio investment. However, some areas for improvement require household surveys and other surveys of individuals, notably for remittances, compensation of employees, and travel. Such surveys could perhaps be undertaken by, or in conjunction with, BHAS and the entity statistical institutes, who have experience in household surveys.

Staff salaries are considered to be competitive in comparison with other government agencies, but lower than the private sector. Staff turnover is considered to be manageable, with two staff members in the balance of payments section each having ten years of experience and the other three each have staff five years of experience.

Computing facilities could be improved. While all staff have computer terminals and the $\mathrm{CBBH}$ information technology unit provides support on technical matters, there are problems in support, repairs, availability of printers, and network access. The computer system is the 
same as the rest of the $\mathrm{CBBH}$, built on Microsoft-Office, with no adaptation to the particular needs associated with large statistical surveys. In particular, Excel and Access are used, rather than specialized data collection systems that would be capable of undertaking printing and addressing questionnaires, packing and addressing envelopes, collection control, and data verification. While Excel is currently used for data storage and tabulation, a database package is usually preferred by statistical compilers for large sets of data. Data collected and reports are backed up, including off-site copies.

Staff mentioned concerns about the lighting and ventilation systems in mostly windowless offices and lack of meeting space. Transport for survey follow-up is provided when requested, but depends on the current availability of $\mathrm{CBBH}$ drivers and cars. Time for onsite visits to data suppliers is limited by staff workload. When requested by respondents, staff have visited companies in areas around Sarajevo, while follow-up of nonreporting enterprises in other areas away from Sarajevo has been limited to mail, fax, and telephone.

\subsubsection{Measures to ensure efficient use of resources are implemented}

Promotion and staff selection is based on merit. Staff receive training on the job and at courses and seminars sponsored by the IMF, the Center of Excellence in Finance (Ljubljana, Slovenia), and various EU member states and agencies.

The efficient use of existing resources is promoted by the ERSD through (i) periodic performance reviews for staff for Governor Rewards, (ii) staff training in relevant areas to enhance their technical knowledge and skills, (iii) periodic reviews of work processes when needs arise and adjustments to improve work processes, and (iv) extensive computerization of the statistics production process. As evidence of efforts to improve efficiency, CBBH staff have tried to encourage electronic reporting, although there has been limited acceptance by reporting enterprises, mostly due to the lack of information technology infrastructure in most resident enterprises.

New staff receive on-the-job training. CBBH staff participate in regional and international conferences. In addition, the $\mathrm{CBBH}$ encourages staff to pursue advanced studies in workrelated fields by providing funds for part-time college courses.

\subsection{Relevance}

\subsubsection{The relevance and practical utility of existing statistics in meeting users' needs are monitored}

The CBBH seeks to monitor the relevance of balance of payments statistics in meeting user needs in various ways. Within $\mathrm{CBBH}$, there is consultation with the management and other relevant departments involved in macroeconomic policy analysis. Because of the limited number of users, the $\mathrm{CBBH}$ has conducted no formal monitoring of user needs (such as a survey or user committee). Nevertheless, comments are initiated by users on a continuing 
basis, which the CBBH staff consider useful in identifying user concerns and emerging issues.

CBBH staff help to maintain the relevance of statistics by monitoring new economic developments from media reports and economic research and making sure that statistics cover new developments and emerging issues, such as new direct investment inflows. They also attend meetings and seminars, such as the IMF courses at the Joint Vienna Institute. $\mathrm{CBBH}$ also makes its statistics relevant by following international guidelines and having a good record of implementation of technical assistance advice, within resource constraints.

The user survey undertaken for the ROSC indicated that most were generally satisfied with the coverage and detail in balance of payments statistics (with some dissatisfaction, mainly focused on the well-recognized data source problems).

Recommendation: Conduct a survey of user views, for example by interviewing a few major users to identify their concerns and needs and inform them of the available published and unpublished data and metadata.

\section{$0.4 \quad$ Other quality management}

\subsubsection{Processes are in place to focus on quality}

The CBBH management attaches importance to its work on statistics and is sensitive to data quality issues and takes initiatives to improve data flows between the $\mathrm{CBBH}$ and other agencies. It updates questionnaires and methods on a continuing basis. It has implemented procedures to focus on quality, such as analyzing and documenting their systems, similar to ISO 9000.

The CBBH reviews data for accuracy. Validation procedures for assessing the plausibility or reasonability of reported data are undertaken by checking accounting relationships and development trends. Should unusual movements in data be identified, in-depth investigations are carried out for possible misclassifications or other errors.

There is a decentralized data collection system for banks. There is a specialist statistics staff member in each of the CBBH main units in Banja Luka, Mostar, and Sarajevo, responsible for dealing with banks with head offices in that region. The arrangements for the supply of balance of payments data from banks to $\mathrm{CBBH}$ are suitable. However, there are some problems in the decentralized structure, in particular, training and communication with regional offices could be improved. Having only one officer in each main unit makes the reporting system vulnerable to staff turnover and absences.

Recommendation: $C B B H$ staff involved in compiling balance of payments from each of the four offices should meet annually to receive training in concepts and discuss data collection issues. A meeting for monetary statistics could be held at the same time. 


\subsubsection{Processes are in place to monitor the quality of the statistical program}

The ERSD has internal processes to identify and resolve issues at various stages of the collection, compilation, and dissemination of balance of payments statistics. The data compilers also monitor new regulations and developments in the economy and statistics. Contact information is provided for sending comments or requests to the $\mathrm{CBBH}$. Comments or requests from data users provide important feedback for monitoring the quality of balance of payments statistics. Technical assistance has been sought and there has been a good track record of implementation of recommendations, within the resource constraints.

Questionnaires and compilation methods are revised on a continuing basis, as staff take into account problems and experience.

\subsubsection{Processes are in place to deal with quality considerations in planning the statistical program}

In formulating its statistical work programs tradeoffs among the dimensions of data quality are recognized. New data requests from the $\mathrm{CBBH}$ Governing Board have guided the planning for meeting emerging data needs. In addition, comments that the $\mathrm{CBBH}$ has received from outside data users have provided useful guidance for improving the data compilation and dissemination, e.g., the expansion in coverage of direct investment and trade credit. Implementation of changes in response to comments has resulted in improvements in the comprehensiveness of balance of payments data. The recent introduction of new surveys (such as foreign investment) and methods (such as compensation of employees) is evidence that $\mathrm{CBBH}$ has responded to the identification of problems and gaps in the data.

\section{Assurances of integrity}

\subsection{Professionalism}

\subsubsection{Statistics are produced on an impartial basis}

The independence of the CBBH is established in the CBBH Law Article 7, which grants the $\mathrm{CBBH}$ the powers to carry out its duties independently of the government. The $\mathrm{CBBH}$ Governing Board consists of five members, who select the Governor from among the members. The term of the Governor and other Governing Board members is six years.

The terms and conditions under which balance of payments statistics are produced promote the professional independence of the CBBH. Professional competence plays a key role in recruitment and promotion policies. Recruitment and promotion are based on relevant aptitude and expertise. Requirements for potential recruits to the Balance of Payments Section include a minimum of education at university level. After a one-year probation period, the decision to convert to regular staff is based on performance. 


\subsubsection{Choices of sources and statistical techniques as well as decisions about dissemination are informed solely by statistical considerations}

Choices of sources and techniques for the compilation of balance of payments statistics made by ERSD are based solely on statistical considerations. The data sources and techniques are similar to those used in other countries in the region. The reasoning for the choice of methodologies is discussed in published notes and in response to queries. The dissemination of balance of payments data is made according to a regular schedule without any interference.

\subsubsection{The appropriate statistical entity is entitled to comment on erroneous interpretation and misuse of statistics}

If there is erroneous interpretation or misuse of the balance of payments statistics in the media or other fora, the CBBH's Public Relations Section comments and provides clarification in the media and publishes statements on its website. If needed, the $\mathrm{CBBH}$ contacts the reporters and other concerned parties to have the erroneous interpretation corrected and has issued statements.

\subsection{Transparency}

\subsubsection{The terms and conditions under which statistics are collected, processed, and disseminated are available to the public}

The laws and regulations under which statistics are collected, processed, and disseminated by the CBBH are available to the public. The $C B B H$ Law and the $C B B H B y-L a w$ are available on the CBBH's website. These laws describe CBBH's policies on (i) treatment of confidential data and (ii) transparency of its operations and information. The CBBH's publications always indicate the address of the CBBH's internet website, where more information about the $\mathrm{CBBH}$, macroeconomic statistics, and metadata are disseminated.

\subsubsection{Internal governmental access to statistics prior to their release is publicly identified}

Access to balance of payments statistics is provided simultaneously to all users when the data are posted on the CBBH website. There have been no instances of internal government access prior to publication.

Recommendation: Consider putting a public statement on the CBBH release policy on the website; in particular, the policy should state that there is no advance internal government access. 


\subsubsection{Products of statistical agencies/units are clearly identified as such}

Balance of payments statistics are published as CBBH products, with the Bank's name and logo shown prominently. When data produced by other agencies are published, the source is indicated in the footnotes. The $\mathrm{CBBH}$ requests attribution when its statistics are used for reproduction or re-dissemination.

\subsubsection{Advance notice is given of major changes in methodology, source data, and statistical techniques}

Some major changes in balance of payments statistics have been announced in advance, such as the introduction of partner data and implementation of the direct investment survey.

(These press releases are available on the CBBH website.) Other changes in methodology, source data, and statistical techniques are announced and explained simultaneously with the publication release of data.

Recommendation: Standardize and improve the policy to give advance notice of major changes in methodology and the incorporation of the results of the new surveys, by advising a wider range of improvements in advance.

\subsection{Ethical standards}

\subsubsection{Guidelines for staff behavior are in place and are well known to the staff}

The Code of Conduct for Employees of the CBBH (Code of Conduct) provides comprehensive ethical guidelines for the staff of the CBBH. These guidelines are well known to CBBH staff and establish the main principles and rules for staff integrity, objectivity, efficiency, professional independence, maintaining confidentiality of data, and avoiding conflict of interest, among others. New staff members are informed of the Code of Conduct when they join the $\mathrm{CBBH}$ and are also required to sign an official document to certify that they have read and understand these guidelines. It is available on the CBBH internal network, but not publicly available.

\section{Methodological soundness}

\subsection{Concepts and definitions}

2.1.1 The overall structure in terms of concepts and definitions follows internationally accepted standards, guidelines, or good practices

The framework for balance of payments statistics follows the fifth edition of the Balance of Payments Manual (BPM5). CBBH publications use a national presentation, which has the same basic structure as the IMF standard presentation, but some differences in the level of detail are introduced to take account of national circumstances (for example, portfolio investment and financial derivatives are omitted). 
The concepts and definitions used are in broad conformity with those used in BPM5. The one-year criterion for residence is adopted in principle with the special treatments adopted for non-local staff of embassies and military bases, and $\mathrm{BiH}$ citizens having a principal residence abroad being treated as nonresidents. This definition is applied as far as practicable for compensation of employees, remittances, and local expenditure by staff of embassies and military bases, although nationality may be used in practice by some banks. International organizations, such as the United Nations and North Atlantic Treaty Organization (NATO) have a significant presence in $\mathrm{BiH}$ and are correctly treated as nonresident entities. Enterprises operating in $\mathrm{BiH}$ are shown as residents, because enterprises undertaking business other than as representative offices need to set up a legal entity in $\mathrm{BiH}$. Definitions of direct investment and reserve assets also follow BPM5.

\section{$2.2 \quad$ Scope}

2.2.1 The scope is broadly consistent with internationally accepted standards, guidelines, or good practices

In principle, the scope of the balance of payments statistics follows international standards in covering all transactions between residents and nonresidents. For items not covered or poorly covered in data sources, such as cash remittances and imports omitted or underinvoiced, adjustments are made to move closer to the full scope. (However, as discussed under 3.3.2 below, these adjustments are conservative, albeit mostly discretionary, and based on several indirect sources and observations, rather than on solid indicators.) Reinvested earnings are included. Transfers of assistance in the form of goods and services are included in principle. There are four free trade zones (of which two are not operating), which are covered in balance of payments statistics.

\subsection{Classification/sectorization}

\subsubsection{Classification/sectorization systems used are broadly consistent with internationally accepted standards, guidelines, or good practices}

The sectorization follows BPM5. Public enterprise debt is reported under general government, but this treatment is correct, because the government undertakes all borrowing abroad, and then on-lends to public enterprises.

Transactions are generally classified according to the standard components of BPM5. There are some minor differences in classification of particular items. The value of private capital transfers is very large and includes some items that should be included in current transfers (namely, gifts from nonresidents of consumer durables) and direct investment (ownership of real estate where the nonresident is the legal owner). In BPM5, capital transfers are limited to cases where the donor ties the gift to a capital purpose. Consumer durables, such as electronics and vehicles for non-business use, are not considered as capital formation in macroeconomic statistical standards, so should not be covered in capital transfers. Furthermore, if donors do not tie funds to a capital purpose, the funds are current transfers, 
even if the recipients later apply the funds to capital purposes. The case where a nonresident $\mathrm{BiH}$ citizen buys $\mathrm{BiH}$ real estate and allows resident relatives to occupy it free of charge should be included under direct investment, unless the donor assigns title to the residents. Gifts of equipment for productive purposes, such as tractors, or funds tied by the donor to the purchase of capital goods for future production (such as houses and business equipment) are correctly included in capital transfers.

Debt between affiliated financial enterprises ("intercompany loans") is shown as direct investment for loans and portfolio investment for deposits. This treatment is considered an acceptable operational approximation to the standards, to the extent that deposits tend to be short-term, while loans tend to be associated with permanent debt. Interest on debt to affiliated enterprises is incorrectly shown under Current account, Income from direct investment; income on equity, but should be shown under Current account, Income from direct investment; income on debt; while the corresponding financial account entries are shown correctly.

The value of banks' holdings of securities issued by nonresidents should be included in portfolio investment, but are recorded under other investment because their value is minor and there is currently no other identified portfolio investment. There is currently no separate item for financial derivatives, as use of these instruments has not yet been identified. As the economy develops, the use of derivatives by $\mathrm{BiH}$ enterprises, such as banks and oil companies, would need to be monitored.

Recommendation: Change the coverage of capital transfers to line up with international definitions. Include interest from inter-company loans in current account/income under direct investment.

\section{$2.4 \quad$ Basis for recording}

\subsubsection{Market prices are used to value flows and stocks}

Valuation principles follow BPM5. Market valuations are used in general. Market price equivalents are used for barter goods, aid in kind, and trade between affiliated enterprises.

Exports and imports are valued f.o.b. (free on board). Imports data are collected on a c.i.f. (cost, insurance, and freight) basis and converted to a f.o.b basis using a fixed ratio of $100 / 107$. This ratio was developed a number of years ago and has not been revised. It was a result of investigation of the sources of imports and expert advice. It is a smaller adjustment than most countries, because the investigation showed that a high proportion of imports comes from close or adjoining countries.

The data are published in convertible marks, and also available on request converted into United States dollars and euros. Conversions from other currencies are made at the relevant mid-rate exchange rate, for the shortest time period to which the data relate. The time of 
conversion does not make a difference for transactions in euros because the exchange rate with the convertible mark is fixed.

Recommendation: investigate updating the c.i.f.-to-f.o.b. adjustment factor, on the basis of information on customs declarations and/or interviews with major importers.

\subsubsection{Recording is done on an accrual basis}

For goods, the data source reflects the time of customs clearance. In principle, if identified, adjustments would be made for large, identified transactions, to make the timing of the goods flow and the corresponding financial flows more consistent and on an accrual basis.

For interest on public debt, the data are supplied by the MOFT and are on a payments basis, rather than an accrual basis. Items reported from transactions reporting by the banks, such as many services, use the time of payment as the basis for recording. For services provided in kind, the time of recording of the donor is used.

Recommendation: Monitor large transactions for significant divergences between the time of payment and time of accrual.

\subsubsection{Grossing/netting procedures are broadly consistent with internationally accepted standards, guidelines, or good practices}

The grossing and netting procedures follow BPM5 guidelines. Data are published in gross terms in the current and capital accounts and net terms in the financial account. In addition, gross data are also available for some components of the financial account and are useful for some analysis.

\section{Accuracy and reliability}

\subsection{Source data}

3.1.1 Source data are obtained from comprehensive data collection programs that take into account country-specific conditions

A wide range of sources are used to compile the balance of payments including:

- BHAS data. Since January 2006 BHAS data derived from customs have been used for exports and imports of goods. In addition, BHAS data on workers' remittances from the household budget survey are taken into account in deriving workers' remittance credits.

- $\mathrm{CBBH}$ surveys. CBBH conducts quarterly surveys on communication, insurance, and financial services, and foreign investment flows, while annual surveys are run for stocks of foreign investment and trade credit stocks and flows. The foreign 
investment survey was introduced in 2004, and the survey on trade credit was introduced in 2005 as part of CBBH's efforts to fill gaps in data.

- Direct reporting. The Ministry of Foreign Affairs supplies data on the government's financial transactions abroad and the CBBH Accounting Department reports for CBBH's own external transactions. The commercial banks and money transfer companies also report their own transactions. In addition, two pension funds and International Airport of Sarajevo also provide some data for balance of payments statistics. There is also some limited reporting by embassies and international organizations.

- International transactions reporting system. The banks report transactions in the case of exports and imports of goods, exports and imports of selected services (transport, travel, financial, and construction), dividends, distributed profits and interest paid to or from non-residents, migrants' transfers, workers' remittances, pensions, grants and aid inflows and outflows. These data cover both credits and debits, but some of them are used for comparison or control purposes only.

- Partner data are used for bank loans from abroad and development assistance.

- Information from specific entities, such as employment agencies.

Compared to internationally accepted practices, the major gaps in source data are:

- Indicators of undervaluation and undercoverage of imports.

- Travel survey.

- Household-based measures of remittances and compensation of employees from short-term work abroad on a quarterly or annual basis.

- Transport operators.

- C.i.f./f.o.b. adjustment.

New data sources will need to be identified in the future as the economy develops in order to cover portfolio investment and financial derivatives. However, these are nil or negligible at present. Good practice would be for statistical collection to be in operation at an early stage as financial innovation occurs.

Recommendation: As resources become available, introduce additional surveys in relevant areas. 


\subsubsection{Source data reasonably approximate the definitions, scope, classifications, valuation, and time of recording required}

While the definitions, classifications, and valuation are generally acceptable approximations, the main shortcoming is that cash and other informal transactions are considered to be large and poorly covered. This conclusion is based on CBBH's own review of the shortcomings of data sources, as well as by the value of net errors and omissions.

The sources for individual components and adjustments needed are shown in the table below.

\section{Overview of Sources and Adjustments}

\begin{tabular}{|c|c|c|}
\hline Item & Major sources & Components needing adjustment \\
\hline \multirow[t]{2}{*}{$\begin{array}{l}\text { Exports and imports of } \\
\text { general merchandise. }\end{array}$} & \multirow[t]{2}{*}{$\begin{array}{l}\text { BHAS data (raw data from customs, } \\
\text { as processed by } \\
\text { BHAS). }\end{array}$} & $\begin{array}{l}\text { Undervaluation and smuggling - estimated } \\
\text { values have been reduced with } \\
\text { improvements in administration (exports } \\
\text { down to zero; imports down to } 7 \text { percent). }\end{array}$ \\
\hline & & Freight and insurance on imports deducted. \\
\hline $\begin{array}{l}\text { Transportation services, } \\
\text { Passengers. }\end{array}$ & Airport Sarajevo Statistics. & $\begin{array}{l}\text { Estimates for road transport, additional } \\
\text { adjustments to air transport. }\end{array}$ \\
\hline Transportation services, Freight. & $\begin{array}{l}\text { Component of imports of goods. } \\
\text { Direct reporting by some providers. }\end{array}$ & Estimates based on export of goods figures. \\
\hline Travel, debit. & $\begin{array}{l}\text { Data found on websites of countries } \\
\text { that are major BiH tourist } \\
\text { destinations. }\end{array}$ & Additional adjustments, if needed. \\
\hline Travel, credit. & BHAS data. & $\begin{array}{l}\text { Adjustment for unregistered tourism } \\
\text { activities and for BiH citizens who live } \\
\text { abroad. }\end{array}$ \\
\hline $\begin{array}{l}\text { Communication, insurance, and } \\
\text { financial services. }\end{array}$ & CBBH surveys. & \\
\hline Construction. & BHAS data. & Adjustment for unregistered services. \\
\hline Other services. & $\begin{array}{l}\text { International transactions reporting } \\
\text { system (ITRS) (reporting of } \\
\text { customer transactions by banks). }\end{array}$ & $\begin{array}{l}\text { Additional and complementary adjustments } \\
\text { for services related to international } \\
\text { organizations in } \mathrm{BiH} \text {. }\end{array}$ \\
\hline $\begin{array}{l}\text { Compensation of employees, } \\
\text { credit. }\end{array}$ & $\begin{array}{l}\text { Survey of employment agencies for } \\
\text { seasonal workers. }\end{array}$ & $\begin{array}{l}\text { Estimates of local employees of embassies, } \\
\text { international organizations. }\end{array}$ \\
\hline $\begin{array}{l}\text { Investment income, } \\
\text { Interest—public sector }\end{array}$ & Ministry of Finance and Treasury. & \\
\hline $\begin{array}{l}\text { Investment income, interest- } \\
\text { CBBH and commercial banks }\end{array}$ & $\begin{array}{l}\text { CBBH—own accounts, bank } \\
\text { reporting. }\end{array}$ & \\
\hline $\begin{array}{l}\text { Investment income, interest - } \\
\text { other sectors. }\end{array}$ & CBBH Survey on trade credits. & $\begin{array}{l}\text { Estimates for interest payments related to } \\
\text { BIS statistics on external debt flows. }\end{array}$ \\
\hline \multirow[t]{2}{*}{$\begin{array}{l}\text { Dividends and reinvested } \\
\text { earnings. }\end{array}$} & \multirow[t]{2}{*}{$\begin{array}{l}\text { Reinvested earnings from annual } \\
\text { foreign investment survey. }\end{array}$} & $\begin{array}{l}\text { Reinvested earnings quarterly are based on } \\
\text { extrapolation. }\end{array}$ \\
\hline & & $\begin{array}{l}\text { Smaller enterprises quarterly based on } \\
\text { extrapolation. }\end{array}$ \\
\hline
\end{tabular}




\begin{tabular}{|c|c|c|}
\hline Item & Major sources & Components needing adjustment \\
\hline \multirow[t]{2}{*}{ Official transfers. } & \multirow[t]{2}{*}{$\begin{array}{l}\text { Data from OECD Development } \\
\text { Assistance Committee (DAC). }\end{array}$} & $\begin{array}{l}\text { Assistance from providers outside DAC } \\
\text { (assumed to be } 9 \% \text {; mainly from Islamic } \\
\text { countries). }\end{array}$ \\
\hline & & $\begin{array}{l}\text { The capital-current split is based on the } \\
\text { description of the purpose of the project. }\end{array}$ \\
\hline Workers' remittances. & Bank and money transfer values. & $\begin{array}{l}\text { Transfers in the form of goods, cash, or } \\
\text { ATM withdrawals. }\end{array}$ \\
\hline Other current private transfers. & ITRS, Pension funds. & \\
\hline Direct investment flows. & $\begin{array}{l}\text { Quarterly and annual foreign } \\
\text { investment survey. }\end{array}$ & $\begin{array}{l}\text { Direct investment abroad identified case-by- } \\
\text { case. }\end{array}$ \\
\hline $\begin{array}{l}\text { Other investment flows, } \\
\text { assets, commercial banks. }\end{array}$ & $\begin{array}{l}\text { CBBH monetary and financial } \\
\text { statistics. }\end{array}$ & \\
\hline \begin{tabular}{|l|} 
Other investment flows, \\
assets, other sectors, trade credits.
\end{tabular} & CBBH Survey on trade credits. & $\begin{array}{l}\text { Adjustments for non-respondents, and for } \\
\text { quarterly data. }\end{array}$ \\
\hline $\begin{array}{l}\text { Other investment flows, } \\
\text { assets, other sectors, currency and } \\
\text { deposits. }\end{array}$ & $\begin{array}{l}\text { Data of Treasury of } \mathrm{CBBH} \text { on } \\
\text { Currency conversion. }\end{array}$ & $\begin{array}{l}\text { Estimates for flows of foreign exchange } \\
\text { cash holdings outside banks: unregistered } \\
\text { net-imports financing, workers remittances, } \\
\text { rents, compensation of employees, travel } \\
\text { expenditures abroad, purchases of non- } \\
\text { residents. }\end{array}$ \\
\hline $\begin{array}{l}\text { Other investment flows, liabilities, } \\
\text { commercial banks. }\end{array}$ & $\begin{array}{l}\text { CBBH monetary and financial } \\
\text { statistics. }\end{array}$ & \\
\hline \begin{tabular}{|l|} 
Other investment flows, \\
Liabilities, Monetary authorities.
\end{tabular} & $\begin{array}{l}\text { CBBH monetary and financial } \\
\text { statistics. }\end{array}$ & \\
\hline $\begin{array}{l}\text { Other investment flows, liabilities, } \\
\text { loans, general government. }\end{array}$ & $\begin{array}{l}\text { Data base on External Debt of } \\
\text { Government sector maintained by } \\
\text { Ministry of Finance and Treasury of } \\
\text { BiH. }\end{array}$ & $\begin{array}{l}\text { Adjustment done in cooperation with } \mathrm{CBBH} \\
\text { GFS and external debt statistics. }\end{array}$ \\
\hline $\begin{array}{l}\text { Other investment flows, liabilities, } \\
\text { loans, other sectors. }\end{array}$ & $\begin{array}{l}\text { Bank for International Settlements } \\
\text { (BIS): Locational statistics; Assets } \\
\text { and liabilities of reporting banks vis- } \\
\text { à-vis BiH nonbanking sector. }\end{array}$ & $\begin{array}{l}\text { Additional estimates for lacking periods } \\
\text { (i.e., for quarterly flows) and adjustments } \\
\text { related to split between new loans and } \\
\text { principal repayments. }\end{array}$ \\
\hline $\begin{array}{l}\text { Other investment flows, liabilities, } \\
\text { trade credits. }\end{array}$ & CBBH Survey on trade credits. & $\begin{array}{l}\text { Adjustments for non-respondents, and for } \\
\text { quarterly data. }\end{array}$ \\
\hline Reserve assets flows. & $\begin{array}{l}\text { CBBH monetary and financial } \\
\text { statistics. }\end{array}$ & \\
\hline
\end{tabular}

The net errors and omissions is significant and positive, which indicates that in net terms, there are credits missing from the data. While the causes are unclear, according the CBBH's assessment, some of the credits possibly missing in the data sources include understatement of workers' remittances and compensation of employees, and the rundown of previously acquired foreign cash holdings. In addition, services, travel and locally-provided services associated with the international presence in the country are difficult to measure, but are a declining factor. Alternatively, debits could be overstated, although this appears less likely because the only large, uncertain component is for the imports adjustment factor. 


\subsubsection{Source data are timely}

Source data are sufficiently timely to allow quarterly data to be produced within a quarter after the reference period. The balance of payments compilers and data suppliers cooperate to meet balance of payments requirements.

\subsection{Assessment of source data}

3.2.1 Source data-including censuses, sample surveys and administrative records-are routinely assessed, e.g., for coverage, sample error, response error, and nonsampling error; the results of the assessments are monitored and made available to guide statistical processes

Balance of payments staff compare data at the micro and macro levels reported for earlier periods to check the plausibility of trends. Large transactions (such as privatizations) are monitored to make sure they are recorded properly. Exports and imports data from customs are compared with the values reported by banks for export and import transactions on behalf of their customers.

The international transactions reporting system only covers a few types of transactions, so cannot be reconciled with opening and closing positions of the banks. However, the banks' reporting of their own transactions is comprehensive, so that they can be checked against positions.

\subsection{Statistical techniques}

\subsubsection{Data compilation employs sound statistical techniques to deal with data sources}

Data entry procedures include checks to avoid miscoding and misreporting. Queries are made to reporters concerning unusual values. Nonreporting enterprises and missing data are estimated on the basis of previous response and trends. Since these items are fairly small at present, relatively simple extrapolation is acceptable. As they are expected to become more significant in the future, different methods may be needed. For example, it is likely that reinvested earnings debits have been growing more rapidly than previous years' trends would indicate, as a result of the improved profitability of some direct investment enterprises caused by strong demand and commodity prices. However, actual data will not reflect this development until the annual foreign investment survey data are available. Possible methods are quarterly data collection from a few large enterprises, if they have quarterly profit and loss statements, or modeling by industry, using specific activity indicators (e.g., metal exports or banking revenue).

\subsubsection{Other statistical procedures (e.g., data adjustments and transformations, and statistical analysis) employ sound statistical techniques}

As shown in Table 1, a range of adjustments is made to account for shortcomings identified in the source data. Many of these shortcomings are caused by factors that are difficult to 
measure and, even if feasible, would require costly data collection to solve. Accordingly, adjustment factors are used to account for the shortcomings in data, that is, discretionary ratio adjustments based on an assessment of the evidence, rather than direct measurements. While it is generally better to make adjustments than to leave data known to be inadequate, the lack of a strong basis from collected data adds a range of uncertainty to balance of payments statistics.

For example, adjustments have been made to exports and imports of goods. Exports were adjusted upwards by 2 percent and imports by 11 percent in 2005, for instance. However, as the customs administration was improved and the value added tax introduced, it was considered that the understatement of values had declined, so that in 2006 , there is no adjustment for exports and only a seven percent adjustment for imports. The CBBH staff have written a paper which shows the adjustments and how they have changed over time. The paper cites a range of evidence, for example, from reports and comments by the Indirect Tax Authority, an IMF Selected Economic Issues paper, and a European Union report, to support the need for adjustment. While the sizes of the adjustments are discretionary and subject to a high range of uncertainty, they seem reasonable in relation to the geographical and institutional realities to which the statistical system is subject, and consistent with the public comments and observation of the domestic and international experts. By providing information about the size and reasons for the adjustments, the $\mathrm{CBBH}$ allows users make their own judgments and do sensitivity testing.

Other examples of adjustments include import price adjustment, freight on imports provided by resident carriers, and remittances outside the banking system.

Seasonally adjusted data on exports and imports of merchandise are produced by using the United States Bureau of Census program ARIMA X-11. Other series were found to have a high degree of irregular element, so that they are not suited to seasonal adjustment.

Recommendation: Continue to review assumptions and collect additional data to replace them, where possible.

\subsection{Assessment and validation of intermediate data and statistical outputs}

\subsubsection{Intermediate results are validated against other information where applicable}

Information from the press on acquisitions and major new projects is used to verify highvalue direct and other transactions.

\subsubsection{Statistical discrepancies in intermediate data are assessed and investigated}

The international investment position data are compared to the corresponding income and financial transactions data. 


\subsubsection{Statistical discrepancies and other potential indicators of problems in statistical outputs are investigated}

The net errors and omissions value is monitored closely. The CBBH considers that credits tend to be understated, most likely for services rendered to nonresidents and remittances in the form of cash.

Trade data are compared with partner data, although the results tend to be lower than $\mathrm{CBBH}$ data. Because many goods are transshipped through Croatia and Serbia, identification of countries of origin and final destination make reconciliation particularly difficult in the case of $\mathrm{BiH}$.

\subsection{Revision studies}

3.5.1 Studies and analyses of revisions are carried out routinely and used internally to inform statistical processes (see also 4.3.3)

The aggregates are compared with data for the same quarter reported in the previous publication. Revisions are verified, and explanations are noted.

Studies of long-term patterns in revisions have not yet been undertaken. That is, the value of an item as originally published for a particular period can be compared with the revised value for the same item and period as shown one, two, three, or five years later. For example, if changes from the first preliminary value published to final value were usually upward, it suggests that there was a downward bias in the preliminary data.

Recommendation: Undertake a revision study of long-term patterns in main aggregates.

\section{Serviceability}

\subsection{Periodicity and timeliness}

\subsubsection{Periodicity follows dissemination standards}

Balance of payments data are produced quarterly, which exceeds the GDDS recommendation of annual data and in line with the Special Data Dissemination Standard requirement of quarterly data.

\subsubsection{Timeliness follows dissemination standards}

Balance of payments data are generally released within three months after the end of the reference quarter. This performance is better than the GDDS recommendation of six months, and consistent with the Special Data Dissemination Standard requirement.

\subsection{Consistency}




\subsubsection{Statistics are consistent within the dataset}

Checks ensure that sub-items are consistent with aggregate data. Annual data are derived as totals of quarterly data. The item net errors and omissions is identified in published data. In recent years, the annual values have been fairly large, positive, and stable. The values are more volatile in the quarterly estimates than the annual estimates. The staff monitor the size of the item, and are aware that it is caused by the problems in data sources identified in 3.1.1 and 3.1.2 above.

International investment position data were prepared for 2004 and 2005 for internal use. These data were reconciled with transaction data over the period.

\subsubsection{Statistics are consistent or reconcilable over a reasonable period of time}

Time series data are available back to 1998 (annually) and 2001 (quarterly). When new methods are introduced, so far, the data have been revised all the way back to 1998 to allow a consistent time series. However, in future, it is planned to revise a shorter period, while still allowing a consistent time series of several years. Any breaks in the series will be identified by notes or footnotes.

\subsubsection{Statistics are consistent or reconcilable with those obtained through other data sources and/or statistical frameworks}

The same data sources are used for monetary, government finance, and public external debt statistics, so balance of payments data are consistent with these statistics. However, government finance data differ from balance of payments in that they do not take into account disbursements under donor-funded projects. The CBBH balance of payments staff are aware of this difference and explain it to users.

Data for exports and imports are derived from customs statistics. It is possible to show the derivation of trade data on a balance of payments basis from BHAS trade data and other adjustments (such as for general trade, import valuation, undercoverage, and undervaluation.

Data for gross national income and gross national disposable income have been prepared by BHAS on the basis of CBBH data on income and transfers and, so, are fully consistent. National accounts estimates of expenditure on GDP are being prepared by BHAS and it is planned to use balance of payments data on exports and imports of goods and services, so the data will be consistent.

\subsection{Revision policy and practice}

\subsubsection{Revisions follow a regular and transparent schedule}


$\mathrm{CBBH}$ has a written statement of its regular revision cycle which is available on request. In addition to the predictable revisions cycle reflecting arrival of data, other revisions are made as methods and sources are refined.

Recommendation: Include the revisions timetable, with a brief explanation of the circumstances under which unscheduled revisions will be made, on the CBBH website.

\subsubsection{Preliminary and/or revised data are clearly identified}

A footnote in the $C B B H$ Bulletin is used to identify preliminary data. The revisions policy also identifies which items are subject to revision.

\subsubsection{Studies and analyses of revisions are made public (see also 3.5.1)}

Information on the causes of revisions prepared for internal purposes would be made available if requested.

The major revisions made in 2005 were explained in a note included on the CBBH website. Other less significant revisions are only publicized in the form of brief footnotes below the table, while minor revisions are not explained in publications or on the website.

Recommendation: Publish existing internal notes on revision. The commentary could also mention the effect of the latest revisions on major aggregates.

\section{Accessibility}

\subsection{Data accessibility}

5.1.1 Statistics are presented in a way that facilitates proper interpretation and meaningful comparisons (layout and clarity of text, tables, and charts)

Data are available in tables in the CBBH's Bulletin (published quarterly) and Annual Report, both available in local languages and English on the CBBH website. Charts and commentary in four languages are provided. Additionally, more detailed tables are provided online.

\subsubsection{Dissemination media and format are adequate}

Data are included in the quarterly CBBH Bulletin, which covers a range of macroeconomic statistics. The Bulletin, balance of payments publications, and Excel spreadsheets showing complete time series of balance of payments data are available on the $\mathrm{CBBH}$ website.

\subsubsection{Statistics are released on a preannounced schedule}

The data are released according to an advance release calendar on the $\mathrm{CBBH}$ website. The release dates specify a deadline beyond which data will not be released, and data have always 
been released before that time. Some users were not aware of this information, as evidenced by a user survey conducted by the mission (see appendix III).

\subsubsection{Statistics are made available to all users at the same time}

Statistics are first published on the $\mathrm{CBBH}$ website, which is publicly available to all users at the same time.

\subsubsection{Statistics not routinely disseminated are made available upon request}

Data are made available on request free of charge. The ability to supply data is only limited by confidentiality and the level of detail that is collected.

\subsection{Metadata accessibility}

5.2.1 Documentation on concepts, scope, classifications, basis of recording, data sources, and statistical techniques is available, and differences from internationally accepted standards, guidelines, or good practices are annotated

The CBBH website has notes on methodology for various statistics. The notes on balance of payments and international investment position statistics comprise 11 pages in English with versions also available in three local languages. While the User Survey indicated that some users were not yet aware of this information, it is readily available. In addition, notes are included in the IMF Balance of Payments Statistics Yearbook. A paper providing more detailed information on adjustments has been prepared and is made available to users on request.

\subsubsection{Levels of detail are adapted to the needs of the intended audience}

The level of detail in metadata is adequate for broad general users. For the more sophisticated users, additional information on the size and sources of the adjustments to raw data is of particular interest, to allow users to assess their appropriateness and do sensitivity testing. While only available on request at the time of the mission, the $\mathrm{CBBH}$ stated its intention to make this information available on its website in future.

Recommendation: More information on the size and basis of adjustments should be made available on the $C B B H$ website.

\subsection{Assistance to users}

\subsubsection{Contact points for each subject field are publicized}

CBBH publications and its internet website provide contact information to data users for sending comments, queries, and requests. The contact options include telephone and fax numbers, as well as mail and e-mail addresses. Comments, queries, and requests are addressed promptly and monitored by management. 
5.3.2 Catalogs of publications, documents, and other services, including information on any charges, are widely available

A listing of available publications and tables is shown in the CBBH website. It is very visible and accessible as there is a tab called "Publications" in the index on the left side of the first webpage. From that link, it is easy to identify and access all CBBH statistical publications, as well as gain information on how to order hardcopy versions. A formal catalogue is considered unnecessary due to the small number of publications and the use of a more flexible and accessible alternative on the website. 
Table 5. Bosnia and Herzegovina: Data Quality Assessment Framework (July 2003):

Summary of Results for Balance of Payments

(Compiling Agency: Central Bank of Bosnia and Herzegovina)

Key to symbols: NA = Not Applicable; $\mathrm{O}=$ Practice Observed; $\mathrm{LO}=$ Practice Largely Observed; LNO = Practice Largely Not Observed; NO = Practice Not Observed; GDDS = Complies with GDDS Criteria

\begin{tabular}{|c|c|c|c|c|c|c|c|}
\hline \multirow{2}{*}{ Element } & \multirow{2}{*}{ NA } & \multicolumn{4}{|c|}{ Assessment } & \multirow{2}{*}{ Comments on Assessment } & \multirow{2}{*}{ Plans for Improvement and Target Dates } \\
\hline & & ( & LO & $\mathrm{LNO}$ & $\mathrm{NO}$ & & \\
\hline
\end{tabular}

\section{Prerequisites of quality}

\begin{tabular}{|c|c|c|c|c|}
\hline 0.1 Legal and institutional environment & $\mathrm{X}$ & & $\begin{array}{l}\text { Government agencies other than the } \\
\text { CBBH could be sources of information } \\
\text { but these alternatives have not been } \\
\text { developed. }\end{array}$ & $\begin{array}{l}\text { Continue to liaise with other agencies to keep } \\
\text { them aware of balance of payments statistics } \\
\text { needs (medium-term). }\end{array}$ \\
\hline 0.2 Resources & & $\mathrm{X}$ & $\begin{array}{l}\text { The number of employees is insufficient } \\
\text { and specialized statistical collection } \\
\text { software is not available. }\end{array}$ & $\begin{array}{l}\text { Strengthen and increase resources for work on } \\
\text { balance of payments statistics (medium-term). }\end{array}$ \\
\hline 0.3 Relevance & $\mathrm{X}$ & & $\begin{array}{l}\text { No formal monitoring of user needs has } \\
\text { been undertaken. }\end{array}$ & $\begin{array}{l}\text { Establish formal procedures, such as } \\
\text { interviews or surveys (short-term). }\end{array}$ \\
\hline 0.4 Other quality management & $\mathrm{X}$ & & $\begin{array}{l}\text { Training and communication in main } \\
\text { units is limited. }\end{array}$ & $\begin{array}{l}\text { Improve training and communication for main } \\
\text { units (medium-term). }\end{array}$ \\
\hline
\end{tabular}

\section{Assurances of integrity}

1.1 Professionalism

1.2 Transparency

1.3 Ethical standards

\begin{tabular}{|l|l|l|l|l}
$\mathrm{X}$ & & & \\
$\mathrm{X}$ & & & \\
$\mathrm{X}$ & & & & \\
\hline
\end{tabular}

\section{Methodological soundness}

\subsection{Concepts and definitions}

2.2 Scope

2.3 Classification/sectorization

Basis for recording

\begin{tabular}{c|c|c|c|}
$\mathrm{X}$ & & & \\
$\mathrm{X}$ & & & \\
& $\mathrm{X}$ & & \\
& $\mathrm{X}$ & & \\
& & &
\end{tabular}

Classification of intercompany loans and Reclassify items in line with BPM5 (shortcapital transfers differs from international standards.

Some data sources use different timing Identify variations in timing of recording and of recording and valuation bases. term). valuation for large transactions. Short-term. Update cif-fob factor (medium-term). 


\begin{tabular}{|c|c|c|c|c|c|}
\hline \multicolumn{6}{|l|}{ 3. Accuracy and reliability } \\
\hline 3.1 Source data & & & $\mathrm{X}$ & $\begin{array}{l}\text { Incomplete coverage of trade, travel, } \\
\text { compensation of employees, and } \\
\text { remittances. }\end{array}$ & $\begin{array}{l}\text { Develop additional data sources as resources } \\
\text { become available (medium- to long-term). }\end{array}$ \\
\hline $\begin{array}{l}\text { 3.2 Assessment of source data } \\
\text { 3.3 } \text { Statistical techniques }\end{array}$ & $\mathrm{X}$ & $\mathrm{X}$ & & $\begin{array}{l}\text { A range of adjustments made without } \\
\text { strong survey basis. }\end{array}$ & $\begin{array}{l}\text { Develop additional data sources as resources } \\
\text { become available (medium- to long-term). }\end{array}$ \\
\hline $\begin{array}{l}\text { 3.4 Assessment and validation of inter- } \\
\text { mediate data and statistical outputs } \\
\text { 3.5 Revision studies }\end{array}$ & $\mathrm{X}$ & $\mathrm{X}$ & & $\begin{array}{l}\text { Studies of long-term patterns in } \\
\text { revisions have not been undertaken. }\end{array}$ & $\begin{array}{l}\text { Undertake study of patterns of revisions and } \\
\text { use information to correct for any biases that } \\
\text { are identified (medium-term). }\end{array}$ \\
\hline \multicolumn{6}{|l|}{ 4. Serviceability } \\
\hline $\begin{array}{l}\text { 4.1 Periodicity and timeliness } \\
\text { 4.2 Consistency } \\
\text { 4.3 Revision policy and practice }\end{array}$ & $\begin{array}{l}\mathrm{X} \\
\mathrm{X}\end{array}$ & $\mathrm{X}$ & & Large net errors and omissions. & $\begin{array}{l}\text { Develop additional data sources as resources } \\
\text { become available (medium- to long-term). }\end{array}$ \\
\hline \multicolumn{6}{|l|}{ 5. Accessibility } \\
\hline $\begin{array}{l}\text { 5.1 Data accessibility } \\
\text { 5.2 Metadata accessibility } \\
\text { 5.3 Assistance to users }\end{array}$ & $\begin{array}{l}\mathrm{X} \\
\mathrm{X}\end{array}$ & $\mathrm{X}$ & & $\begin{array}{l}\text { Metadata on adjustments not published } \\
\text { or notified. }\end{array}$ & $\begin{array}{l}\text { Include additional paper on website (short- } \\
\text { term). }\end{array}$ \\
\hline
\end{tabular}




\section{Appendix I. Summary Of The General Data Dissemination System (GDDS)}

\section{Data coverage, periodicity, and timeliness}

Dissemination of reliable, comprehensive, and timely economic, financial, and sociodemographic data is essential to the transparency of macroeconomic performance and policy. The GDDS contains specific recommendations concerning coverage, periodicity, and timeliness for comprehensive frameworks as well as for data categories and indicators.

\section{Quality}

Data quality must have a high priority. Data users must be provided with information to assess quality and quality improvements. The GDDS recommends:

- $\quad$ dissemination of documentation on methodology and sources used in preparing statistics; and

- $\quad$ dissemination of component detail, reconciliations with related data, and statistical frameworks that support statistical cross-checks and provide assurance of reasonableness.

\section{Integrity}

To fulfill the purpose of providing the public with information, official statistics must have the confidence of their users. In turn, confidence in the statistics ultimately becomes a matter of confidence in the objectivity and professionalism of the agency producing the statistics. Transparency of practices and procedures is a key factor in creating this confidence. The GDDS, therefore, recommends:

- dissemination of the terms and conditions under which official statistics are produced, including those relating to the confidentiality of individually identifiable information;

- $\quad$ identification of internal government access to data before release;

- $\quad$ identification of ministerial commentary on the occasion of statistical releases; and

- $\quad$ provision of information about revision and advance notice of major changes in methodology.

\section{Access to the public}

Dissemination of official statistics is an essential feature of statistics as a public good. Ready and equal access by the public are principal requirements. The GDDS recommends

- dissemination of advance release calendars; and 
- $\quad$ simultaneous release to all interested parties.

\section{Plans for improvement}

The GDDS recommends that plans for improvement be developed for all areas in which shortcomings exist and that these plans be disseminated.

The GDDS also recommends that any needs for assistance be identified in the metadata. This may also be helpful for donors and technical assistance providers to prioritize their activities.

For each participating member country, the GDDS metadata provide descriptions of the dimensions listed above, together with plans for improvement and needs for assistance. This information is posted on the DSBB; participating countries are encouraged to also post the metadata on their national websites.

Source: Guide to the GDDS, March 2002 (http://dsbb.imf.org). 


\section{Appendix II. Data Quality Assessment Framework-Generic Framework (July 2003 Framework)}

\begin{tabular}{|c|c|c|}
\hline Quality Dimensions & Elements & Indicators \\
\hline \multirow[t]{10}{*}{$\begin{array}{l}\text { 0. Prerequisites of } \\
\text { quality }\end{array}$} & \multirow{4}{*}{$\begin{array}{l}\text { 0.1 Legal and institutional } \\
\text { environment-The environment } \\
\text { is supportive of statistics }\end{array}$} & $\begin{array}{l}\text { 0.1.1 The responsibility for collecting, processing, and } \\
\text { disseminating the statistics is clearly specified. }\end{array}$ \\
\hline & & $\begin{array}{l}\text { 0.1.2 Data sharing and coordination among data- } \\
\text { producing agencies are adequate. }\end{array}$ \\
\hline & & $\begin{array}{l}\text { 0.1.3 Individual reporters' data are to be kept } \\
\text { confidential and used for statistical purposes only. }\end{array}$ \\
\hline & & $\begin{array}{l}\text { 0.1.4 Statistical reporting is ensured through legal } \\
\text { mandate and/or measures to encourage response. }\end{array}$ \\
\hline & \multirow{2}{*}{$\begin{array}{l}\text { 0.2 Resources-Resources are } \\
\text { commensurate with needs of } \\
\text { statistical programs. }\end{array}$} & $\begin{array}{l}\text { 0.2.1 Staff, facilities, computing resources, and } \\
\text { financing are commensurate with statistical programs. }\end{array}$ \\
\hline & & $\begin{array}{l}\text { 0.2.2 Measures to ensure efficient use of resources are } \\
\text { implemented. }\end{array}$ \\
\hline & $\begin{array}{l}\text { 0.3 Relevance-Statistics cover } \\
\text { relevant information on the } \\
\text { subject field. }\end{array}$ & $\begin{array}{l}\text { 0.3.1 The relevance and practical utility of existing } \\
\text { statistics in meeting users' needs are monitored. }\end{array}$ \\
\hline & \multirow{3}{*}{$\begin{array}{l}\text { 0.4 Other quality } \\
\text { management-Quality is a } \\
\text { cornerstone of statistical work. }\end{array}$} & 0.4.1 Processes are in place to focus on quality. \\
\hline & & $\begin{array}{l}0.4 .2 \text { Processes are in place to monitor the quality of } \\
\text { the statistical program. }\end{array}$ \\
\hline & & $\begin{array}{l}\text { 0.4.3 Processes are in place to deal with quality } \\
\text { considerations in planning the statistical program. }\end{array}$ \\
\hline \multirow{8}{*}{$\begin{array}{l}\text { 1. Assurances of } \\
\text { integrity } \\
\text { The principle of } \\
\text { objectivity in the } \\
\text { collection, } \\
\text { processing, and } \\
\text { dissemination of } \\
\text { statistics is firmly } \\
\text { adhered to. }\end{array}$} & \multirow{3}{*}{$\begin{array}{l}\text { 1.1 Professionalism-Statistical } \\
\text { policies and practices are } \\
\text { guided by professional } \\
\text { principles. }\end{array}$} & 1.1.1 Statistics are produced on an impartial basis. \\
\hline & & $\begin{array}{l}\text { 1.1.2 Choices of sources and statistical techniques as } \\
\text { well as decisions about dissemination are informed } \\
\text { solely by statistical considerations. }\end{array}$ \\
\hline & & $\begin{array}{l}\text { 1.1.3 The appropriate statistical entity is entitled to } \\
\text { comment on erroneous interpretation and misuse of } \\
\text { statistics. }\end{array}$ \\
\hline & \multirow[t]{4}{*}{$\begin{array}{l}\text { 1.2 Transparency-Statistical } \\
\text { policies and practices are } \\
\text { transparent. }\end{array}$} & $\begin{array}{l}\text { 1.2.1 The terms and conditions under which statistics } \\
\text { are collected, processed, and disseminated are available } \\
\text { to the public. }\end{array}$ \\
\hline & & $\begin{array}{l}1.2 .2 \text { Internal governmental access to statistics prior to } \\
\text { their release is publicly identified. }\end{array}$ \\
\hline & & $\begin{array}{l}\text { 1.2.3 Products of statistical agencies/units are clearly } \\
\text { identified as such. }\end{array}$ \\
\hline & & $\begin{array}{l}\text { 1.2.4 Advance notice is given of major changes in } \\
\text { methodology, source data, and statistical techniques. }\end{array}$ \\
\hline & $\begin{array}{l}1.3 \text { Ethical standards-Policies } \\
\text { and practices are guided by } \\
\text { ethical standards. }\end{array}$ & $\begin{array}{l}\text { 1.3.1 Guidelines for staff behavior are in place and are } \\
\text { well known to the staff. }\end{array}$ \\
\hline
\end{tabular}




\begin{tabular}{|c|c|c|}
\hline Quality Dimensions & Elements & Indicators \\
\hline $\begin{array}{l}\text { 2. Methodological } \\
\text { soundness } \\
\text { The methodological } \\
\text { basis for the } \\
\text { statistics follows } \\
\text { internationally } \\
\text { accepted standards, } \\
\text { guidelines, or good } \\
\text { practices. }\end{array}$ & $\begin{array}{l}\text { 2.1 Concepts and definitions-- } \\
\text { Concepts and definitions used } \\
\text { are in accord with } \\
\text { internationally accepted } \\
\text { statistical frameworks. } \\
\mathbf{2 . 2} \text { Scope-The scope is in } \\
\text { accord with internationally } \\
\text { accepted standards, guidelines, } \\
\text { or good practices. } \\
\mathbf{2 . 3} \text { Classification/ } \\
\text { sectorization-Classification } \\
\text { and sectorization systems are in } \\
\text { accord with internationally } \\
\text { accepted standards, guidelines, } \\
\text { or good practices. } \\
\mathbf{2 . 4} \text { Basis for recording-Flows } \\
\text { and stocks are valued and } \\
\text { recorded according to } \\
\text { internationally accepted } \\
\text { standards, guidelines, or good } \\
\text { practices }\end{array}$ & $\begin{array}{l}\text { 2.1.1 The overall structure in terms of concepts and } \\
\text { definitions follows internationally accepted standards, } \\
\text { guidelines, or good practices. } \\
\text { 2.2.1 The scope is broadly consistent with } \\
\text { internationally accepted standards, guidelines, or good } \\
\text { practices. } \\
\text { 2.3.1 Classification/sectorization systems used are } \\
\text { broadly consistent with internationally accepted } \\
\text { standards, guidelines, or good practices. }\end{array}$ \\
\hline $\begin{array}{l}\text { 3. Accuracy and } \\
\text { reliability } \\
\text { Source data and } \\
\text { statistical techniques } \\
\text { are sound and } \\
\text { statistical outputs } \\
\text { sufficiently portray } \\
\text { reality }\end{array}$ & $\begin{array}{l}\text { 3.3 Statistical techniques-- } \\
\text { Statistical techniques employed } \\
\text { conform to sound statistical } \\
\text { procedures } \\
\text { 3.4 Assessment and validation } \\
\text { of intermediate data and } \\
\text { statistical outputs- } \\
\text { Intermediate results and } \\
\text { statistical outputs are regularly } \\
\text { assessed and validated. } \\
\text { 3.5 Revision studies- } \\
\text { Revisions, as a gauge of } \\
\text { reliability, are tracked and } \\
\text { mined for the information they } \\
\text { may provide. }\end{array}$ & $\begin{array}{l}\text { 3.1.1 Source data are obtained from comprehensive } \\
\text { data collection programs that take into account } \\
\text { country-specific conditions. } \\
\text { 3.1.2 Source data reasonably approximate the } \\
\text { definitions, scope, classifications, valuation, and time } \\
\text { of recording required. } \\
\text { 3.1.3 Source data are timely. } \\
\text { 3.2.1 Source data-including censuses, sample } \\
\text { surveys, and administrative records-are routinely } \\
\text { assessed, e.g., for coverage, sample error, response } \\
\text { error, and nonsampling error; the results of the } \\
\text { assessments are monitored and made available to guide } \\
\text { statistical processes. } \\
\text { 3.3.1 Data compilation employs sound statistical } \\
\text { techniques to deal with data sources. } \\
\text { 3.3.2 Other statistical procedures (e.g., data } \\
\text { adjustments and transformations, and statistical } \\
\text { analysis) employ sound statistical techniques. } \\
\text { 3.4.1 Intermediate results are validated against other } \\
\text { information where applicable. } \\
\text { 3.4.2 Statistical discrepancies in intermediate data are } \\
\text { assessed and investigated. } \\
\text { 3.4.3 Statistical discrepancies and other potential } \\
\text { indicators or problems in statistical outputs are } \\
\text { investigated. } \\
\text { 3.5.1 Studies and analyses of revisions are carried out } \\
\text { routinely and used internally to inform statistical } \\
\text { processes (see also } 4.3 .3 \text { ). }\end{array}$ \\
\hline
\end{tabular}




\begin{tabular}{|c|c|c|}
\hline Quality Dimensions & Elements & Indicators \\
\hline $\begin{array}{l}\text { 4. Serviceability } \\
\text { Statistics, with } \\
\text { adequate periodicity } \\
\text { and timeliness, are } \\
\text { consistent and } \\
\text { follow a predictable } \\
\text { revisions policy. }\end{array}$ & 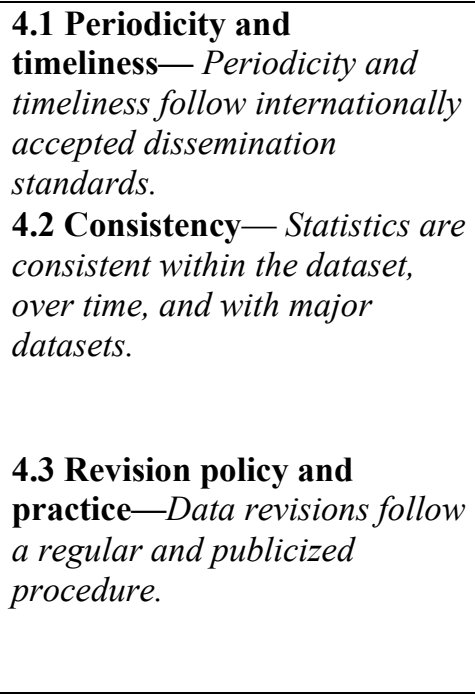 & $\begin{array}{l}\text { 4.2.1 Statistics are consistent within the dataset. } \\
\text { 4.2.2 Statistics are consistent or reconcilable over a } \\
\text { reasonable period of time. } \\
\text { 4.2.3 Statistics are consistent or reconcilable with those } \\
\text { obtained through other data sources and/or statistical } \\
\text { frameworks. } \\
\text { 4.3.1 Revisions follow a regular and transparent } \\
\text { schedule. } \\
\text { 4.3.2 Preliminary and/or revised data are clearly } \\
\text { identified. } \\
\text { 4.3.3 Studies and analyses of revisions are made public } \\
\text { (see also 3.5.1). }\end{array}$ \\
\hline $\begin{array}{l}\text { 5. Accessibility } \\
\text { Data and metadata } \\
\text { are easily available } \\
\text { and assistance to } \\
\text { users is adequate. }\end{array}$ & $\begin{array}{l}\text { 5.1 Data accessibility- } \\
\text { Statistics are presented in a } \\
\text { clear and understandable } \\
\text { manner, forms of dissemination } \\
\text { are adequate, and statistics are } \\
\text { made available on an impartial } \\
\text { basis. } \\
\text { 5.2 Metadata accessibility- } \\
\text { Up-to-date and pertinent } \\
\text { metadata are made available. }\end{array}$ & $\begin{array}{l}\text { 5.1.1 Statistics are presented in a way that facilitates } \\
\text { proper interpretation and meaningful comparisons } \\
\text { (layout and clarity of text, tables, and charts). } \\
\text { 5.1.2 Dissemination media and format are adequate. } \\
\text { 5.1.3 Statistics are released on a preannounced } \\
\text { schedule. } \\
\text { 5.1.4 Statistics are made available to all users at the } \\
\text { same time. } \\
\text { 5.1.5 Statistics not routinely disseminated are made } \\
\text { available upon request. } \\
\text { 5.2.1 Documentation on concepts, scope, } \\
\text { classifications, basis of recording, data sources, and } \\
\text { statistical techniques is available, and differences from } \\
\text { internationally accepted standards, guidelines, or good } \\
\text { practices are annotated. } \\
\text { 5.2.2 Levels of detail are adapted to the needs of the } \\
\text { intended audience. } \\
\text { 5.3.1 Contact points for each subject field are } \\
\text { publicized. } \\
\text { 5.3.2 Catalogs of publications, documents, and other } \\
\text { services, including information on any charges, are } \\
\text { widely available. }\end{array}$ \\
\hline
\end{tabular}




\section{Appendix III. Users' Survey}

\section{Summary of Results of Survey of Data Users}

As an input to the Fund's assessment of the quality of official statistics produced by Bosnia and Herzegovina, with assistance from the authorities, the mission conducted an informal survey of key users of macroeconomic statistics. Questionnaires were sent to a broad range of users, including ministries, academics and banks, as well as international organizations and the media.

Users were asked to evaluate the coverage, periodicity, timeliness, dissemination practices, accessibility, and overall quality of the official statistics produced by the Central Bank of Bosnia and Herzegovina and the Bosnia and Herzegovina Agency for Statistics. Of the 58 targeted users, $23-40$ percent submitted responses. Among these respondents, the two official statistical datasets most widely used were the consumer price index and balance of payments statistics; notwithstanding, more than half indicated that they also regularly used national accounts and monetary statistics. The vast majority of the respondents rely on firsthand information from official sources, and the main uses of the official statistics are (i) long-term policy formulation based on economic trends, (ii) short-term decisions based on current economic developments, and (iii) comparing Bosnia and Herzegovina's economic developments to those in other countries.

On a five point scale $(1=$ poor and $5=$ excellent $)$, the average rating for the overall quality of the official statistics for all sectors was 3.2. Among the averages for each of the main datasets there was a one point difference between the sector that scored the highest (monetary - 3.9) and the one that scored the lowest (national accounts - 2.9).

Though acknowledging the unique administrative and institutional situation that exists across sectors, 39 percent of all respondents felt that Bosnia and Herzegovina's statistics were worse than those disseminated by neighboring countries, while only 13 percent felt that they were better. Even though 70 percent of the users noted their satisfaction with the methodological soundness of the official statistics, 29 percent felt that the statistics were not entirely reliable, since, in their view, they did not accurately reflect the true economic situation of the country. Many attributed the apparent inaccuracies of published data to several biases. Among them were the lack of seasonal adjustments, underreporting of some sectors and, in the case of balances of payments, underestimated remittances.

Overall, 76 percent of respondents seemed satisfied with the coverage offered in the official statistics of Bosnia and Herzegovina. About 68 percent of users appeared to be satisfied with the levels of detail generally provided, with a few expressing a desire for additional information in some areas such as the Balance of Payments and Government Finance. While as many as 86 percent of users appeared to be content with the periodicity of published data, with respect to timeliness, however, satisfaction levels decreased to about 69 percent, with several users expressing the need for compilers to reduce the lag in the publication of National Accounts and Government Finance Statistics. 
With respect to dissemination practices, as many as 65 percent of respondents indicated that they were unaware of the existence of any official calendar of release dates. Regarding revisions of previously published data, more than half of all users felt that not enough useful information was provided along with newly released statistics.

Accessibility to official information was considered to be broadly satisfactory. Despite the lag in some series and absence of historical data in others, 85 percent of respondents stated that they could easily access official statistics, while about 70 percent felt that they could easily find the related methodological and explanatory information they needed on a regular basis, and that this information was sufficiently clear and detailed enough. The most popular means of obtaining Bosnia and Herzegovina's statistics was through hard copy publications, with about 78 percent of the respondents relying on this method; a similar percentage obtained statistics via official websites. Respondents appeared to generally appreciate that $a d$ hoc requests were handled satisfactorily.

Many respondents took advantage of the survey to provide additional comments and suggestions concerning Bosnia and Herzegovina's statistics. Among several of these, which are summarized below, users expressed interest in receiving statistics on tourism and shortterm indicators of economic activity, the implementation of more frequent censuses, accessing more accurate metadata for all sectors, the publication of more frequent data on national accounts and labor statistics, and the need for appropriate indicators to measure inflation for the country as a whole.

The comments, shown below following Tables 8 and 9, are grouped into five categories: (i) Coverage and Detail, (ii) Periodicity and Timeliness, (iii) Dissemination Practices and Accessibility, (iv) Methodological Soundness, Accuracy and Reliability, and (v) General Comments. 
Table 6. Bosnia and Herzegovina:

Questionnaire Results Analyzed by Type of User

March 2007

\begin{tabular}{|l|c|c|c|}
\hline \multicolumn{1}{|c|}{ Respondent } & Sent & Received & $\begin{array}{c}\text { Percent Received } \\
\text { Within Each Group }\end{array}$ \\
\hline $\begin{array}{l}\text { 1. Public Sector (central bank, } \\
\text { ministries, agencies, nonfinancial } \\
\text { corporations) }\end{array}$ & 24 & 10 & $42 \%$ \\
\hline $\begin{array}{l}\text { 2. Financial Sector } \\
\text { 3. Private Nonfinancial Corporations }\end{array}$ & 13 & 5 & $38 \%$ \\
\hline $\begin{array}{l}\text { 4. Embassies and International } \\
\text { Organizations }\end{array}$ & 11 & 5 & $45 \%$ \\
\hline 5. Universities & 5 & 0 & $5 \%$ \\
\hline 6. Media & 58 & 23 & $40 \%$ \\
\hline Total & 6 & 1 & $50 \%$ \\
\hline
\end{tabular}


Table 7. Bosnia and Herzegovina:

Results of Users' Survey

(in percentage of total responses)

March 2007

General Information About

Uses of Official Macroeconomic Statistics of Bosnia and Herzegovina

\begin{tabular}{|c|c|c|c|}
\hline \multicolumn{4}{|c|}{ Which official statistics do you use regularly? } \\
\hline & \multicolumn{2}{|c|}{ National accounts (NA) } & $57 \%$ \\
\hline & \multicolumn{2}{|c|}{ Prices } & $61 \%$ \\
\hline & \multicolumn{2}{|c|}{ Government finance statistics (GFS) } & $48 \%$ \\
\hline & \multicolumn{2}{|c|}{ Monetary statistics (Monetary) } & $57 \%$ \\
\hline & \multicolumn{2}{|c|}{ Balance of payments (BOP) } & $61 \%$ \\
\hline & \multicolumn{2}{|c|}{ Other: } & \\
\hline & 1.6.1 & Production indices & $48 \%$ \\
\hline & 1.6.2 & Labor market & $39 \%$ \\
\hline & 1.6.3 & Merchandise trade & $48 \%$ \\
\hline & 1.6.4 & International reserves and foreign currency liquidity & $35 \%$ \\
\hline & 1.6.5 & External debt & $39 \%$ \\
\hline & 1.6.6 & International investment position & $48 \%$ \\
\hline & 1.6.7 & Other & $0 \%$ \\
\hline
\end{tabular}

2 Where do you obtain the official statistics?

\begin{tabular}{|c|c|c|}
\hline 2.1 & Official press releases and publications on macroeconomic statistics & $96 \%$ \\
\hline 2.2 & Private sector summaries and analyses & $13 \%$ \\
\hline 2.3 & Official policy papers & $61 \%$ \\
\hline 2.4 & Publications from international organizations about the country & $43 \%$ \\
\hline 2.5 & Other sources & $9 \%$ \\
\hline
\end{tabular}

3 Do you refer to official descriptions of the sources and methods that were used to compile the official statistics?

\begin{tabular}{|c|c|c|c|}
\hline & \multicolumn{2}{|c|}{ Yes } & $\begin{array}{l}73 \% \\
27 \%\end{array}$ \\
\hline & & & $100 \%$ \\
\hline 4 & \multicolumn{3}{|c|}{ For what purposes do you use the official statistics? } \\
\hline & 4.1 & Analysis of current developments for short-term decision making & $57 \%$ \\
\hline & 4.2 & Analysis of trends for longer-term policy formulation? & $65 \%$ \\
\hline & 4.3 & Econometric model building and forecasting & $22 \%$ \\
\hline & 4.4 & Economic research & $43 \%$ \\
\hline & 4.5 & Comparison with economic developments in other countries & $57 \%$ \\
\hline & 4.6 & General economic background & $48 \%$ \\
\hline & 4.7 & Other & $0 \%$ \\
\hline
\end{tabular}




\begin{tabular}{|c|c|c|c|c|c|}
\hline NA & CPI & GFS & MS & BOP & Other \\
\hline
\end{tabular}

Averages

\section{Coverage and detail}

5.1 In general, are you satisfied with the coverage of official statistics?

\begin{tabular}{|c|c|c|c|c|c|c|}
\hline Yes & $65 \%$ & $89 \%$ & $69 \%$ & $87 \%$ & $79 \%$ & $57 \%$ \\
No & $35 \%$ & $11 \%$ & $31 \%$ & $13 \%$ & $21 \%$ & $43 \%$ \\
\hline
\end{tabular}

5.2 In general, are you satisfied with the official statistics in terms of their level of detail?

\begin{tabular}{|c|c|c|c|c|c|c|}
\hline Yes & $56 \%$ & $88 \%$ & $53 \%$ & $75 \%$ & $73 \%$ & $50 \%$ \\
No & $44 \%$ & $12 \%$ & $47 \%$ & $25 \%$ & $27 \%$ & $50 \%$ \\
\hline & $100 \%$ & $100 \%$ & $100 \%$ & $100 \%$ & $100 \%$ & $100 \%$ \\
\hline
\end{tabular}

\begin{tabular}{|c|}
\hline $68 \%$ \\
$32 \%$ \\
\hline $100 \%$ \\
\hline
\end{tabular}

6 Periodicity and timeliness

6.1 Are you satisfied with the frequency of compilation of the official statistics (e.g., weekly, monthly, quarterly, annual)?

\begin{tabular}{|c|c|c|c|c|c|c|}
\hline Yes & $65 \%$ & $94 \%$ & $82 \%$ & $93 \%$ & $93 \%$ & $100 \%$ \\
No & $35 \%$ & $6 \%$ & $18 \%$ & $7 \%$ & $7 \%$ & $0 \%$ \\
\hline
\end{tabular}

\begin{tabular}{|c|}
\hline $86 \%$ \\
$14 \%$ \\
\hline $100 \%$ \\
\hline
\end{tabular}

In general, do you consider that the official statistics are disseminated with the appropriate

6.2 timeliness (the time lag after the period to which they pertain, e.g., 60 days after the reference period)?

\begin{tabular}{|c|c|c|c|c|c|c|}
\hline Yes & $41 \%$ & $88 \%$ & $59 \%$ & $80 \%$ & $79 \%$ & $67 \%$ \\
No & $59 \%$ & $12 \%$ & $41 \%$ & $20 \%$ & $21 \%$ & $33 \%$ \\
\hline & $100 \%$ & $100 \%$ & $100 \%$ & $100 \%$ & $100 \%$ & $100 \%$ \\
\hline
\end{tabular}

\begin{tabular}{|c|}
\hline $69 \%$ \\
$31 \%$ \\
\hline $100 \%$ \\
\hline
\end{tabular}

\section{Other dissemination practices}

7.1 Do you know if there is a publicly disseminated calendar that announces in advance the dates on which the various official statistics will be disseminated?

\begin{tabular}{|c|c|c|c|c|c|c|}
\hline Yes & $19 \%$ & $44 \%$ & $19 \%$ & $57 \%$ & $31 \%$ & $67 \%$ \\
No & $81 \%$ & $56 \%$ & $81 \%$ & $43 \%$ & $69 \%$ & $33 \%$ \\
\hline & $100 \%$ & $100 \%$ & $100 \%$ & $100 \%$ & $100 \%$ & $100 \%$ \\
\hline
\end{tabular}

\begin{tabular}{|c|}
\hline $35 \%$ \\
$65 \%$ \\
\hline $100 \%$ \\
\hline
\end{tabular}

7.2 If there is a calendar of release dates, in your experience, are the official statistics released on the dates announced?

\begin{tabular}{|c|c|c|c|c|c|c|c|}
\hline & Yes & $33 \%$ & $75 \%$ & $38 \%$ & $67 \%$ & $50 \%$ & $67 \%$ \\
& No & $67 \%$ & $25 \%$ & $63 \%$ & $33 \%$ & $50 \%$ & $33 \%$ \\
\hline
\end{tabular}

\begin{tabular}{|c|}
\hline $55 \%$ \\
$45 \%$ \\
\hline $100 \%$ \\
\hline
\end{tabular}

7.3 Is there enough information about revisions to official statistics?

\begin{tabular}{|c|}
\hline $42 \%$ \\
$58 \%$ \\
\hline $100 \%$ \\
\hline
\end{tabular}




\begin{tabular}{|l|l|l|l|l|l|}
\hline NA & CPI & GFS & MS & BOP & Other \\
\hline
\end{tabular}

Averages

\begin{tabular}{|c|c|c|c|c|c|c|c|}
\hline \multirow{5}{*}{$\begin{array}{l}\text { Acce } \\
8.1\end{array}$} & ssibility & & & & & & \\
\hline & \multicolumn{7}{|c|}{ Can you easily access the official statistics? } \\
\hline & Yes & $87 \%$ & $80 \%$ & $81 \%$ & $86 \%$ & $87 \%$ & $100 \%$ \\
\hline & \multirow{2}{*}{ No } & $13 \%$ & $20 \%$ & $19 \%$ & $14 \%$ & $13 \%$ & $0 \%$ \\
\hline & & $100 \%$ & $100 \%$ & $100 \%$ & $100 \%$ & $100 \%$ & $100 \%$ \\
\hline \multirow[t]{4}{*}{8.2} & \multicolumn{7}{|c|}{$\begin{array}{l}\text { Can you easily access information pertaining to official statistics you use (explanatory } \\
\text { notes, methodological descriptions, reference concerning concepts, classification, statistical } \\
\text { practice)? }\end{array}$} \\
\hline & Yes & $71 \%$ & $71 \%$ & $67 \%$ & $100 \%$ & $85 \%$ & $75 \%$ \\
\hline & \multirow[t]{2}{*}{ No } & $29 \%$ & $29 \%$ & $33 \%$ & $0 \%$ & $15 \%$ & $25 \%$ \\
\hline & & $100 \%$ & $100 \%$ & $100 \%$ & $100 \%$ & $100 \%$ & $100 \%$ \\
\hline \multirow[t]{4}{*}{8.3} & \multicolumn{7}{|c|}{$\begin{array}{l}\text { Is the above information on methodology sufficiently clear and at an adequate level of detail } \\
\text { to be useful to you? }\end{array}$} \\
\hline & \multicolumn{7}{|c|}{ Yes } \\
\hline & \multicolumn{7}{|c|}{ No } \\
\hline & \multicolumn{7}{|c|}{ No Opinion } \\
\hline 8.4 & \multicolumn{7}{|c|}{ How do you get access to official statistics? } \\
\hline & \multicolumn{7}{|c|}{ Hard Copy } \\
\hline & 8.4 .1 & \multicolumn{6}{|c|}{ Official releases } \\
\hline & 8.4 .2 & \multicolumn{6}{|c|}{ Hard copy publications } \\
\hline & 8.4 .3 & \multicolumn{6}{|c|}{ Data specifically requested } \\
\hline & \multicolumn{7}{|c|}{ Electronic Form } \\
\hline & 8.4 .4 & \multicolumn{6}{|c|}{ Official website } \\
\hline & 8.4 .5 & \multicolumn{6}{|c|}{ Other } \\
\hline & 8.4.6 & \multicolumn{6}{|c|}{ E-mail requests } \\
\hline
\end{tabular}

\begin{tabular}{|c|}
\hline $78 \%$ \\
$22 \%$ \\
\hline $100 \%$ \\
\hline
\end{tabular}
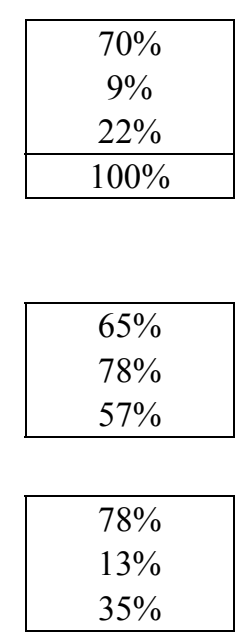

\section{Overall assessment}

9.1 In your opinion, is the underlying methodology of official statistics sound and appropriate?

\begin{tabular}{|c|c|c|c|c|c|c|}
\hline Yes & $62 \%$ & $64 \%$ & $73 \%$ & $75 \%$ & $71 \%$ & $100 \%$ \\
No & $38 \%$ & $36 \%$ & $27 \%$ & $25 \%$ & $29 \%$ & $0 \%$ \\
\hline
\end{tabular}

\begin{tabular}{|c|}
\hline $70 \%$ \\
$30 \%$ \\
\hline $100 \%$ \\
\hline
\end{tabular}

9.2 In general, do you consider the official statistics to be unbiased and accurate?

\begin{tabular}{|c|c|c|c|c|c|c|}
\hline Yes & $62 \%$ & $67 \%$ & $73 \%$ & $77 \%$ & $67 \%$ & $100 \%$ \\
No & $38 \%$ & $33 \%$ & $27 \%$ & $23 \%$ & $33 \%$ & $0 \%$ \\
\hline
\end{tabular}

\begin{tabular}{|c|}
\hline $71 \%$ \\
$29 \%$ \\
\hline $100 \%$ \\
\hline
\end{tabular}




\begin{tabular}{|l|l|l|l|l|l|l|}
\hline NA & CPI & GFS & MS & BOP & Other & Averages \\
\cline { 2 - 5 }
\end{tabular}

9.3 How would you compare the quality of official statistics of the country with those of other countries in the region?

\begin{tabular}{|c|c|c|c|c|c|c|c|}
\hline \multirow{2}{*}{ Better } & $15 \%$ & $7 \%$ & $14 \%$ & $15 \%$ & $14 \%$ & $0 \%$ \\
Same & $38 \%$ & $53 \%$ & $50 \%$ & $54 \%$ & $50 \%$ & $33 \%$ \\
Worse & $46 \%$ & $40 \%$ & $36 \%$ & $31 \%$ & $36 \%$ & $67 \%$ \\
\hline & $100 \%$ & $100 \%$ & $100 \%$ & $100 \%$ & $100 \%$ & $100 \%$ \\
\hline
\end{tabular}

9.4 How do you assess the overall quality of the official statistics?

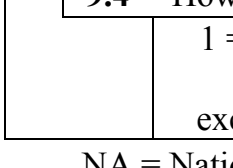

$1=$ poor
$5=$
excellent

2.9

3.5

3.

3.1

3.9

\begin{tabular}{|l|l|}
\hline 3.3 & 2.7 \\
\hline
\end{tabular}

\begin{tabular}{|r|}
\hline $13 \%$ \\
$49 \%$ \\
$39 \%$ \\
\hline $100 \%$ \\
\hline
\end{tabular}

$\mathrm{MS}=$ Monetary Statistics; and BOP $=$ Balance of Payments Statistics 


\section{Bosnia and Herzegovina: Comments by Users of Macroeconomic Statistics}

\section{Coverage and Detail}

$>$ There is a need to increase coverage of statistics to include more details in trade statistics such as country and category of items traded.

$>$ Statistics should include GFS data with full coverage of institutions.

\section{Periodicity and Timeliness}

$>$ There is a need for quarterly statistics on National Accounts. Currently only annual data are available.

$>$ The lag in publication of some statistics is extremely long. This is mostly the case for national accounts and government finance statistics

\section{Dissemination Practices and Accessibility}

$>$ It would be beneficial to have a calendar announcing the date that statistics are expected to be released to the public.

$>$ Need to increase dissemination of statistics by including them in already widely disseminated media such as newspapers.

$>$ While current data may be accessible, historical data is generally never available.

$>$ Methodology is readily accessible, however, explanatory notes, especially regarding patterns or radical movements in statistics are absent.

$>$ When requesting data from the entities, especially the Federation Statistical Agency, the procedures are cumbersome - a formal letter has to be sent to the Director, even for time series data that were once published but no longer appear on the website.

$>$ Not all official sites provide the option of downloading data.

\section{Methodological Soundness, Accuracy, and Reliability}

$>$ Exact methodology for producing statistics is not available.

$>$ Explanation not provided for unusual observations.

$>$ Reliability of National Accounts is questionable.

$>$ Price statistics contain several biases in underlying data.

$>$ Data don't always seem to reflect actual economic situation.

$>$ Accuracy of government finance data statistics is doubtful.

$>$ Remittance estimates in balance of payments is likely underestimated. This leads to large net errors and omissions.

$>$ Data that are not seasonally adjusted reflect seasonal biases. Hidden biases may exist due to underreporting in certain sectors.

$>$ National Accounts, Prices (including a deflator, and PPI), and labor market statistics desperately need improvement.

$>$ Leading indicators are of a poor quality, including Industrial Production and Retail Sales data.

$>$ Labor market data that is clearly inaccurate and inconsistent should not be published. 


\section{General Comments}

$>$ The overall approach of the entities' statistical agencies is not user friendly. Apart from the poor quality of the statistics, the manner of dissemination and presentation makes time series difficult to construct.

$>$ The State Agency does not help by simply adding-up and republishing data that is clearly misleading data prepared by the entities.

$>$ Estimates of the grey economy should be published, and more realistic estimates of remittances included in the BOP.

$>$ Monetary statistics should be expanded to cover quarterly data for non-bank financial institutions that extend credits (leasing, micro-credits etc).

$>$ Procedures should be streamlined for ad hoc requests and for establishing a more customer oriented approach for providing responses.

$>$ Existing real sector data do not provide an adequate basis for macroeconomic analysis.

$>$ We often need trade statistics based on various parameters, and in most cases, our needs can only be met by direct requests. It would be helpful to regularly publish time series on trade with individual countries, and by type of product.

$>$ Statistics on domestic production by individual sectors and products is often lacking. These data are mainly publicized by entity agencies for statistics but it is often difficult to aggregate them. Also we are lacking data on domestic consumption per product.

$>$ Balance of Payment statistics do not encompass inflows from citizens who work abroad.

$>$ There is no data available to measure the effects generated by tourism.

$>$ There is no data available to measure the effects of value added tax

$>$ There is room for improvement in foreign trade statistics. 